NIST Special Publication 1182

\title{
Simulated versus Measured Energy Performance of the NIST Net Zero Energy Residential Test Facility Design
}

\author{
Joshua Kneifel \\ William V. Payne \\ Tania Ullah \\ Lisa $\mathrm{Ng}$
}

This publication is available free of charge from:

http://dx.doi.org/10.6028/NIST.SP.1182
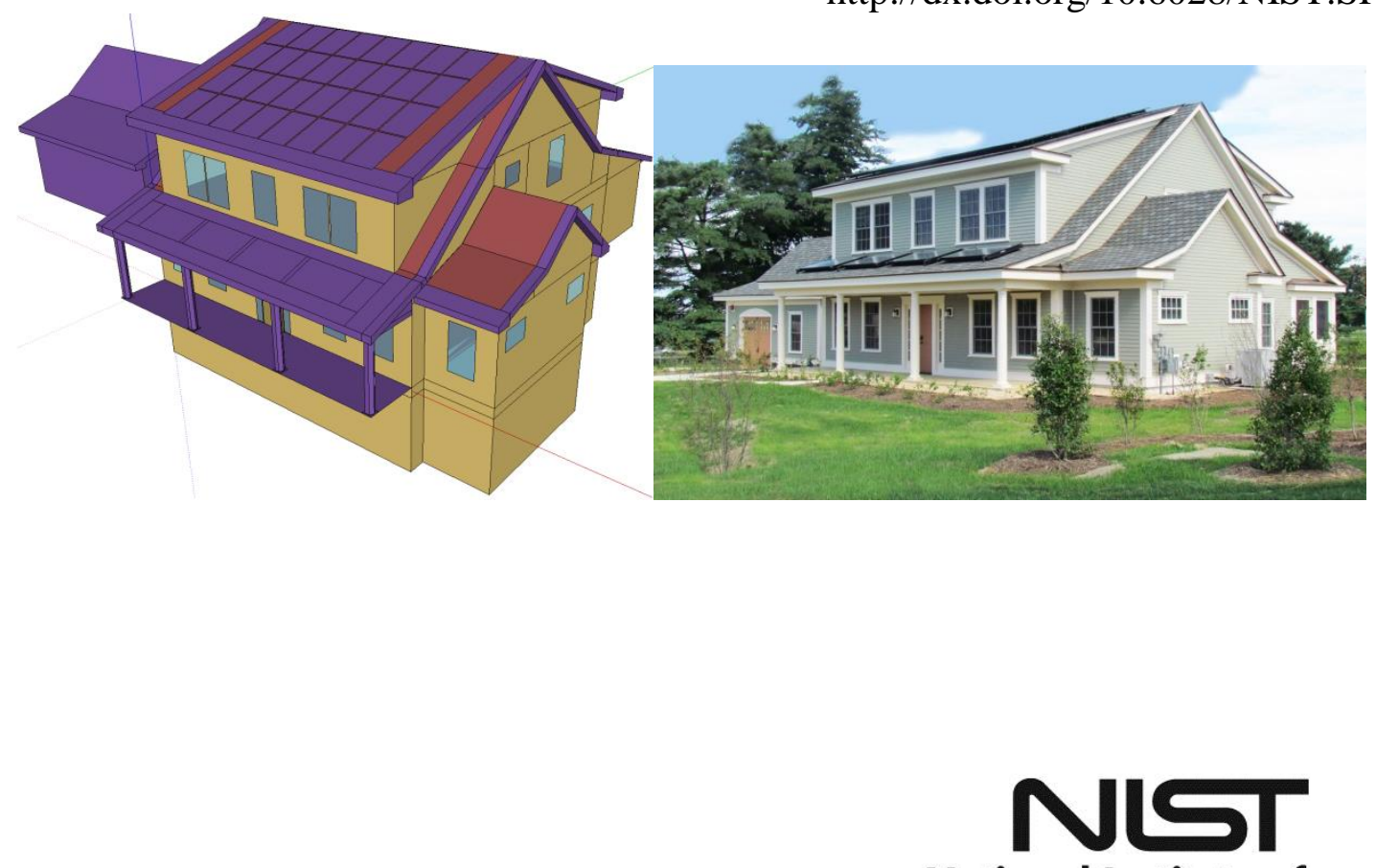

National Institute of Standards and Technology

U.S. Department of Commerce 

NIST Special Publication 1182

\title{
Simulated versus Measured Energy Performance of the NIST Net Zero Energy Residential Test Facility Design
}

\author{
Joshua Kneifel \\ Applied Economics Office \\ Engineering Laboratory \\ William V. Payne \\ Tania Ullah \\ Lisa $\mathrm{Ng}$ \\ Energy and Environment Division \\ Engineering Laboratory
}

This publication is available free of charge from: http://dx.doi.org/10.6028/NIST.SP.1182

March 2015

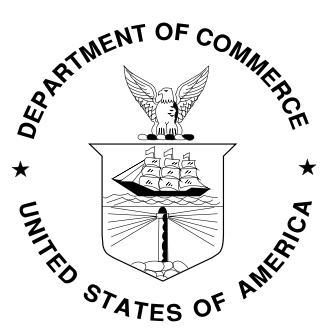

U.S. Department of Commerce Penny Pritzker, Secretary

National Institute of Standards and Technology Willie May, Acting Under Secretary of Commerce for Standards and Technology and Director 
Certain commercial entities, equipment, or materials may be identified in this document in order to describe an experimental procedure or concept adequately. Such identification is not intended to imply recommendation or endorsement by the National Institute of Standards and Technology, nor is it intended to imply that the entities, materials, or equipment are necessarily the best available for the purpose.

National Institute of Standards and Technology Special Publication 1182 Natl. Inst. Stand. Technol. Spec. Pub. 1182, 95 pages (March 2015) This publication is available free of charge from: http://dx.doi.org/10.6028/NIST.SP.1182 


\begin{abstract}
The National Institute of Standards and Technology (NIST) received funding through the American Recovery and Reinvestment Act (ARRA) to construct a Net Zero Energy Residential Test Facility (NZERTF). The initial goal of the NZERTF is to demonstrate that a net-zero energy residential design can "look and feel" like a typical home in the Gaithersburg area. The demonstration phase of the project was from July 2013 through June 2014, during which it successfully demonstrated that the house performed at "net zero," or produced as much electricity as it consumed over the entire year.

The purpose of this report is twofold. The first is to compare the pre-demonstration phase whole building energy simulation to the measured performance of the NZERTF during the demonstration phase, which will identify where the measured performance deviates from the simulated performance of the house in its design state. These variations may be due to incorrect simulation assumptions (e.g., incorrect efficiency parameters) or faulty demonstration phase operation control of the NZERTF itself (e.g., equipment failures). The components of the NZERTF for which the simulation and measured performance vary the most can be used as a "lessons learned" guide for other researchers to consider in other low-energy house simulation efforts. The second purpose is to adjust the predemonstration phase simulation specifications to better represent the actual performance of the NZERTF during the demonstration phase. The adjustments will lead to the development of a validated simulation model that can be used for analysis of "what-if" scenarios, such as alternative configurations of equipment, occupancy activity/behavior, building envelope options, or sensitivity analysis.

There is significant variation between the pre-demonstration phase simulation results and measured demonstration phase performance. First, the initial simulation assumptions were incorrect due to a lack of information on the specifications of the installed equipment. Second, where information was lacking, conservative parameter values were used in the model in order to not underestimate consumption. Third, there was an inability to directly model some of the installed equipment in the software. Fourth, the operation schedules and controls of the NZERTF were adjusted throughout the preparation for the demonstration phase. Finally, there were faults and adjustments in the operation of the NZERTF during the demonstration phase.
\end{abstract}

\title{
Keywords
}

Net zero energy construction; energy efficiency; residential building; whole building energy simulation 


\section{Preface}

This study was conducted by the Applied Economics Office (AEO) in the Engineering Laboratory (EL) at the National Institute of Standards and Technology (NIST). The study is designed to compare the pre-demonstration phase whole building energy simulation to the measured energy performance during the demonstration phase of the Net Zero Energy Residential Test Facility project, determine the reasons for any variations between the simulated and measured performance, and develop a validated simulation that better represents the performance of the NZERTF. The intended audience includes researchers in the residential building sector concerned with net zero energy residential performance.

\section{Disclaimer}

The policy of the National Institute of Standards and Technology is to use metric units in all of its published materials. Because this report is intended for the U.S. construction industry that uses U.S. customary units, it is more practical and less confusing to include U.S. customary units as well as metric units. Measurement values in this report are therefore stated in metric units first, followed by the corresponding values in U.S. customary units within parentheses. 


\section{Acknowledgements}

The author wishes to thank everyone involved in the NZERTF project. A special thanks to Farhad Omar, Dr. Hunter Fanney, Brian Dougherty, Dr. Andrew Persily, Steven Emmerich, Dr. William Healy, Mark Davis, Piotr Domanski, and Matthew Boyd from NIST, Cathy Gates, Betsy Pettit, and Daniel Bergey from Building Science Corporation (BSC), and Richard Raustad and the other EnergyPlus Help Desk team members for their assistance in designing the simulation model. Thank you to everyone for their advice and recommendations for the writing of this report, including Dr. Eric O'Rear and Dr. Robert Chapman of EL's Applied Economics Office, Dr. William Healy of EL's Energy and Environment Division, and Dr. Nicos S. Martys of EL's Materials and Structural Systems Division. 


\section{Author Information}

Joshua D. Kneifel

Economist

National Institute of Standards and Technology

100 Bureau Drive, Mailstop 8603

Gaithersburg, MD 20899-8603

Tel.: 301-975-6857

Email: joshua.kneifel@nist.gov

William V. Payne

Mechanical Engineer

National Institute of Standards and Technology

100 Bureau Drive, Mailstop 8631

Gaithersburg, MD 20899-8631

Tel.: 301-975-6663

Email: vance.payne@ nist.gov

Tania Ullah

Mechanical Engineer

National Institute of Standards and Technology

100 Bureau Drive, Mailstop 8632

Gaithersburg, MD 20899-8632

Tel.: 301-975-5433

Email: tania.ullah@nist.gov

\section{Lisa $\mathrm{Ng}$}

Mechanical Engineer

National Institute of Standards and Technology

100 Bureau Drive, Mailstop 8633

Gaithersburg, MD 20899-8633

Tel.: 301-975-4832

Email: lisa.ng@nist.gov 


\section{Contents}

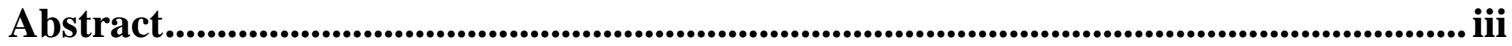

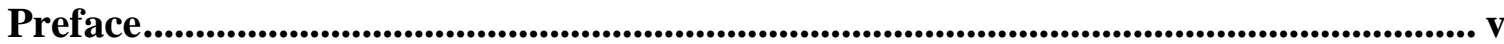

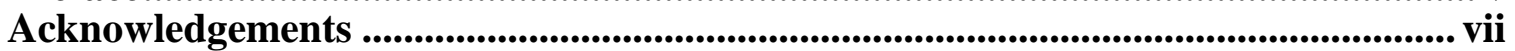

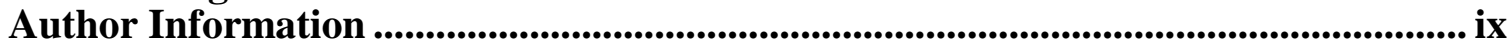

List of Acronyms ............................................................................................................. xvii

1 Introduction .............................................................................................................. 1

1.1 Background and Purpose .......................................................................... 1

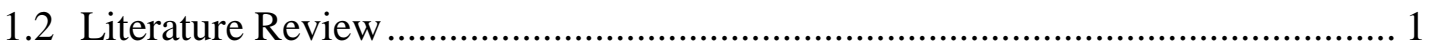

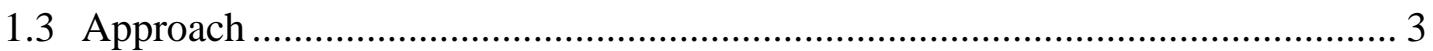

2 Pre-Demonstration Phase Assumptions...........................................................5

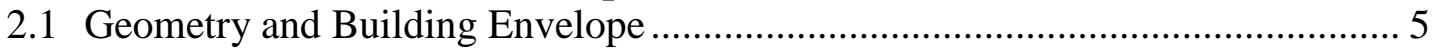

2.2 Pre-Demonstration Adjustments to NZERTF Simulation ................................. 9

2.3 Systems, Occupancy, and Operation........................................................... 10

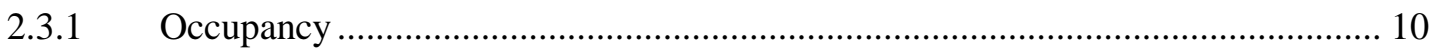

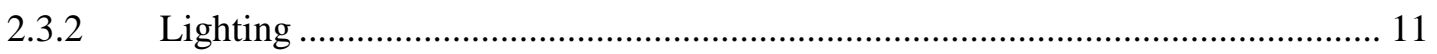

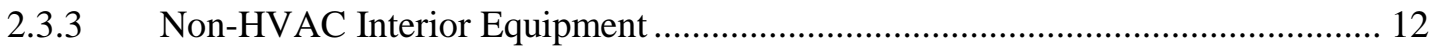

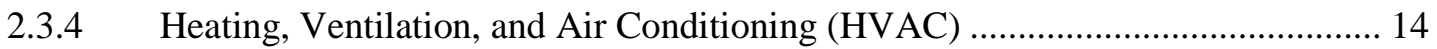

2.3.5 Domestic Hot Water ....................................................................................... 22

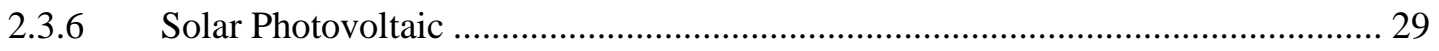

3 Pre-Demonstration Phase Model Results .......................................................... 33

3.1 Total Electricity Consumption and Production ................................................ 33

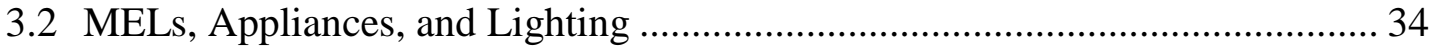

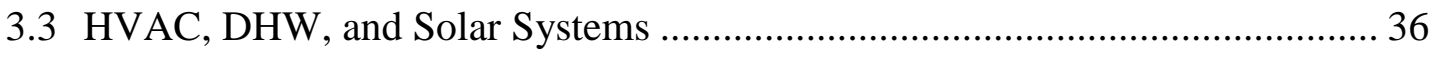

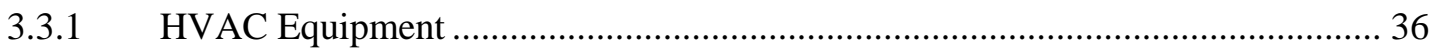

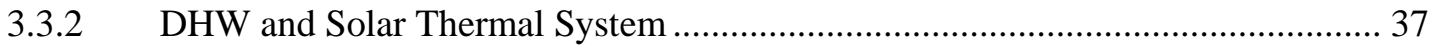

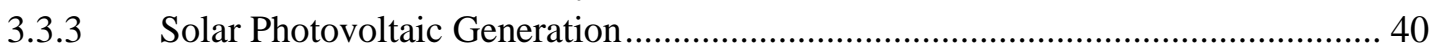

4 Adjustments to Simulation Model ................................................................................ 43

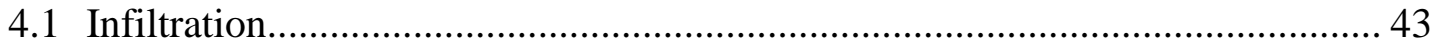

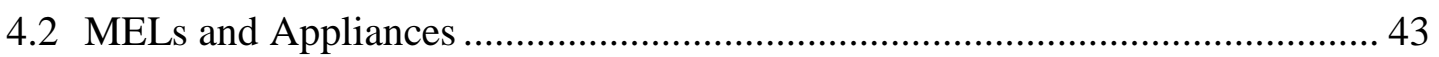

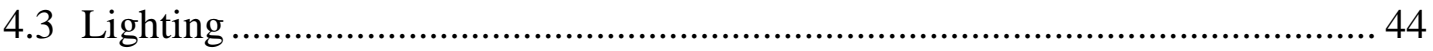

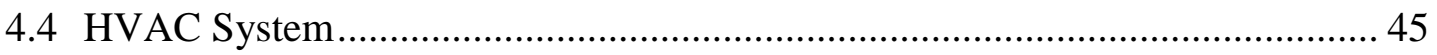

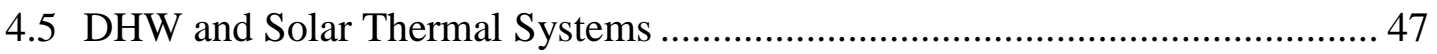

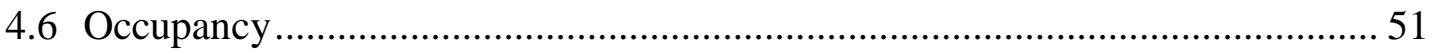

4.7 Missing Experimental Data and Equipment Faults for the Demonstration Phase 52

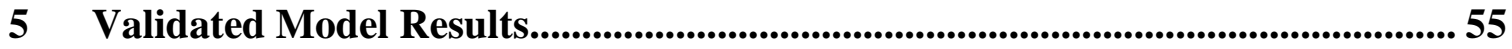

5.1 Total Electricity Consumption and Production ............................................. 55

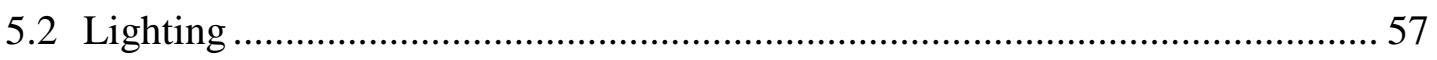

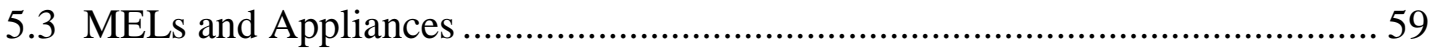

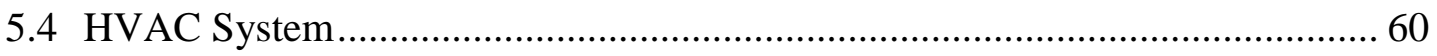

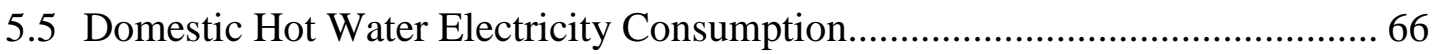

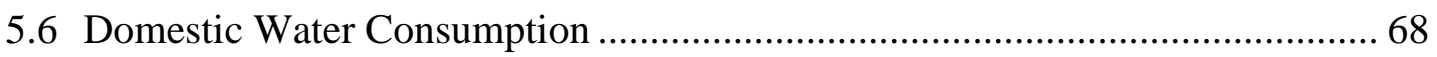




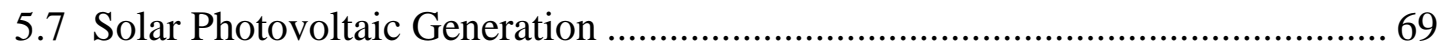

6 Limitations .......................................................................................................... 71

7 Discussion and Future Research........................................................................ 73

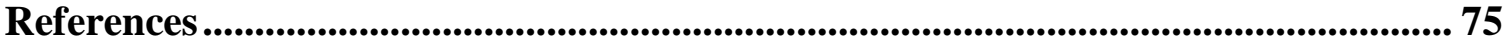




\section{List of Figures}

Figure 2-1 Location of Weather Station used for E+ Simulation................................. 5

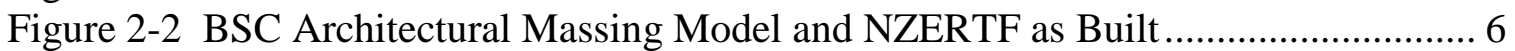

Figure 2-3 Google SketchUp 3-D Representation of the E+ Model................................. 6

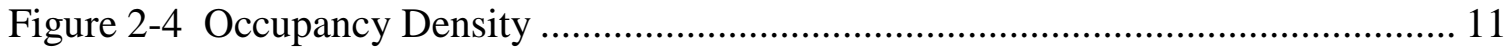

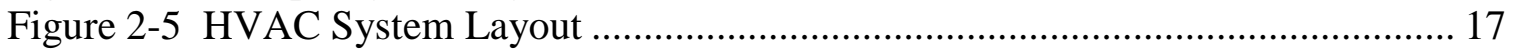

Figure 2-6 Domestic Hot Water Heating System ...................................................... 23

Figure 2-7 Domestic Hot Water End Use Schedules - Fraction of Peak Flow .............. 28

Figure 3-1 Annual Electricity Consumption and Production $(\mathrm{kWh})$............................ 33

Figure 3-2 Total Electricity Consumption by Category - kWh .................................... 34

Figure 3-3 Appliances and Plug Loads (MELs) by Room - kWh................................ 35

Figure 3-4 Lighting by Room - kWh ............................................................... 35

Figure 3-5 Heating and Cooling Consumption by Month $-\mathrm{kWh}$................................ 36

Figure 3-6 HRV Electricity Consumption by Month - kWh ........................................ 37

Figure 3-7 DHW and Solar Loop Pump Electricity Consumption by Month $-\mathrm{kWh}$...... 38

Figure 3-8 DHW and Solar Loop Pump Electricity Consumption by Month - kWh...... 39

Figure 3-9 Daily Water Consumption - Gallons ....................................................... 40

Figure 3-10 Total Electricity Consumption and Solar PV Production (kWh) - Monthly 41

Figure 4-1 Adjusted Domestic Hot Water Heating System......................................... 48

Figure 4-2 Air Temperature, Total Heating Electricity Consumption, Auxiliary

Electricity Consumption, and Combined Heating COP - December 1, 2013 ................. 54

Figure 5-1 Annual Electricity Consumption and Production - kWh ............................. 55

Figure 5-2 Monthly Electricity Consumption and Production - kWh ............................ 56

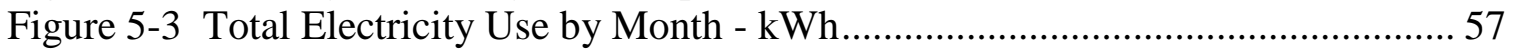

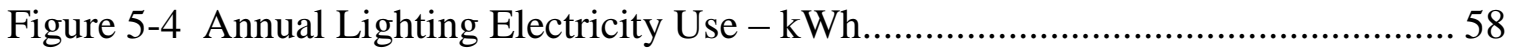

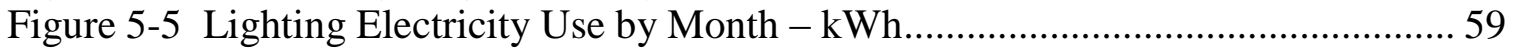

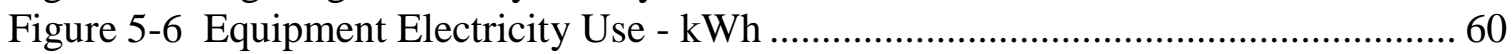

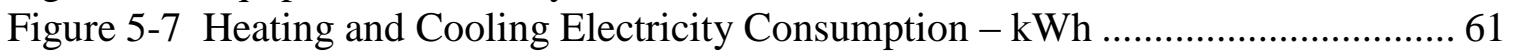

Figure 5-8 Monthly Heating Electricity Consumption by Component - kWh............... 62

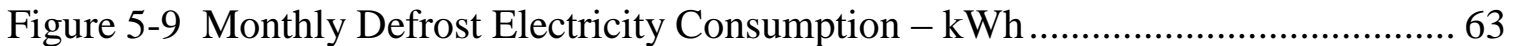

Figure 5-10 Monthly Heat Pump Standby Electricity Consumption - kWh .................. 63

Figure 5-11 Updated Heating Electricity Consumption (2014) - kWh.......................... 64

Figure 5-12 Updated Heating Electricity Consumption by Component - kWh............. 65

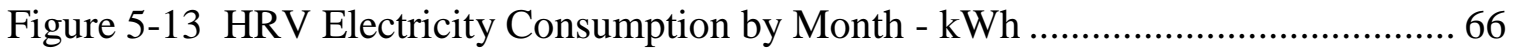

Figure 5-14 Heat Pump Water Heater and Pump Electricity Use (kWh) - Monthly ...... 67

Figure 5-15 DHW Tank Average Water Temperatures $\left({ }^{\circ} \mathrm{C}\right)$ - Monthly ......................... 68

Figure 5-16 Daily DHW Water Consumption - Gallons per Day .................................. 69

Figure 5-17 Total Solar PV Electricity Production (kWh) - Monthly ........................... 70 


\section{List of Tables}

Table 2-1 Framing and Insulation............................................................................. 7

Table 2-2 Window Specifications............................................................................. 7

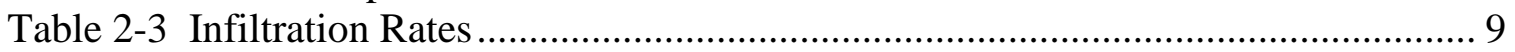

Table 2-4 Changes in NZERTF Assumptions ................................................................ 9

Table 2-5 Systems, Occupants, and Operating Conditions............................................... 10

Table 2-6 Occupant Activity Level............................................................................ 11

Table 2-7 Lighting Total Wattage by Room.................................................................... 12

Table 2-8 Appliance Wattage and Sensible and Latent Load Fractions .......................... 13

Table 2-9 Miscellaneous Electrical Load Wattage and Sensible and Latent Loads ........ 13

Table 2-10 Thermostat Setpoints .............................................................................. 15

Table 2-11 Heat Recovery Ventilator .......................................................................... 16

Table 2-12 Zone Sizing Parameters ........................................................................... 17

Table 2-13 HVAC System Sizing Parameters …………………………………….... 18

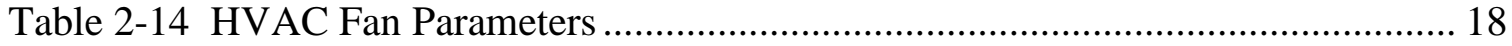

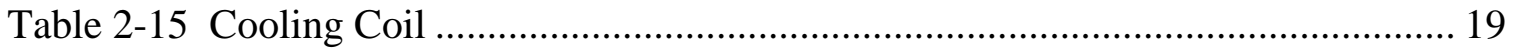

Table 2-16 Cooling Coil Performance Curves......................................................... 19

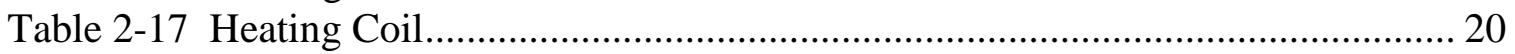

Table 2-18 Heating Coil Performance Curves ................................................................ 20

Table 2-19 Dehumidifier Parameters....................................................................... 21

Table 2-20 Dehumidifier Performance Curves.............................................................. 22

Table 2-21 Solar Thermal Collector Parameters ………........................................... 24

Table 2-22 Storage Tank and Water Heater Tank Parameters ....................................... 25

Table 2-23 Heat Pump Water Heater Operational Parameters ........................................ 26

Table 2-24 Hot Water Heat Pump Coil Parameters.......................................................... 26

Table 2-25 Heat Pump Water Heater Fan and DHW Fan Parameters.............................. 27

Table 2-26 Domestic Hot Water Loop Pump Parameters ............................................... 27

Table 2-27 Domestic Hot Water Use and Thermal Load Fractions ................................. 29

Table 2-28 Solar Photovoltaic Panel Parameters .......................................................... 30

Table 2-29 Solar Photovoltaic Inverter Parameters ....................................................... 31

Table 4-1 Adjustments to Peak Wattage for Appliances and MELs ................................ 44

Table 4-2 Adjustments to Lighting Peak Wattage by Room ........................................... 45

Table 4-3 Changes in Cooling DX Coil Parameters ....................................................... 45

Table 4-4 Changes in Heating DX Coil Parameters ………............................................ 46

Table 4-5 Changes in Heat Recovery Ventilator Parameters ........................................... 47

Table 4-6 Changes in Dehumidifier Parameters.......................................................... 47

Table 4-7 Solar Thermal Collector Parameters …………............................................. 48

Table 4-8 Solar Loop Pump Parameters ........................................................................ 49

Table 4-9 Changes in Storage Tank and Hot Water Heater Tank Parameters.................. 50

Table 4-10 Changes in Hot Water Heat Pump Coil Parameters ....................................... 50

Table 4-11 Domestic Hot Water Use and Thermal Load Fractions ................................. 51

Table 4-12 Domestic Hot Water Target Temperature .................................................... 51

Table 4-13 Occupant Activity Level........................................................................ 52

Table 4-14 Missing Experimental Data ………………............................................. 52

Table 4-15 Equipment Faults................................................................................. 53 


\section{List of Acronyms}

\section{Acronym Definition}

$\mathrm{ACH} \quad$ Air Changes Per Hour

AEO Applied Economics Office

AMY Actual Meteorological Year

ARRA American Recovery and Reinvestment Act

ASHRAE American Society of Heating, Refrigerating and Air-Conditioning Engineers

BA Building America

BSC Building Science Corporation

BTP Building Technology Program

CFM Cubic Feet Per Minute

COP Coefficient of Performance

DHW Domestic Hot Water

DOE Department of Energy

DX direct expansion

E+ EnergyPlus

EERE Energy Efficiency and Renewable Energy

EL Engineering Laboratory

ELA Effective Leakage Area

ETL Electrical Testing Labs

FPW Fraction of Peak Wattage

FPF Fraction of Peak Flow

gpm gallons per minute

HVAC Heating, Ventilating, and Air Conditioning

HRV heat recovery ventilator

MEL Miscellanous Electric Load

NIST National Institute of Standards and Technology

NREL National Renewable Energy Laboratory

NZERTF Net Zero Energy Residential Test Facility

$\mathrm{OC} \quad$ on center

ODB Outdoor Dry-Bulb

PCI Peripheral Component Interconnect 


\section{Acronym Definition}

PXI Peripheral Component Interconnect Extensions for Instrumentation

PV Photovoltaic

SHGC Solar Heat Gain Coefficient

TMY Typical Meteorological Year

VT Visual Transmittance 


\section{Introduction}

\subsection{Background and Purpose}

The National Institute of Standards and Technology (NIST) received funding through the American Recovery and Reinvestment Act (ARRA) to construct a Net Zero Energy Residential Test Facility (NZERTF). The initial goal of the NZERTF is to demonstrate that a net-zero energy residential design can "look and feel" like a typical home in the Gaithersburg area. The demonstration phase of the project was from July 2013 through June 2014, during which it successfully demonstrated the house performed at "net zero," or produced as much electricity as it consumed over the entire year.

The purpose of this report is twofold. The first is to compare the pre-demonstration phase whole building energy simulation to the measured performance of the NZERTF during the demonstration phase, which will identify where the measured performance deviates from the simulated performance of the house in its design state. These variations may be due to incorrect simulation assumptions (e.g., incorrect efficiency parameters) or faulty demonstration phase operation control of the NZERTF itself (e.g., equipment failures). The components of the NZERTF for which the simulation and measured performance vary the most can be used as a "lessons learned" guide for other researchers to consider in other low-energy house simulation efforts. The second purpose is to adjust the pre-demonstration phase simulation specifications to better represent the actual performance of the NZERTF during the demonstration phase. The adjustments will lead to the development of a validated simulation model that can be used for analysis of "what-if" scenarios, such as alternative configurations of equipment, occupancy activity/behavior, building envelope options, or sensitivity analysis.

\subsection{Literature Review}

The Department of Energy's (DOE) Building Technologies Program within the Office of Energy Efficiency and Renewable Energy is responsible for funding research at the national laboratories for the Building America (BA) program. The Building America (BA) program has been at the forefront of research of low-energy single-family housing design through a variety of outlets, including the BA Best Practices Series, case studies for new construction and retrofits, and technical reports and fact sheets. Hendron and Engebrecht (2010) defines the BA house protocols to be implemented when simulating house energy performance.

Kneifel (2012) defines the assumptions and parameters for an EnergyPlus (E+) whole building energy simulation (DOE 2013) based on the NZERTF construction and equipment specifications to forecast the energy performance during the demonstration phase of the NZERTF project, both in aggregate as well as at the individual occupant and equipment level. The results show that the NZERTF design will not only reach net-zero performance, but produce significant excess electricity for an entire year using Typical Meteorological Year (TMY) weather data. 
Kneifel (2013) uses the $E+$ simulation model developed in Kneifel (2012), adjusts some parameters in the model based on new information regarding the NZERTF's construction and intended operation, and compares the energy performance of the NZERTF design to a comparable Maryland code-compliant building design. The analysis includes a total of eleven $E+$ simulations, starting with the Maryland code-compliant design and then adding energy efficiency measures incrementally until all measures are included to reach the NZERTF design. This approach allows for a comparison across energy efficiency measures to determine the incremental impact for each energy efficiency measure on energy consumption. The NZERTF leads to a reduction of $60 \%$ in energy consumption (118\% in net energy consumption) relative to the 2012 International Energy Conservation Code (IECC) design while doing a better job at controlling the indoor environment in terms of temperature and relative humidity.

Kneifel (2014) compares the life-cycle cost performance of the NZERTF design to a comparable Maryland code-compliant building design using the results from the NZERTF E+ simulation defined in Kneifel (2013), local utility electricity rate schedules, and a contractor report estimating the associated construction costs. The combination of initial construction costs and future energy costs are used to estimate the total present value costs of constructing and operating the NZERTF relative to the Maryland code-compliant house design. The NZERTF is more costly to build, but saves the homeowner money in energy costs and increases the market value of the home at resale. Assuming the NZERTF is purchased with a 30-year mortgage at $4.5 \%$ and a $20 \%$ down payment, the home owner would realize net savings of $\$ 41714$, or a $5.6 \%$ adjusted internal rate of return.

Pettit et al. (2015) describes the general approach implemented in the design of the NZERTF, which reduces energy use through methods that are consistent with a homeowner's means and way of life using available technologies, using on-site generation of energy for the energy required after energy consumption has been reduced as much as is feasible. The report presents and discusses the ten general principles for the design of net-zero energy capable houses, and then describes the strategies implemented and design and construction details specifically related to the NZERTF. This provides a concrete example of a net-zero capable house for which the development of the design is consistent with the ten underlying principles.

Fanney et al. (2015) summarizes the design of the NZERTF and operation of the facility during its one-year demonstration phase (July 2013 through June 2014). The article includes descriptions of the architectural design and construction of the NZERTF, the virtual family that resides in the NZERTF, the instrumentation developed to control and monitor activity and electricity consumption within the facility, presents measured performance data from the demonstration phase, and explains the key lessons learned throughout the process of operating such a complex facility continuously for an entire year. 


\subsection{Approach}

This report compares the pre-demonstration phase $E+$ simulation to the measured performance of the NZERTF during the demonstration phase using actual weather data, determines the variations in energy performance, and adjusts the simulation model to better represent the measured performance of the NZERTF. The pre-demonstration phase simulation results are obtained from the $E+$ simulation model defined in Kneifel (2013), which is the most up-to-date model that was developed before the beginning of the demonstration phase. The measured performance data for the demonstration phase are obtained and compiled by NIST's building component expert(s) for each building system (Davis et al. 2014, Fanney et al. 2015). By comparing annual and monthly consumption values for the simulation estimate and measured performance, the reasons for the differences can be identified. These reasons include the following:

- Lack of information on the specifications of the installed equipment

- Usage of conservative parameter values where information is lacking in order to not underestimate consumption

- Inability to directly model some of the installed equipment

- Adjustment of operation schedules and controls of the NZERTF during preparation for the demonstration phase

- Faults and adjustments in the operation of the NZERTF during the demonstration phase

The appropriate adjustments are then incorporated into the $E+$ simulation model from Kneifel (2013) and rerun to see how those changes impacted the performance of the simulation model relative to the measured performance. 


\section{Pre-Demonstration Phase Assumptions}

The $E+$ software was chosen to simulate the whole building energy performance. As in Kneifel (2012) and Kneifel (2013), the simulations are run using a one-minute timestep. However, the Actual Meteorological Year (AMY) weather file for the NZERTF demonstration phase (July 1, 2013 through June 30, 2014) for the KGAI weather station (Weather Analytics 2014) located less than $11 \mathrm{~km}$ (7 miles) from the NIST campus as shown in Figure 2-1 is used in place of the TMY file used in Kneifel (2012) and Kneifel (2013). The use of the AMY file leads to simulation results that are directly comparable to the measured performance because the weather used to create the results are for the same weather conditions.

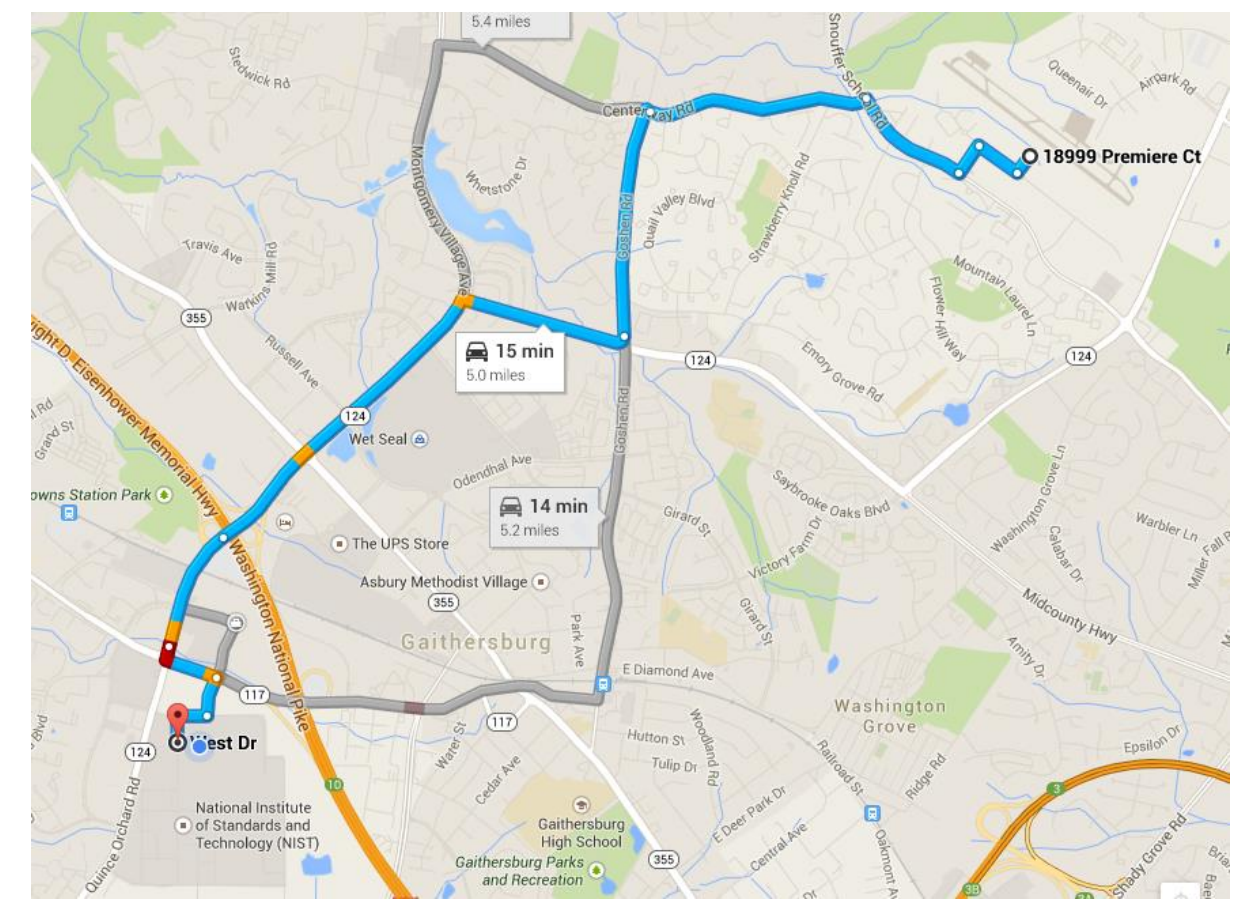

Figure 2-1 Location of Weather Station used for $E+$ Simulation

The general assumptions required by $E+$ are described in detail in Kneifel (2012) while the changes made to the simulation in Kneifel (2013) are shown in Section 2.2.

\subsection{Geometry and Building Envelope}

The dimensions specified in BSC (2009) and shown in the architectural massing model in Figure 2-2 are used along with Google SketchUp and National Renewable Energy Laboratory's (NREL) Legacy Open Studio plug-in to construct the building geometry of the NZERTF. Total conditioned floor area of the $E+$ model is $284.6 \mathrm{~m}^{2}\left(3063 \mathrm{ft}^{2}\right)$. Actual conditioned floor area of the NZERTF is $251.7 \mathrm{~m}^{2}\left(2709 \mathrm{ft}^{2}\right)$. There are two reasons the conditioned floor area of the simulation model is $32.9 \mathrm{~m}^{2}\left(354 \mathrm{ft}^{2}\right)$ greater than the actual house design. First, the $E+$ model does not account for the open foyer/stairway, which is approximately $19.0 \mathrm{~m}^{2}\left(204 \mathrm{ft}^{2}\right)$. Second, 
the gable walls (west wall and east wall) of the $2^{\text {nd }}$ floor have built in storage under the gable, which decreases the conditioned floor area by approximately $14.3 \mathrm{~m}^{2}\left(154 \mathrm{ft}^{2}\right)$. These two aspects of the model account for approximately $33.3 \mathrm{~m}^{2}\left(358 \mathrm{ft}^{2}\right)$, which decreases the conditioned floor area to $251.3 \mathrm{~m}^{2}\left(2705 \mathrm{ft}^{2}\right)$ or a difference of only $0.4 \mathrm{~m}^{2}\left(4 \mathrm{ft}^{2}\right)$. Even though these two aspects of the house are not considered finished floor area, their volume of space will be conditioned.

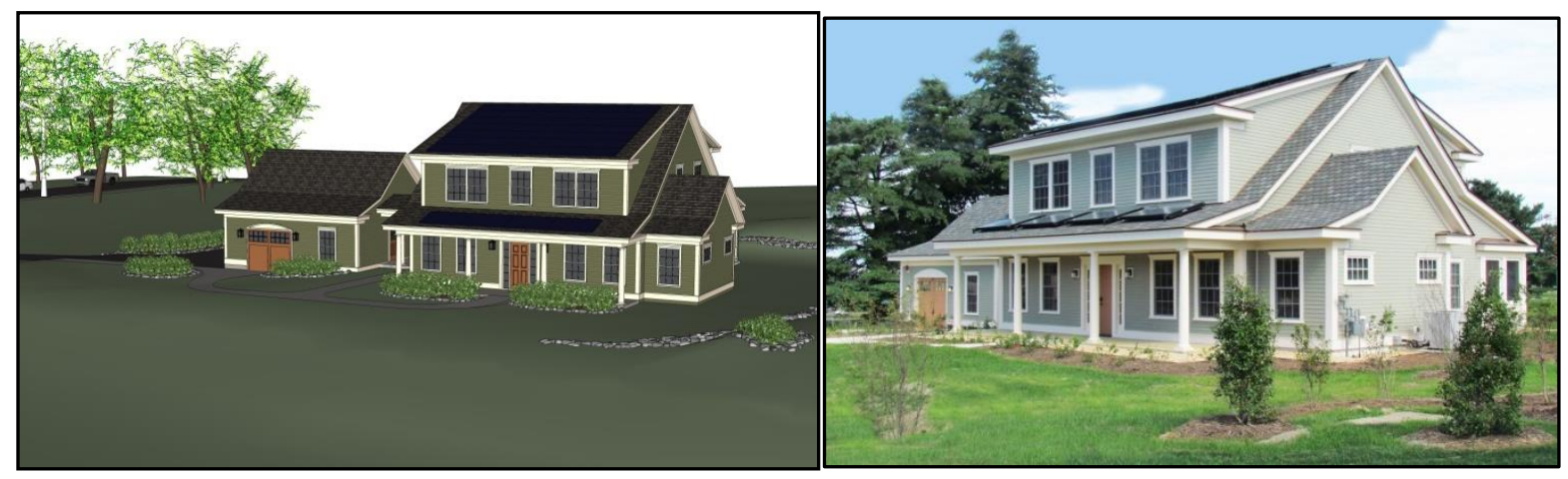

Figure 2-2 BSC Architectural Massing Model and NZERTF as Built

Figure 2-3 shows the Google SketchUp three-dimensional geometry of the $E+$ model for the NZERTF. The model includes seven separate zones with three actively conditioned $\left(1^{\text {st }}\right.$ floor, $2^{\text {nd }}$ floor, and basement), three inactively conditioned zones - a.k.a. within the conditioned space without ductwork to the space (open web joist space between the $1^{\text {st }}$ and $2^{\text {nd }}$ floors, main attic, and living room attic) -, and one unconditioned zone (patio). The front porch and detached garage with the covered walkway are all treated as shading surfaces, which block sunlight but do not impact the thermal performance of the building envelope.

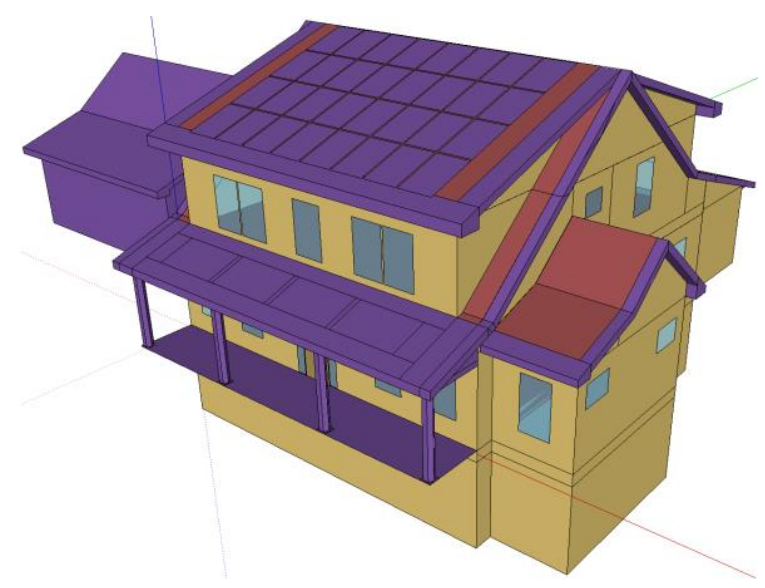

Figure 2-3 Google SketchUp 3-D Representation of the E+ Model

The NZERTF design adds energy efficiency measures to each aspect of the building envelope listed in Table 2-1, Table 2-2, and Table 2-3: framing, wall, roof, fenestration, and infiltration. The NZERTF is constructed using "advanced framing," which uses $5.1 \mathrm{~cm} \mathrm{x} 15.2 \mathrm{~cm}$ (2 in x 
6 in) $61.0 \mathrm{~cm}$ (24 in) on center (OC) framing instead of the common practice of $5.1 \mathrm{~cm} \mathrm{x}$ $10.2 \mathrm{~cm}$ ( 2 in $x 4$ in) $40.6 \mathrm{~cm}$ (16 in) OC framing (Lstiburek 2010). The thicker framing allows for greater levels of insulation within the wall cavity while decreasing the amount of wood required for framing the house, making it easier to increase the thermal performance of the building envelope.

\section{Table 2-1 Framing and Insulation}

\begin{tabular}{|l|c|}
\hline Insulation & NZERTF \\
\hline Framing & $5.1 \mathrm{~cm} \times 15.2 \mathrm{~cm}(2$ in $\times 6$ in $) 61.0 \mathrm{~cm}(24$ in $)$ OC \\
Exterior Wall & $\mathrm{R}_{\mathrm{SI}}-3.5+4.2(\mathrm{R}-20+24)$ \\
Basement Wall & $\mathrm{R}_{\mathrm{SI}}-3.9(\mathrm{R}-22)$ \\
Roof & $\mathrm{R}_{\mathrm{SI}}-7.9+5.3(\mathrm{R}-45+30)$ \\
\hline \multicolumn{2}{|l|}{ Note 1: Interior + Exterior R-Value } \\
\hline
\end{tabular}

The NZERTF design uses advanced framing and adds an additional $\mathrm{R}_{\mathrm{SI}^{-}}-4.2$ (R-24) of rigid insulation to the $\mathrm{R}_{\mathrm{SI}}-3.5$ (R-20) in the wall cavity. The basement wall requirement for 2012 IECC is $\mathrm{R}_{\mathrm{SI}}-1.8$ (R-10) of rigid insulation while the NZERTF adds $\mathrm{R}_{\mathrm{SI}}-2.1(\mathrm{R}-12)$ to the interior of the basement wall. The 2012 IECC design with typical framing uses blown-in insulation on the attic floor to reach $\mathrm{R}_{\mathrm{SI}}-8.6$ (R-49) of continuous insulation. The NZERTF roof construction uses the $\mathrm{R}_{\mathrm{SI}}-7.9$ (R-45) insulation in the rafters and adds rigid insulation to the exterior roof to reach an additional $\mathrm{R}_{\mathrm{SI}}-5.3$ (R-30).

The fenestration surface construction materials for windows are defined based on three simple parameters: U-factor, Solar Heat Gain Coefficient (SHGC), and Visible Transmittance (VT). This approach allows the rated window performance to be modeled while simplifying window "materials" and "constructions" in the simulation. The window parameters can be seen in Table 2-2, and are based on the minimum requirements specified in 2012 IECC and the BSC window specifications. ${ }^{1}$

Table 2-2 Window Specifications

\begin{tabular}{|l|l|c|}
\hline Field & Units & NZERTF \\
\hline U-Factor & $\mathrm{W} / \mathrm{m}^{2}-\mathrm{K}$ & 1.1356 \\
Solar Heat Gain Coefficient & & 0.25 \\
Visible Transmittance & & 0.40 \\
\hline
\end{tabular}

The NZERTF specifications from BSC include a target envelope tightness of 1 air change per hour $\left(0.352 \mathrm{~m}^{3} / \mathrm{s}\right.$ or $\left.749 \mathrm{CFM}\right)$ based on a blower door test at $50 \mathrm{~Pa}$ of air pressure $\left(\mathrm{ACH}_{50}\right)$. The air leakage test performed by Everyday Green (Everyday Green 2012) resulted in a whole house

\footnotetext{
${ }^{1}$ These parameters assume no difference in performance of the windows regardless of the window type (awning or double hung).
} 
air tightness of $0.215 \mathrm{~m}^{3} / \mathrm{s}$ (456 cubic feet per minute) at $50 \mathrm{~Pa}$, or $0.61 \mathrm{ACH}_{50}{ }^{2}$ In order to account for this envelope airtightness in $E+$, it must be converted to either an infiltration rate in air changes per hour or an effective leakage area (ELA), in both cases at a specific pressure difference, which does not account for HVAC system or weather. ELA is the area of an orifice with a discharge coefficient of 1.0 that would allow the same amount of airflow through it as that measured through the entire building envelope during the pressurization test and is usually determined at $4 \mathrm{~Pa}^{3}$

The approach chosen to model the building envelope in the occupied zones of the NZERTF is ELA. The whole building leakage test estimates the ELA to be $189.0 \mathrm{~cm}^{2}\left(29.3 \mathrm{in}^{2}\right)$, and is split between the $1^{\text {st }}$ floor and $2^{\text {nd }}$ floor based on occupied floor volume. The $1^{\text {st }}$ floor accounts for $52.3 \%$ of the occupied volume while the $2^{\text {nd }}$ floor accounts for the remaining $47.7 \%$, which leads to an ELA of $98.8 \mathrm{~cm}^{2}\left(15.3 \mathrm{in}^{2}\right)$ and $90.2 \mathrm{~cm}^{2}\left(14.0 \mathrm{in}^{2}\right)$, respectively.

All infiltration is assumed to occur in the occupied zones while the unoccupied zones in the conditioned space (basement, open web joists, and attic space) have no infiltration. The basement is fully underground and will only have infiltration through the egress window. The open web joists have minimal surface area shared with the exterior building envelope. The attic space may have some air leakage, but its leakage is grouped in with the $2^{\text {nd }}$ floor. The patio is not in the conditioned space, and will not impact the heating and cooling energy use.

A blower door test is performed to determine the envelope airtightness. It does not account for the effect of opening windows and doors (as a result of occupant activity) on infiltration. American Society of Heating, Refrigerating and Air-Conditioning Engineers (ASHRAE) 90.2-2007 assumes 0.15 ACH due to exhaust fans and occupants opening and closing of exterior doors and windows (ASHRAE 2007). Based on the way in which the NZERTF will be operated, there will be minimal occupant activity. For this reason, the model assumes no infiltration due to occupant activity. Nevertheless, the model was run with and without $0.15 \mathrm{ACH}$ for occupant activity and it resulted in an increase of $1825 \mathrm{kWh}(18 \%)$ in energy use relative to the model with no occupant activity credit, which emphasizes the importance of correctly accounting for building occupancy. Table 2-3 shows the parameters used to simulate air infiltration in the $E+$ model. The stack coefficient controls for the hydrostatic pressure resulting from changes in air density while the wind coefficient controls for the static pressure exerted by wind on the building. ${ }^{4}$ The stack coefficient value was selected based on the recommendations in the $E+$ documentation for a two-story house in the suburbs ("shelter class" 2).

\footnotetext{
${ }^{2}$ Note that the most recent air leakage test (March 9, 2013) led to a nearly identical leakage rate of $802 \mathrm{~m} 3 / \mathrm{h}$ at 50 $\mathrm{Pa}\left(470 \mathrm{CFM}_{50} ; 0.63 \mathrm{ACH}_{50}\right)$.

${ }^{3}$ Source: ASHRAE Fundamentals (2012) - Chapter 16

${ }^{4}$ For more details regarding the stack and wind coefficients, see the "Basic Model Stack Coefficient" and "Basic Model Wind Coefficient" in ASRHAE Fundamentals Handbook.
} 
Table 2-3 Infiltration Rates

\begin{tabular}{|l|c|c|}
\hline Name & $1^{\text {st }}$ Floor & $2^{\text {nd }}$ Floor \\
\hline ELA $\left(\mathrm{cm}^{2}\right)$ & 98.8 & 90.2 \\
\hline Stack Coeff. & 0.00029 & 0.00029 \\
\hline Wind Coeff. & 0.000325 & 0.000325 \\
\hline
\end{tabular}

\subsection{Pre-Demonstration Adjustments to NZERTF Simulation}

Kneifel (2013) makes some adjustments to the NZERTF simulation model to better match the planned operation of the NZERTF during the demonstration phase. Each of the changes, most of which will have minor to no impact on energy performance, is listed in Table 2-4. The most significant changes are the lighting wattage adjustments, which will increase the lighting-based energy consumption.

Table 2-4 Changes in NZERTF Assumptions

\begin{tabular}{|c|c|c|c|}
\hline Category & Subcategory & Day of Week & Detail of Change \\
\hline Occupancy & $\begin{array}{l}\text { Child A in Bedroom } \\
\text { Activity Levels }\end{array}$ & $\begin{array}{l}\text { Saturday } \\
\text { All Days }\end{array}$ & $\begin{array}{l}\text { Starts @ 19:30 instead of 20:30 } \\
\text { Constant 65 W Sensible, 31 W Latent }\end{array}$ \\
\hline Domestic Hot Water & $\begin{array}{l}\text { Kitchen Sink } \\
\text { Master Bedroom Sink } \\
\text { Dishwasher } \\
\text { Clothes Washing Machine }\end{array}$ & $\begin{array}{l}\text { Monday } \\
\text { Saturday } \\
\text { Friday } \\
\text { Wednesday }\end{array}$ & $\begin{array}{l}\text { Added } 1 \text { min @ 6:05 } \\
\text { Added } 1 \text { min @ 8:50 } \\
\text { Changed 20:28\&21:28 from 20:15\&21:15 } \\
\text { Added 1 Load @ 18:30 }\end{array}$ \\
\hline Electrical Equipment & $\begin{array}{l}\text { Range Hood } \\
\text { Iron }\end{array}$ & $\begin{array}{l}\text { All Days } \\
\text { All Days }\end{array}$ & $\begin{array}{l}\text { Changed Wattage to } 75 \mathrm{~W} \text { from } 330 \mathrm{~W} \\
\text { Added to Master Bedroom }\end{array}$ \\
\hline Lighting & $\begin{array}{l}\text { Kitchen } \\
\text { Dining Room } \\
\text { Living Room } \\
\text { Office } \\
\text { Master Bedroom } \\
\text { Bedroom } 2 \\
\text { Bedroom } 3 \\
\text { Master Bathroom } \\
\text { Bathroom } 2 \\
1^{\text {st }} \text { Floor Bathroom }\end{array}$ & $\begin{array}{l}\text { All Days } \\
\text { All Days } \\
\text { All Days } \\
\text { All Days } \\
\text { All Days } \\
\text { All Days } \\
\text { All Days } \\
\text { All Days } \\
\text { All Days } \\
\text { All Days }\end{array}$ & $\begin{array}{l}\text { Changed to } 118 \mathrm{~W} \text { from } 107 \mathrm{~W} \\
\text { Changed to } 65 \mathrm{~W} \text { from } 13 \mathrm{~W} \\
\text { Changed to } 118 \mathrm{~W} \text { from } 92 \mathrm{~W} \\
\text { Changed to } 41 \mathrm{~W} \text { from } 28 \mathrm{~W} \\
\text { Changed to } 41 \mathrm{~W} \text { from } 13 \mathrm{~W} \\
\text { Changed to } 41 \mathrm{~W} \text { from } 28 \mathrm{~W} \\
\text { Changed to } 41 \mathrm{~W} \text { from } 28 \mathrm{~W} \\
\text { Changed to } 81 \mathrm{~W} \text { from } 72 \mathrm{~W} \\
\text { Changed to } 63 \mathrm{~W} \text { from } 24 \mathrm{~W} \\
\text { Changed to } 44 \mathrm{~W} \text { from } 46 \mathrm{~W}\end{array}$ \\
\hline Roof Assembly & Insulation & All Days & $\begin{array}{l}\text { Changed to } 3.81 \mathrm{~cm}(1.5 \mathrm{in}) \text { isocyanurate } \\
\text { from } 2.54 \mathrm{~cm}(1.0 \mathrm{in})\end{array}$ \\
\hline Thermostat & $\begin{array}{l}\text { Cooling Setpoint } \\
\text { Heating Setpoint } \\
\text { Availability }\end{array}$ & $\begin{array}{l}\text { All Days } \\
\text { All Days } \\
\text { All Days }\end{array}$ & $\begin{array}{l}\text { Changed to constant } 75^{\circ} \mathrm{F} \\
\text { Changed to constant } 70^{\circ} \mathrm{F} \\
\text { Changed to always available }\end{array}$ \\
\hline
\end{tabular}




\subsection{Systems, Occupancy, and Operation}

The occupant's use of the NZERTF is just as important as the building envelope design when it comes to meet its annual net zero energy goal. The building components (e.g., interior equipment and lighting systems), occupant preferences (e.g., thermostat setpoints), and occupant behavior (e.g., occupancy, hot water use, and activity levels) all impact a house's energy performance (see Table 2-5).

Table 2-5 Systems, Occupants, and Operating Conditions

\begin{tabular}{|c|c|c|}
\hline Building System & Component & Details \\
\hline Occupants & People & 4 \\
\hline Setpoints & & $\begin{array}{l}23.9^{\circ} \mathrm{C}\left(75^{\circ} \mathrm{F}\right) \text { Cooling } \\
21.1^{\circ} \mathrm{C}\left(70^{\circ} \mathrm{F}\right) \text { Heating } \\
50 \% \text { Maximum Humidity }\end{array}$ \\
\hline Lighting & Light Bulbs & $100 \%$ High Efficiency Lighting \\
\hline HVAC & $\begin{array}{l}\text { Air Conditioning } \\
\text { Heating } \\
\text { Ventilation/Outdoor Air }\end{array}$ & $\begin{array}{l}\text { Heat Pump (SEER 15.8) } \\
\text { Heat Pump (HSPF 9.05) } \\
\text { Electric Resistance (0.98) } \\
\text { Heat Recovery Ventilator }\end{array}$ \\
\hline DHW & Water Heater Tank & Heat Pump Water Heater $(\mathrm{COP}=2.6)$ \\
\hline Solar & $\begin{array}{l}\text { Solar Thermal System } \\
\text { Solar PV System }\end{array}$ & $\begin{array}{l}2 \text { Panel with } 303 \mathrm{~L} \text { ( } 80 \text { gallon) tank } \\
10.2 \mathrm{~kW}\end{array}$ \\
\hline
\end{tabular}

The NZERTF includes a high-efficiency heat pump, dedicated outdoor air system with a heat recovery ventilator (HRV), and heat pump water heater with a coefficient of performance (COP) of 2.6 and electric back up element (thermal efficiency of 0.98) internal to the water heater tank. Additionally, the NZERTF installs two solar thermal panels and $303 \mathrm{~L}$ (80 gallon) storage tank to preheat water entering the heat pump water heater. The NZERTF installs the largest possible solar photovoltaic (PV) system $(10.2 \mathrm{~kW})$ based on the surface areas of the roof. All lighting fixtures $(100 \%)$ in the NZERTF are high-efficiency bulbs (compact fluorescent or light emitting diode).

\subsubsection{Occupancy}

The occupancy is assumed to be a family of four, two parents and two children (14 years old and 8 years old). The assumed occupant activity levels and the resulting sensible and latent heat gains shown in Table 2-6 are based on Hendron and Engebrecht (2010). The loads are assumed to be constant, which should be representative of the occupancy impacts, on average. There will be some variation depending on the actual activity of the occupants. 
Table 2-6 Occupant Activity Level

\begin{tabular}{|l|c|c|}
\hline \multirow{2}{*}{$\begin{array}{l}\text { Occupant } \\
\text { Internal Load }\end{array}$} & \multicolumn{2}{|c|}{$\mathrm{kJ}(\mathrm{Btu})$ Per Hour } \\
\cline { 2 - 3 } & $1^{\text {st }}$ Floor & $2^{\text {nd }}$ Floor \\
\hline Sensible & $243(230)$ & $221(210)$ \\
\hline Latent & $200(190)$ & $148(140)$ \\
\hline
\end{tabular}

Occupancy schedules for each of the four family members are based on a meticulously detailed 7 day narrative defined in Omar and Bushby (2013). Figure 2-4 condenses the occupancy schedules to create an occupancy density in the NZERTF by hour of each day of the week. For greater detail, see Omar and Bushby (2013), Kneifel (2012), and Kneifel (2013).

Occupancy Densities

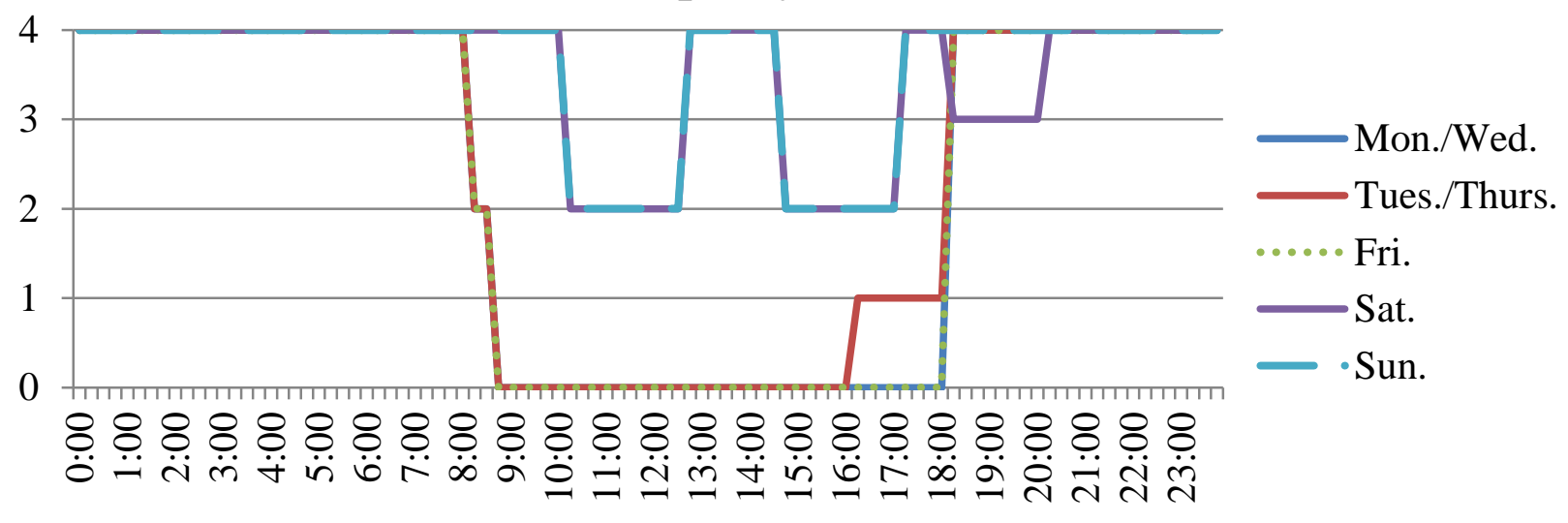

Figure 2-4 Occupancy Density

\subsubsection{Lighting}

Electricity use and internal loads from interior lighting in the NZERTF are estimated based on Omar and Bushby (2013) to determine occupancy by room, and then turning on all lights in the room while it is occupied. The sum of lighting wattage by room is shown in Table 2-7. Only some of the rooms in the conditioned space are assumed to be occupied during the narrative. For example, lights in the office and hallways are never turned on. Based on the narrative, the use of these areas should be minimal (i.e., a few seconds at a time). The lighting schedules in terms of fraction of peak wattage (FPW) can be found in Kneifel (2012). 


\section{Table 2-7 Lighting Total Wattage by Room}

\begin{tabular}{|ll|r|}
\hline Floor & Room & Watts \\
\hline $1^{\text {st }}$ & Kitchen & 118 \\
& Dining Room & 65 \\
& Living Room & 118 \\
& Office & 0 \\
& $1^{\text {st }}$ Floor Bath & 46 \\
\hline $2^{\text {nd }}$ & Master Bedroom & 41 \\
& $2^{\text {nd }}$ Bedroom & 41 \\
& $3^{\text {rd }}$ Bedroom & 41 \\
& Master Bathroom & 81 \\
& $2^{\text {nd }}$ Bathroom & 63 \\
\hline Basement & \multicolumn{2}{|c|}{} \\
\hline
\end{tabular}

All other lighting is assumed to be zero. The office lights are assumed to never be used based on the defined occupant schedule for the NZERTF. The lighting in the basement is currently assumed to never be used because it is neither finished nor occupied during the year. Exterior lighting for the patio, garage, and the outdoor lights has been excluded. Garage and exterior lighting are not of a major concern because the lighting does not impact the thermal load of the NZERTF, and will only slightly increase electricity use if included in the model.

\subsubsection{Non-HVAC Interior Equipment}

Non-HVAC interior equipment includes large appliances and any miscellaneous electrical loads (MELs), such as televisions, computers, hair dryers, etc. Table 2-8 shows the large appliances to be installed in the NZERTF by the contractor, their wattage, and the fraction of electricity used by the appliances that is converted into sensible and latent loads. ${ }^{5}$ The Energy Star ratings are used to calculate the average wattage for the operation of the refrigerator, clothes washer, and dishwasher (EnergyStar 2012). The dishwasher is rated at $234 \mathrm{kWh}$ per year for 215 loads. Assuming a 1-hour cleaning cycle, the average wattage is $1090 \mathrm{~W}$. The clothes washer is rated at $155 \mathrm{kWh}$ per year for 416 loads. Assuming a 45-minute cleaning cycle, the average wattage is $500 \mathrm{~W}$. The refrigerator combines the Energy Star rated energy use (335 kWh) and the load profile from Hendron and Engebrecht (2010) to reverse engineer the peak wattage $(45.7 \mathrm{~W})$ to generate the target electricity use. The wattages of the clothes dryer and cooking equipment are based on the manufacturing specifications. ${ }^{6}$

\footnotetext{
${ }^{5}$ The NZERTF will simulate the cooktop in a different manner. Once the approach is finalized, the model will be updated.

${ }^{6}$ The clothes dryer is assumed to run at peak wattage the entire drying cycle, which likely overestimates electricity use. The range hood wattage is based on initial equipment specifications because information was not available on the Wolf range hood at the time of simulation development.
} 
Table 2-8 Appliance Wattage and Sensible and Latent Load Fractions

\begin{tabular}{|l|l|l|r|r|r|}
\hline Appliance & Brand & Model & Average & Sensible Load & Latent Load \\
\hline Refrigerator & Frigidaire & FPUI1888L & 45.7 & 1.00 & 0.00 \\
\hline Clothes Washer & Whirlpool & WFW97HEX & 500 & 0.80 & 0.00 \\
\hline Clothes Dryer & Whirlpool & WED97HEX & 5200 & 0.15 & 0.05 \\
\hline Dishwasher & Bosch & SHX68E15UC & 1090 & 0.60 & 0.15 \\
\hline Range - Oven & Wolf & SO30-2F/S-TH & 5100 & 0.40 & 0.30 \\
\hline Range - Cooktop & Wolf & CT301/S & $3600^{*}$ & 0.40 & 0.30 \\
\hline Range - Hood & Wolf & CTWH30 & 330 & 0.00 & 0.00 \\
\hline Microwave & Wolf & MWD30-2F/S & 950 & 1.00 & 0.00 \\
\hline *Assumes the use of only 2 burners.
\end{tabular}

The MELs listed in Table 2-9 are defined in Omar and Bushby (2013) with any item that is used in an "average" household included in the $E+$ model. $^{7}$ The total annual electricity use for each MEL is used to reverse engineer the wattage for the equipment. The MELs can be grouped into constant loads and variable loads. The sensible and latent load fractions are based on Hendron and Engebrecht (2010). The sensible load is assumed to be split 50/50 with convection/radiant fraction.

Table 2-9 Miscellaneous Electrical Load Wattage and Sensible and Latent Loads

\begin{tabular}{|l|l|l|r|r|r|}
\hline Location & Miscellaneous & Constant or & Watts & Sensible Load & Latent Load \\
\hline Bathroom & Curling Iron & Variable & 85 & 0.734 & 0.16 \\
\cline { 2 - 6 } & Hair Dryer & Variable & 1875 & 0.734 & 0.16 \\
\hline \multirow{4}{*}{ Kitchen } & Blender & Variable & 450 & 0.734 & 0.16 \\
\cline { 2 - 6 } & Can Opener & Variable & 70 & 0.734 & 0.16 \\
\cline { 2 - 6 } & Coffee Maker & Variable & 550 & 0.734 & 0.16 \\
\cline { 2 - 6 } & Hand Mixer & Variable & 250 & 0.734 & 0.16 \\
\cline { 2 - 6 } & Toaster & Variable & 1400 & 0.734 & 0.16 \\
\cline { 2 - 6 } & Toaster Oven & Variable & 1200 & 0.734 & 0.16 \\
\cline { 2 - 6 } & Slow Cooker & Variable & 25.64 & 0.734 & 0.16 \\
\hline \multirow{5}{*}{ Living Room } & Television & Variable & 62.2 & 0.734 & 0.16 \\
\cline { 2 - 6 } & Blu-Ray & Variable & 17 & 0.734 & 0.16 \\
\cline { 2 - 6 } & Cablebox & Constant & 17.48 & 0.734 & 0.16 \\
\cline { 2 - 6 } & Clock & Constant & 2.98 & 0.734 & 0.16 \\
\cline { 2 - 6 } & Stereo & Constant & 17.51 & 0.734 & 0.16 \\
\cline { 2 - 6 } & Video Game System & Variable & 26.98 & 0.734 & 0.16 \\
\hline \multirow{5}{*}{ Office } & Desktop Computer & Variable & 74 & 0.734 & 0.16 \\
\cline { 2 - 6 } & Desktop Monitor & Variable & 27.6 & 0.734 & 0.16 \\
\cline { 2 - 6 } & Answering Machine & Constant & 6.49 & 0.734 & 0.16 \\
\cline { 2 - 6 } & Modem & Constant & 2.01 & 0.734 & 0.16 \\
\cline { 2 - 6 } & & & &
\end{tabular}

${ }^{7}$ A particular MEL is included if the average number per household is greater than 0.5 . 


\begin{tabular}{|l|l|l|r|r|r|}
\cline { 2 - 6 } & Inkjet Printer & Constant & 4.46 & 0.734 & 0.16 \\
\cline { 2 - 6 } & Wireless Router & Constant & 24 & 0.734 & 0.16 \\
\cline { 2 - 6 } & Vacuum & Variable & 542 & 0.734 & 0.16 \\
\hline \multirow{5}{*}{ Master Bedroom } & & & & \\
& Heating Pad & Variable & 32.97 & 0.734 & 0.16 \\
\cline { 2 - 6 } & Television & Variable & 45.36 & 0.734 & 0.16 \\
\cline { 2 - 6 } & Blu-Ray & Variable & 17 & 0.734 & 0.16 \\
\cline { 2 - 6 } & Clock Radio & Constant & 1.71 & 0.734 & 0.16 \\
\cline { 2 - 6 } & Portable Fan & Variable & 19.76 & 0.734 & 0.16 \\
\cline { 2 - 6 } & 2 Cell Phones & Constant & 17.72 & 0.734 & 0.16 \\
\cline { 2 - 6 } & Other & Constant & 1.07 & 0.734 & 0.16 \\
\cline { 2 - 6 } & Cablebox & Constant & 17.48 & 0.734 & 0.16 \\
\hline $2^{\text {nd }}$ Bedroom & Boombox & Constant & 1.92 & 0.734 & 0.16 \\
\cline { 2 - 6 } & 1 Cell Phone & Constant & 8.86 & 0.734 & 0.16 \\
\cline { 2 - 6 } & Clock Radio & Constant & 1.71 & 0.734 & 0.16 \\
\cline { 2 - 6 } & Laptop A & Variable & 36.88 & 0.734 & 0.16 \\
\hline $3^{\text {rd }}$ Bedroom & Laptop B & Variable & 36.8 & 0.734 & 0.16 \\
\hline Note: Sensible and latent load fractions are based on Hendron and Engebrecht (2010). & \\
\hline
\end{tabular}

The MEL use schedules by room are defined in Omar and Bushby (2013) and can be found in Kneifel (2012). Some rooms have fairly consistent occupancy behavior (kitchen) while others vary significantly throughout the week (living room).

\subsubsection{Heating, Ventilation, and Air Conditioning (HVAC)}

The $E+$ model must specify all aspects of an HVAC system and the conditions to which the system must perform, including the thermostat setpoints, infiltration and ventilation rates, humidity controls, and HVAC equipment specifications. Each of these is defined in this section.

\subsubsection{Thermostat}

The thermostat setpoints for the demonstration phase were chosen after the model in Kneifel (2012) was developed. These setpoints, shown in Table 2-10, are based on protocols defined in Hendron and Engebrecht (2010) for the NZERTF's location. The heating and cooling equipment were also restricted to particular seasons. Kneifel (2013) simplified the setpoints to constants of $21.9^{\circ} \mathrm{C}\left(70.0^{\circ} \mathrm{F}\right)$ for heating and $23.9^{\circ} \mathrm{C}\left(75.0^{\circ} \mathrm{F}\right)$ for cooling, respectively. Additionally, heating and cooling are both made available year-round. These changes are based on the operation controls set for the demonstration phase of the NZERTF. 
Table 2-10 Thermostat Setpoints

\begin{tabular}{|c|c|c|c|c|}
\hline \multirow{2}{*}{$\begin{array}{l}\text { HVAC } \\
\text { Condition }\end{array}$} & \multicolumn{3}{|c|}{$\begin{array}{c}\text { Kneifel (2012) } \\
\text { Setpoints } \\
{ }^{\circ} \mathrm{C}\left({ }^{\circ} \mathrm{F}\right) \\
\end{array}$} & $\begin{array}{c}\text { Kneifel (2013) } \\
\text { Setpoints } \\
{ }^{\circ} \mathrm{C}\left({ }^{\circ} \mathrm{F}\right) \\
\end{array}$ \\
\hline & $\begin{array}{l}\text { Occupied- } \\
\text { Day }\end{array}$ & $\begin{array}{l}\text { Unoccupied- } \\
\text { Day }\end{array}$ & $\begin{array}{l}\text { Occupied- } \\
\text { Night }\end{array}$ & Constant \\
\hline Heati & $22.3(72.1)$ & $18.4(65.1)$ & $20.1(68.1)$ & $21.9(70.0)$ \\
\hline Cooling & $23.6(74.4)$ & $26.3(79.4)$ & $23.6(74.4)$ & $23.9(75.0)$ \\
\hline
\end{tabular}

\subsubsection{Outdoor Air Ventilation}

BSC used ASHRAE Standard 62.2-2007 to determine the minimum required mechanical outdoor air flow rate for the entire building to be $0.0392 \mathrm{~m}^{3} / \mathrm{s}$ ( 83 CFM). $E+$ requires a mechanical ventilation rate for each zone. The $1^{\text {st }}$ floor has $52.3 \%$ of the volume while the $2^{\text {nd }}$ floor has $47.7 \%$ of the volume of the occupied space. Based on these values, the required minimum outdoor air flow rates for each zone can be calculated based on a weighted fraction of the whole house mechanical ventilation as $0.02048 \mathrm{~m}^{3} / \mathrm{s}(20.5 \mathrm{~L} / \mathrm{s}$ or $43.4 \mathrm{CFM})$ for the $1^{\text {st }}$ floor, and $0.0187 \mathrm{~m}^{3} / \mathrm{s}(18.7 \mathrm{~L} / \mathrm{s}$ or $39.6 \mathrm{CFM})$ for the $2^{\text {nd }}$ floor. Mechanical ventilation is delivered through a HRV with dedicated ductwork. Currently, exhaust fans (bathroom fans or range hoods) are not included in the model for simplicity.

The HRV system in the NZERTF is a Venmar AVS HRV EKO 1.5 air-to-air heat exchanger. The HRV transfers heat between the exhaust air and supply air to decrease the heating and cooling load impact of the ventilation air. The HRV is the sole source of mechanical ventilation and operates year-round, 24 hours a day. The effectiveness of the HRV varies by the air flow rate and temperature differences across the heat exchange core, but is assumed to be the same for heating and cooling in the $E+$ model. Exhaust air recirculation is used to control for frost. The air flow rates through each HRV are based on the outdoor air requirement for each zone defined in Section 2.3.4.2. The $E+$ input values for the HRVs are listed in Table 2-11 (Venmar 2009). 
Table 2-11 Heat Recovery Ventilator

\begin{tabular}{|c|c|c|}
\hline Parameter & $1^{\text {st }}$ Floor & $2^{\text {nd }}$ Floor \\
\hline \multirow[t]{2}{*}{ Availability Schedule Name } & Always & Always \\
\hline & Available & Available \\
\hline Nominal Supply Air Flow Rate $\left(\mathrm{m}^{3} / \mathrm{s}\right)$ & 0.0205 & 0.0187 \\
\hline Sensible Effectiveness at $100 \%$ Heating Air Flow & 0.72 & 0.72 \\
\hline Latent Effectiveness at $100 \%$ Heating Air Flow & 0 & 0 \\
\hline Sensible Effectiveness at 75\% Heating Air Flow & 0.78 & 0.78 \\
\hline Latent Effectiveness at $75 \%$ Heating Air Flow & 0 & \\
\hline Sensible Effectiveness at $100 \%$ Cooling Air Flow & 0.72 & 0.72 \\
\hline Latent Effective & 0 & \\
\hline Sensible Effectiveness at $75 \%$ Cooling Air Flow & 0.78 & 0.78 \\
\hline Latent Effectiveness at $75 \%$ Cooling Air Flow & 0 & \\
\hline Nominal Electric Power (W) & 16.0 & 16.0 \\
\hline Supply Air Outlet Temperature Control & No & No \\
\hline Heat Exchanger Type & Plate & Plat \\
\hline \multirow[t]{2}{*}{ Frost Control Type } & Exhaust Air & Exhaust Air \\
\hline & Recirculation & Recirculation \\
\hline Threshold T & -5 & -5 \\
\hline Initial Defrost Time Fraction & 0.21875 & 0.21875 \\
\hline Rate of Defrost Time Fraction Increase & 0.004261 & 0.004261 \\
\hline Economizer Lockout & No & No \\
\hline
\end{tabular}

\subsubsection{Heating and Cooling Equipment}

Heating and air conditioning during the demonstration phase are accomplished with a multispeed air-to-air heat pump with dehumidification-only mode. $E+$ does not currently allow a multispeed air-to-air heat pump to run in dehumidification-only mode, requiring modeling of separate equipment to dehumidify the occupied space. It is not currently possible to simulate a whole house dehumidifier in $E+$. As a result, the $E+$ model simulates a dehumidifier in each of the occupied zones $\left(1^{\text {st }}\right.$ floor and $2^{\text {nd }}$ floor $)$. The model also does not allow more than one whole house air loop, which forces the splitting of the HRV system into two zone-level HRV systems. Figure 2-5 shows the HVAC system modeled in the $E+$ simulation. 


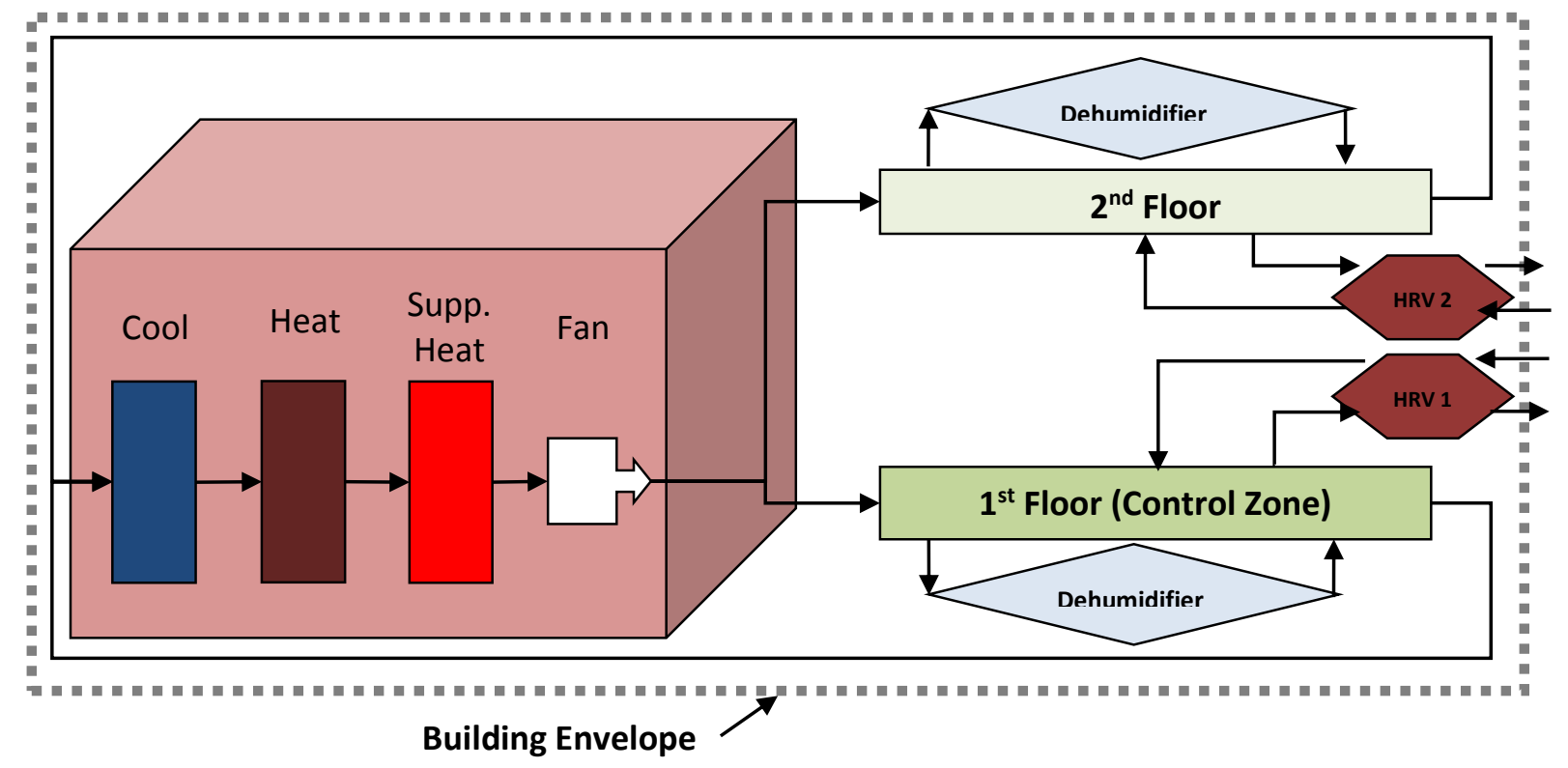

Figure 2-5 HVAC System Layout

The HVAC air-to-air heat pump is properly sized based on the assumed design day conditions (i.e., oversized by $0 \%$ ). There are only 2 zones that require their temperature to be controlled by the HVAC equipment, the $1^{\text {st }}$ floor and $2^{\text {nd }}$ floor. The $1^{\text {st }}$ floor is used as the controlling zone, or the location of the thermostat. This location will result in a floating of the $2^{\text {nd }}$ floor air temperatures. The basement is conditioned, but since the space is not finished and will not be occupied during the demonstration phase, it is not necessary for the setpoint temperatures to be met in the basement. The open web joist space and attic space are in the conditioned space, but there is supply air from ductwork entering those spaces and the temperatures are allowed to fully float.

The $E+$ input list in Table 2-12 are made for the sizing of thermal loads for each conditioned zone. Note that there is no outdoor air drawn through the heating and cooling system ductwork. All mechanical ventilation of outdoor air is supplied by the HRVs.

Table 2-12 Zone Sizing Parameters

\begin{tabular}{|ll|l|l|l|}
\hline Parameter & Units & $\mathbf{1}^{\text {st }}$ Floor & $\mathbf{2}^{\text {nd }}$ Floor & Basement \\
\hline Zone Cooling Design Supply Air Temperature & ${ }^{\circ} \mathrm{C}\left({ }^{\circ} \mathrm{F}\right)$ & $12(54)$ & $12(54)$ & $12(54)$ \\
Zone Heating Design Supply Air Temperature & ${ }^{\circ} \mathrm{C}\left({ }^{\circ} \mathrm{F}\right)$ & $30(86)$ & $30(86)$ & $30(86)$ \\
Zone Cooling Design Supply Air Humidity & $\mathrm{kg}-\mathrm{H} 2 \mathrm{O} / \mathrm{kg}-\mathrm{air}$ & 0.008 & 0.008 & 0.008 \\
Zone Heating Design Supply Air Humidity & $\mathrm{kg}-\mathrm{H} 2 \mathrm{O} / \mathrm{kg}-\mathrm{air}$ & 0.008 & 0.008 & 0.008 \\
Outdoor Air Method & & Flow/Zone & Flow/Zone & Flow/Zone \\
Outdoor Air Flow Per Zone & $\mathrm{m}^{3} / \mathrm{s}$ & 0.0 & 0.0 & 0.0 \\
Cooling Design Air Flow Method & & Design Day & Design Day & Design Day \\
Heating Design Air Flow Method & & Design Day & Design Day & Design Day \\
\hline
\end{tabular}


The E+ input list in Table 2-13 is for the sizing of the air-to-air heat pump, which includes the fan and coils. The outdoor air flow rate is autosized as the sum of the zone-specific outdoor air flow rates, which totals to zero because the HRV system will meet all outdoor air requirements.

\section{Table 2-13 HVAC System Sizing Parameters}

\begin{tabular}{|ll|l|}
\hline Field & Units & Value \\
\hline Type of Load to Size On & & Sensible \\
Design Outdoor Air Flow Rate & $\mathrm{m}^{3} / \mathrm{s}$ & Autosize \\
Minimum System Air Flow Ratio & & 0.40 \\
Preheat Design Temperature & ${ }^{\circ} \mathrm{C}\left({ }^{\circ} \mathrm{F}\right)$ & $7(45)$ \\
Preheat Design Humidity Ratio & $\mathrm{kg}-\mathrm{H} 2 \mathrm{O} / \mathrm{kg}$-air & 0.008 \\
Precool Design Temperature & ${ }^{\circ} \mathrm{C}\left({ }^{\circ} \mathrm{F}\right)$ & $25(77)$ \\
Precool Design Humidity Ratio & $\mathrm{kg}-\mathrm{H} 2 \mathrm{O} / \mathrm{kg}$-air & 0.008 \\
Central Cooling Design Supply Air Temperature & ${ }^{\circ} \mathrm{C}\left({ }^{\circ} \mathrm{F}\right)$ & $12(54)$ \\
Central Heating Design Supply Air Temperature & ${ }^{\circ} \mathrm{C}\left({ }^{\circ} \mathrm{F}\right)$ & $30(86)$ \\
Sizing Option & & Non-Coincident \\
100\% Outdoor Air in Cooling & & No \\
100\% Outdoor Air in Heating & & No \\
Central Cooling Design Supply Air Humidity Ratio & $\mathrm{kg}-\mathrm{H}_{2} \mathrm{O} / \mathrm{kg}$-air & 0.008 \\
Central Heating Design Supply Air Humidity Ratio & $\mathrm{kg}-\mathrm{H}_{2} \mathrm{O} / \mathrm{kg}$-air & 0.008 \\
Cooling Design Air Flow Method & & Design Day \\
Heating Design Air Flow Method & & Design Day \\
\hline
\end{tabular}

The HVAC fan is a constant volume draw-through fan and has the E+ inputs listed in Table 2-14.

Table 2-14 HVAC Fan Parameters

\begin{tabular}{|l|l|}
\hline Availability & Always Available \\
\hline Fan Efficiency & $70 \%$ \\
Pressure Rise & $125 \mathrm{~Pa}$ \\
Maximum Flow Rate & $0.42 \mathrm{~m}^{3} / \mathrm{s}$ \\
Motor Efficiency & $90 \%$ \\
Motor in Airstream Fraction & 1.0 \\
\hline
\end{tabular}

The NZERTF has a 2-ton AAON heat pump that has 2 speeds with gas reheat for dehumidification control. The following tables define the parameters for a the 2-ton, 2-speed heat pump based on Electrical Testing Labs (ETL) test data.

Table 2-15 shows the $E+$ inputs for the cooling coil, which is a multispeed air-cooled electric direct expansion (DX) coil. The cooling coil is assumed to have two speeds, referred to as "low 
speed" and "high speed." At low speed, the coil capacity is $5483 \mathrm{~W}$ with a rated coefficient of performance (COP) of 3.73 and a rated air flow rate of $0.23 \mathrm{~m}^{3} / \mathrm{s}$ (487 CFM). At high speed, the coil capacity is $7751 \mathrm{~W}$ with a rated COP of 3.69 and a rated air flow rate of $0.42 \mathrm{~m}^{3} / \mathrm{s}$ (890 CFM).

\section{Table 2-15 Cooling Coil}

\begin{tabular}{|lc|c|}
\hline Field & Units & Values \\
\hline Availability & & Always Available \\
Condenser Type & Air Cooled \\
Apply Part Load Fraction to Speeds Greater than 1 & No \\
Apply Latent Degradation to Speeds Greater than 1 & & No \\
Fuel Type & & Electricity \\
Number of Speeds & & 2 \\
Speed 1 Rated Total Cooling Capacity & $\mathrm{W}$ & 5483 \\
Speed 1 Rated Sensible Heat Ratio & & 0.7 \\
Speed 1 Rated COP & & 3.73 \\
Speed 1 Rated Air Flow Rate & $\mathrm{m} 3 / \mathrm{s}$ & 0.23 \\
Speed 1 Rated Waste Heat Fraction of Power Input & & 0.1 \\
Speed 1 Evaporative Condenser Effectiveness & & 0.9 \\
Speed 2 Rated Total Cooling Capacity & $\mathrm{W}$ & 7751 \\
Speed 2 Rated Sensible Heat Ratio & & 0.7 \\
Speed 2 Rated COP & & 3.69 \\
Speed 2 Rated Air Flow Rate & 0.42 \\
Speed 2 Rated Waste Heat Fraction of Power Input & & 0.1 \\
Speed 2 Evaporative Condenser Effectiveness & & 0.9 \\
\hline
\end{tabular}

The cooling coil performance curve types can be found in Table 2-16. The specifics of each curve are not reported here because of their complexity. Details on the functions are available upon request.

\section{Table 2-16 Cooling Coil Performance Curves}

\begin{tabular}{|l|l|l|}
\hline Cooling Coil Performance Curve Type & Name & Form \\
\hline Total Cooling Capacity Function of Temp. Curve & Heat Pump Cool Coil Cap-FT & Biquadratic \\
Total Cooling Capacity Function of Flow Fraction Curve & Heat Pump Cool Coil Cap-FF & Quadratic \\
Energy Input Ratio Function of Temp. Curve & Heat Pump Cool Coil EIR-FT & Biquadratic \\
Energy Input Ratio Function of Flow Fraction Curve & Heat Pump Cool Coil EIR-FF & Quadratic \\
Part Load Fraction Correlation Curve & Heat Pump Cool Coil PLF & Quadratic \\
Waste Heat Function of Temperature Curve & Waste Heat-FT & Biquadratic \\
\hline
\end{tabular}

The heating coil E+ inputs can be found in Table 2-17. The heating coil is a multispeed electric DX coil, and as with the cooling coil, the heating coil is assumed to have two speeds, referred to 
as "low speed" and "high speed." At low speed, the coil capacity is $4908 \mathrm{~W}$ with a rated COP of 4.02 and a rated air flow rate of $0.21 \mathrm{~m}^{3} / \mathrm{s}$ (487 CFM). At high speed, the coil capacity is $7675 \mathrm{~W}$ with a rated COP of 4.19 and a rated air flow rate of $0.42 \mathrm{~m}^{3} / \mathrm{s}(890 \mathrm{CFM})$.

\section{Table 2-17 Heating Coil}

\begin{tabular}{|lc|c|}
\hline Field & Units & Value \\
\hline Availability & & Always Available \\
Minimum ODB Temp. for Compressor Operation & ${ }^{\circ} \mathrm{C}$ & -17 \\
Crankcase Heater Capacity & $\mathrm{W}$ & 0 \\
Maximum ODB Temp. for Crankcase Heater Operation & ${ }^{\circ} \mathrm{C}$ & 10 \\
Maximum ODB Temp. for Defrost Operation & ${ }^{\circ} \mathrm{C}$ & 7.22 \\
Defrost Strategy & & Reverse Cycle \\
Defrost Control & & On Demand \\
Defrost Time Period Fraction & & 0.058333 \\
Resistive Defrost Heater Capacity & $\mathrm{W}$ & Autosize \\
Apply Part Load Fraction to Speeds Greater than 1 & & No \\
Fuel Type & & Electricity \\
Number of Speeds & & 2 \\
Speed 1 Rated Total Heating Capacity & $\mathrm{W}$ & 4908 \\
Speed 1 Rated COP & & 4.02 \\
Speed 1 Rated Air Flow Rate & $\mathrm{m}{ }^{3} / \mathrm{s}$ & 0.21 \\
Speed 1 Rated Waste Heat Fraction of Power Input & & 0.1 \\
Speed 2 Rated Total Heating Capacity & $\mathrm{W}$ & 7675 \\
Speed 2 Rated COP & & 4.19 \\
Speed 2 Rated Air Flow Rate & $\mathrm{m}^{3} / \mathrm{s}$ & 0.42 \\
Speed 2 Rated Waste Heat Fraction of Power Input & & 0.1 \\
\hline Note: ODB = Outdoor Dry-Bulb & \\
\hline
\end{tabular}

The heating coil performance curve types can be found in Table 2-18. The specifics of each curve are not reported here because of their complexity. Function details are available upon request.

\section{Table 2-18 Heating Coil Performance Curves}

\begin{tabular}{|l|l|l|}
\hline Heating Coil Performance Curve Category & Name & Form \\
\hline Total Heating Capacity Function of Temp. Curve & Heat Pump Heat Coil Cap-FT & Cubic \\
Total Heating Capacity Function of Flow Fraction Curve & Heat Pump Heat Coil Cap-FF & Cubic \\
Energy Input Ratio Function of Temp. Curve & Heat Pump Heat Coil EIR-FT & Cubic \\
Energy Input Ratio Function of Flow Fraction Curve & Heat Pump Heat Coil EIR-FF & Quadratic \\
Part Load Fraction Correlation Curve & Heat Pump Heat Coil PLF & Quadratic \\
Waste Heat Function of Temperature Curve & Waste Heat-FT & Biquadratic \\
Defrost Energy Input Ratio Function of Temp. Curve & Heat Pump Heat Coil DefCap-FT & Biquadratic \\
\hline
\end{tabular}


The supplemental heating coil is an electric resistance heating element with an efficiency of 1.0 and an autosized capacity. The operation of the NZERTF will attempt to minimize the need for the supplemental heating element.

The "tight" building envelope design could lead to high humidity issues throughout the year. The advanced technology heat pump being installed in the NZERTF has the capability to run in dehumidification-only mode. However, $E+$ cannot currently model such advanced equipment and can only model dehumidifiers for a single zone. To overcome this limitation, the model instead assumes operation of two dehumidifiers, one dedicated to each of the two occupied floors. Since the building specifications include an Ultra-Aire $70 \mathrm{H}$ whole house ventilating dehumidifier that was not actually used during the first year of operation, the simulations use characteristics of that unit. The humidity level in the simulation model is controlled by two DX dehumidifiers, one for each floor.

The dehumidifiers are operated based on the dehumidifying setpoint of $60 \%$ (Hendron and Engebrecht 2010). The equipment is available year-round to run whenever the relative humidity reaches $60 \%$ in its zone ( $1^{\text {st }}$ floor or $2^{\text {nd }}$ floor) regardless of whether the heat pump is running to meet the setpoint temperature and when the heat pump is not running when the setpoint temperature is met.

The specifications for this dehumidifier along with estimated water removal and energy factor curves from the Ultra-Aire $70 \mathrm{H}$ are used to define the parameters and performance curves shown in Table 2-19 and Table 2-20, which are used for the DX humidifiers in the simulation (Christensen and Winkler 2009; Ultra-Aire 2011). The rated energy factor is assumed to be half (1.0 L ( 0.26 gal.) per kWh) of the Ultra-Aire equipment rating (2.0 L ( 0.53 gal.) per $\mathrm{kWh})$ to ensure a conservative (high) electricity consumption estimate. The water removal rate of $30.75 \mathrm{~L}$ (8.1 gal.) per day for the Ultra-Aire $70 \mathrm{H}$ is split between the $1^{\text {st }}$ floor $(16.08 \mathrm{~L}$ [4.24 gal.] per day) and $2^{\text {nd }}$ floor (14.67 L [3.86 gal.] per day) based on occupied volume. The model assumes $100 \%$ of compressor heat is rejected into the conditioned zone. The Ultra-Aire $70 \mathrm{H}$ dehumidifier will be located in the basement, causing the simulation model to slightly overestimate the temperature level in each occupied zone.

\section{Table 2-19 Dehumidifier Parameters}

\begin{tabular}{|lc|c|c|}
\hline Field & Units & $\mathbf{1}^{\text {st }}$ Floor & $\mathbf{2}^{\text {nd }}$ Floor \\
\hline Availability & & Always Available & Always Available \\
Rated Water Removal & L/day (pints/day) & $16.08(33.98)$ & $14.67(31.00)$ \\
Rated Energy Factor & $\mathrm{L} / \mathrm{kWh}$ & 1.0 & 1.0 \\
Rate Air Flow Rate & $\mathrm{m}^{3} / \mathrm{s}(\mathrm{CFM})$ & $0.897(190)$ & $0.897(190)$ \\
Min. Dry-Bulb & ${ }^{\circ} \mathrm{C}\left({ }^{\circ} \mathrm{F}\right)$ & $-1.1(30.0)$ & $-1.1(30.0)$ \\
Max. Dry-Bulb & ${ }^{\circ} \mathrm{C}\left({ }^{\circ} \mathrm{F}\right)$ & $32.2(90.0)$ & $32.2(90.0)$ \\
Off-Cycle Parasitic Elect. Load & $\mathrm{W}$ & 0.0 & 0.0 \\
\hline
\end{tabular}


The dehumidifier water removal curve and energy factor curve coefficient values are shown in Table 2-20.

\section{Table 2-20 Dehumidifier Performance Curves}

\begin{tabular}{|l|r|r|}
\hline Curves & Water Removal & Energy Factor \\
\hline Constant & -1.281357458 & -2.743752887 \\
$X$ & 0.032064893 & 0.114491512 \\
$X^{2}$ & -0.000280794 & -0.001456831 \\
Y & 0.028356002 & 0.053860412 \\
$Y^{2}$ & -0.000134939 & -0.000244965 \\
$X^{*} Y$ & 0.000271496 & -0.000362021 \\
Min. X & 4.4 & 4.4 \\
Max. X & 50 & 50 \\
Min. Y & 0 & 0 \\
Max. Y & 100 & 100 \\
\hline X= Inlet Air Dry-Bulb Temperature \\
Y= Inlet Air Relative Humidity \\
\hline
\end{tabular}

\subsubsection{Domestic Hot Water}

The domestic hot water (DHW) system installed in the NZERTF includes a number of potential combinations of equipment, including 4 solar thermal collectors, two storage tanks, a heat exchanger, and a heat pump water heater. The remainder of this section will define the DHW system and the DHW consumption simulated during the demonstration phase of the NZERTF.

\subsubsection{Domestic Hot Water Heater Equipment}

The DHW system simulated in the model, as shown in Figure 2-6, is a two tank system located in the basement with two solar thermal panels located on the east half of the front porch heating a storage tank and an air-to-water heat pump downstream of the storage tank. The solar thermal system uses a 50/50 water/glycol mix and indirectly heats the water in the storage tank through a heat exchanger. The heat pump draws water from the storage tank and will further heat the water if necessary to meet the target exit temperature of $48.9^{\circ} \mathrm{C}\left(120^{\circ} \mathrm{F}\right)$ for hot water use. 


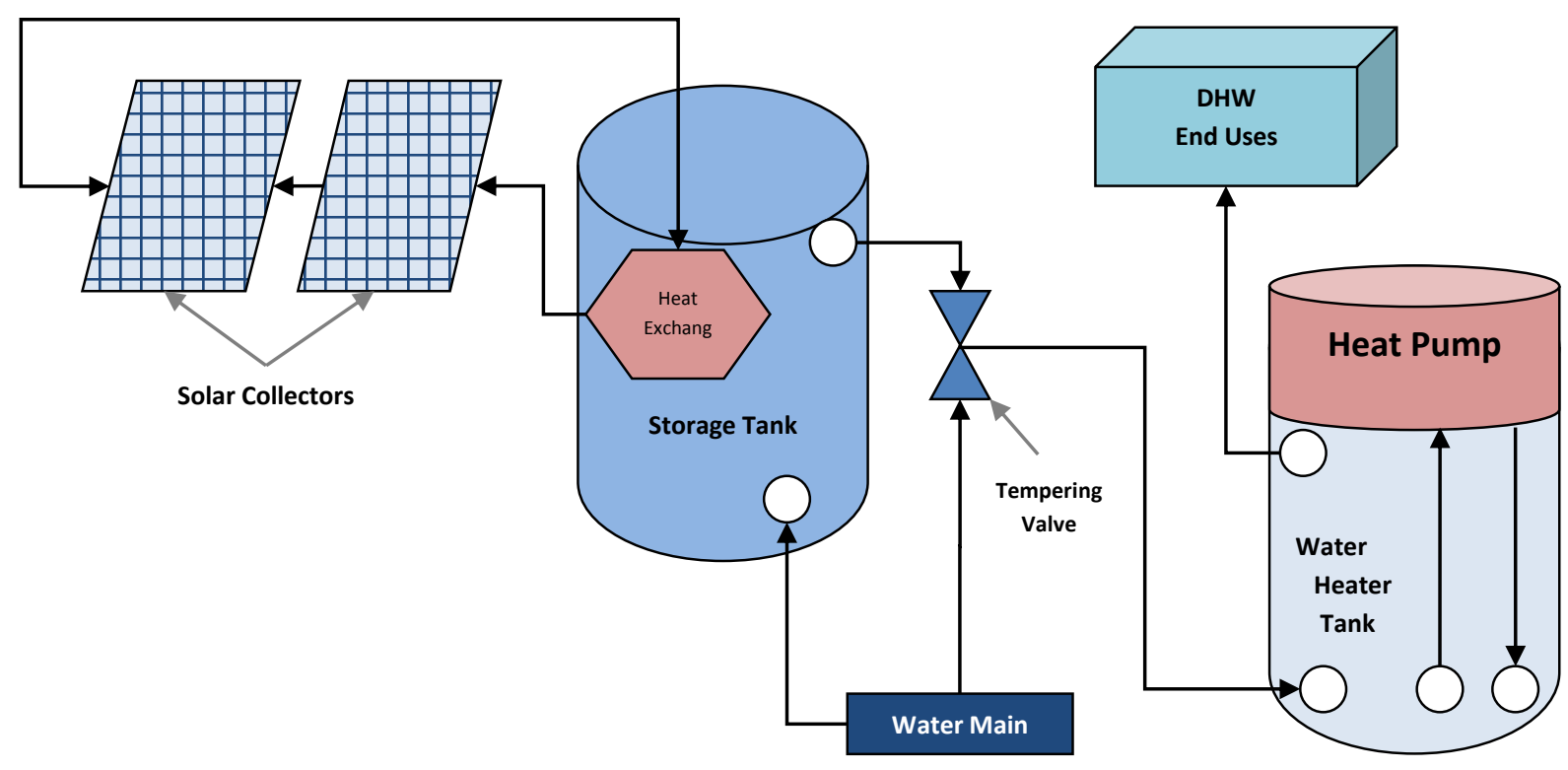

Figure 2-6 Domestic Hot Water Heating System

There are two tanks in the system, a $0.30 \mathrm{~m}^{3}$ ( 80 gal.) storage tank pre-heated by the solar thermal system and a $0.19 \mathrm{~m}^{3}$ (50 gal.) tank connected to the heat pump. The maximum temperature allowed is $76.6^{\circ} \mathrm{C}\left(170.0^{\circ} \mathrm{F}\right)$ for the storage tank and $71.1{ }^{\circ} \mathrm{C}\left(160.0{ }^{\circ} \mathrm{F}\right)$ for the water heater tank. The heat pump turns on when the water heater tank water temperature drops below $49.0^{\circ} \mathrm{C}\left(120.2^{\circ} \mathrm{F}\right)$ and turns off once the temperature increases to $54.0^{\circ} \mathrm{C}\left(129.2{ }^{\circ} \mathrm{F}\right)$. The back-up supplemental electric heating coil will turn on if the heat pump cannot maintain the water temperature above $48.9^{\circ} \mathrm{C}\left(120.2^{\circ} \mathrm{F}\right)$ at the location in the tank of the electric coil. Based on the heat pump characteristics and the location, the back-up electric heater should rarely be required to meet the hot water demand. The Heliodyne HPAK heat exchanger is able to transfer $80 \%$ of the energy from the solar thermal closed-loop system (Heliodyne 2012a).

The solar thermal collectors are Heliodyne GOBI 406001 flat plate collectors with the performance characteristics provided in Table 2-21 (Heliodyne 2012b). The maximum flow rate is assumed to be the test flow rate. 
Table 2-21 Solar Thermal Collector Parameters

\begin{tabular}{|lc|r|}
\hline Field & Units & \multicolumn{1}{c|}{ Value } \\
\hline Gross Area & $\mathrm{m}^{2}$ & 2.503 \\
Test Fluid & & Water \\
Test Flow Rate & $\mathrm{m}^{3} / \mathrm{s}$ & 0.0000498 \\
Test Correlation Type & & \multicolumn{1}{l|}{ Inlet } \\
Efficiency Equation Coefficient 1 & & 0.732 \\
Efficiency Equation Coefficient 2 & $\mathrm{W} / \mathrm{m}^{2}-\mathrm{K}$ & -4.195 \\
Efficiency Equation Coefficient 3 & $\mathrm{W} / \mathrm{m}^{2}-\mathrm{K}^{2}$ & 0 \\
Incident Angle Modifier Coefficient 2 & & 0.0581 \\
Incident Angle Modifier Coefficient 2 & & -0.2744 \\
Max Flow Rate & $\mathrm{m}^{3} / \mathrm{s}$ & 0.0000498 \\
\hline
\end{tabular}

The solar thermal loop pump operation control is based on 4 conditions. In order to ensure the temperature in solar loop system does not get too high, the solar collector loop pump has a safety mechanism that turns the pump on when the temperature of the gycol/water mix leaving the solar collectors reaches $100^{\circ} \mathrm{C}\left(212^{\circ} \mathrm{F}\right)$. The solar collector loop pump is turned off when the temperature in the water heater reaches $80^{\circ} \mathrm{C}\left(176^{\circ} \mathrm{F}\right)$. The solar collector loop pump is turned on whenever the temperature of the fluid in the solar collector loop is $10^{\circ} \mathrm{C}\left(18^{\circ} \mathrm{F}\right)$ greater than the water in the storage tank. The solar collector loop pump is turned off when the temperature of the fluid in the solar collector loop is less than $2{ }^{\circ} \mathrm{C}\left(3.6^{\circ} \mathrm{F}\right)$ higher than the water in the storage tank.

Two plant loops are required in the simulation: the solar collector loop and domestic hot water loop. The solar collector loop has a maximum temperature in the loop of $163{ }^{\circ} \mathrm{C}\left(325.4{ }^{\circ} \mathrm{F}\right)$ and a minimum temperature of $-45.6^{\circ} \mathrm{C}\left(-50.1^{\circ} \mathrm{F}\right)$. The domestic hot water loop has a maximum temperature in the loop of $100^{\circ} \mathrm{C}\left(212^{\circ} \mathrm{F}\right)$ and a minimum temperature of $3.0^{\circ} \mathrm{C}\left(37.4{ }^{\circ} \mathrm{F}\right)$. The maximum flow rate for each plant loop is autosized while the minimum loop flow rate is $0.0 \mathrm{~m}^{3} / \mathrm{s}$ $(0.0 \mathrm{gpm})$. The loop is designed for an exit temperature - the temperature supplied to the "use side" - of $48.9^{\circ} \mathrm{C}\left(120.0{ }^{\circ} \mathrm{F}\right)$ for the domestic hot water loop and $100{ }^{\circ} \mathrm{C}\left(212^{\circ} \mathrm{F}\right)$ for the solar collector loop. For the solar collector loop, the exit temperature of the water is measured at the point it enters the storage tank. For the domestic hot water loop, it is the temperature of the water that is exiting the heat pump.

The storage tank and the water heater tank are both stratified tanks with 6 nodes. Their parameter values are listed in Table 2-22. The storage tank inlet and outlet for the solar collector loop are assumed to be at the lowest and highest node height, respectively. The water heater tank parameters are based on the specifications for the initial equipment selected for installation into the NZERTF. 
Table 2-22 Storage Tank and Water Heater Tank Parameters

\begin{tabular}{|c|c|c|c|}
\hline Field & Units & Storage Tank & Hot Water \\
\hline Tank Volume & $\mathrm{m}^{3}$ & 0.303 & 0.189 \\
\hline Tank Height & $\mathrm{m}$ & 1.594 & 1.14 \\
\hline Tank Shape & & Vertical Cylinder & Vertical Cylinder \\
\hline Max. Temp. Limit & ${ }^{\circ} \mathrm{C}$ & 76.6 & 71.1 \\
\hline Heater 1 Setpoint Temperature & ${ }^{\circ} \mathrm{C}$ & & 48.9 \\
\hline Heater 1 Deadband Temperature Difference & $\Delta^{\circ} \mathrm{C}$ & & 5.0 \\
\hline Heater 1 Maximum Capacity & $\mathrm{W}$ & & 3800 \\
\hline Heater 1 Height & $\mathrm{m}$ & & 0.86 \\
\hline Heater 2 Setpoint Temperature & ${ }^{\circ} \mathrm{C}$ & & 48.9 \\
\hline Heater 2 Deadband Temperature Difference & $\Delta^{\circ} \mathrm{C}$ & & 10.0 \\
\hline Heater 2 Maximum Capacity & $\mathrm{W}$ & & 3800 \\
\hline Heater 2 Height & $\mathrm{m}$ & & 0.5 \\
\hline Ambient Temperature Indicator & & Zone & Zone \\
\hline Ambient Temperature Zone Name & & Basement & Basement \\
\hline Uniform Skin Loss Coefficient to Ambient Temperature & $\mathrm{W} / \mathrm{m}^{2} \cdot \mathrm{K}$ & 0.846 & 0.41 \\
\hline Skin Loss Fraction to Zone & & 1.0 & 1.0 \\
\hline Off Cycle Flue Loss Coefficient to Ambient Temperature & $\mathrm{W} / \mathrm{K}$ & 0.0 & 0.0 \\
\hline Off Cycle Flue Loss Fraction to Zone & & 1.0 & 1.0 \\
\hline Use Side Effectiveness & & 1.0 & 1.0 \\
\hline Use Side Inlet Height & $\mathrm{m}$ & 0.398 & 0.229 \\
\hline Use Side Outlet Height & $\mathrm{m}$ & 1.46 & 1.09 \\
\hline Source Side Effectiveness & & 0.80 & 1.0 \\
\hline Source Side Inlet Height & $\mathrm{m}$ & 1.14 & 0.229 \\
\hline Source Side Outlet Height & $\mathrm{m}$ & 0.398 & 0.229 \\
\hline Inlet Mode & & Fixed & Fixed \\
\hline Use Side Design Flow Rate & $\mathrm{m}^{3} / \mathrm{s}$ & Autosize & Autosize \\
\hline Source Side Design Flow Rate & $\mathrm{m}^{3} / \mathrm{s}$ & Autosize & Autosize \\
\hline Indirect Water Heating Recovery Time & $\mathrm{h}$ & 1.5 & 1.5 \\
\hline Number of Nodes & & 6 & 6 \\
\hline
\end{tabular}

The air-to-water heat pump is a Hubbell PBX 50-SL. The operation and performance parameter values area listed in Table 2-23 and Table 2-24, respectively (Hubbell 2011). The heat pump operation is based on the water temperature at the height of the second electric heating element (0.5 m). 
Table 2-23 Heat Pump Water Heater Operational Parameters

\begin{tabular}{|lc|c|}
\hline Field & Units & Value \\
\hline Dead band Temperature Difference & $\Delta^{\circ} \mathrm{C}$ & 5.0 \\
Compressor Setpoint Temperature & ${ }^{\circ} \mathrm{C}$ & 53.9 \\
Condenser Water Flow Rate & $\mathrm{m}^{3} / \mathrm{s}$ & Autocalculate \\
Evaporator Air Flow Rate & $\mathrm{m}^{3} / \mathrm{s}$ & Autocalculate \\
Inlet Air Configuration & & Zone Air Only \\
Inlet Air Zone Name & & Basement \\
Min. Inlet Air Temp. for Compressor Operation & ${ }^{\circ} \mathrm{C}$ & 5 \\
Compressor Location & & Basement \\
Parasitic Heat Rejection & & Basement \\
Fan Placement & & Draw Through \\
Temperature Control Sensor Location & & Heater 2 \\
\hline
\end{tabular}

The heating coil for the air-to-water heat pump has a rated heating capacity of $1375 \mathrm{~W}$ and a COP of 2.6. A factor not accounted for in the simulation model is that the heat pump will slightly dehumidify the basement while operating.

\section{Table 2-24 Hot Water Heat Pump Coil Parameters}

\begin{tabular}{|lc|c|}
\hline Field & Units & Value \\
\hline Rated Capacity & $\mathrm{W}$ & 1375 \\
Rated COP & W/W & 2.6 \\
Rated Sensible Heat Ratio & & 0.85 \\
Rated Evaporator Inlet Air DB Temp. & ${ }^{\circ} \mathrm{C}$ & 19.7 \\
Rated Evaporator Inlet Air WB Temp. & ${ }^{\circ} \mathrm{C}$ & 13.5 \\
Rated Condenser Inlet Water Temp. & ${ }^{\circ} \mathrm{C}$ & 57.5 \\
Rated Evaporator Air Flow Rate & & Autocalculate \\
Rated Condenser Air Flow Rate & & Autocalculate \\
Evaporator Fan Power Included in Rated COP & & Yes \\
Condenser Pump Power Included in Rated COP & & No \\
Condenser Pump Heat Included in Heat Cap. And COP & & No \\
Condenser Water Pump Power & $\mathrm{W}$ & 0 \\
Fraction of Condenser Pump Heat to Water & & 0.2 \\
\hline
\end{tabular}

The heat pump water heater fan and DHW fan parameter values are listed in Table 2-25. 
Table 2-25 Heat Pump Water Heater Fan and DHW Fan Parameters

\begin{tabular}{|l|c|}
\hline Field & Fans \\
\hline Availability & Always Available \\
Fan Efficiency & $80 \%$ \\
Pressure Rise & $100 \mathrm{~Pa}$ \\
Maximum Flow Rate & Autosize \\
Motor Efficiency & $90 \%$ \\
Motor in Airstream Fraction & 1.0 \\
\hline
\end{tabular}

There are two intermittent pumps used in the DHW system, one for the solar thermal collectors and one for the DHW loop. The parameter values for both pumps are shown in Table 2-26.

\section{Table 2-26 Domestic Hot Water Loop Pump Parameters}

\begin{tabular}{|ll|c|c|}
\hline Field & Units & DHW & Solar Collector \\
\hline Rate Flow Rate & $\mathrm{m}^{3} / \mathrm{s}$ & autosize & 0.0000997 \\
Rated Pump Head & $\mathrm{Pa}$ & 15000 & 15000 \\
Rated Power Consumption & $\mathrm{W}$ & Autosize & Autosize \\
Motor Efficiency & & 0.87 & 0.87 \\
Fraction of Motor Inefficiency to Fluid Stream & & 0 & 0 \\
Part Load Perf. Curve - Coefficient 1 & & 0 & 0 \\
Part Load Perf. Curve - Coefficient 2 & & 1 & 1 \\
Part Load Perf. Curve - Coefficient 3 & & 0 & 0 \\
Part Load Perf. Curve - Coefficient 4 & & 0 & 0 \\
Minimum Flow Rate & $\mathrm{m}^{3} / \mathrm{s}$ & 0 & 0 \\
Pump control Type & & Intermittent & Intermittent \\
\hline
\end{tabular}

\subsubsection{Domestic Hot Water End Use}

The DHW end use in the NZERTF has 5 categories: bath, shower, sinks, dishwasher, and clothes washer. The use schedules in terms of fraction of peak flow (FPF) are shown in Figure 2-7, and are based on Omar and Bushby (2013). The clothes washer is used 5 times a week: one load on Wednesday and two loads on both Saturday and Sunday. The dishwasher is used for one load five days a week: Monday, Wednesday, Friday, Saturday, and Sunday. The sink, shower, and bath water draws vary by the occupancy schedule to match the target water use from Hendron and Engebrecht (2010). 

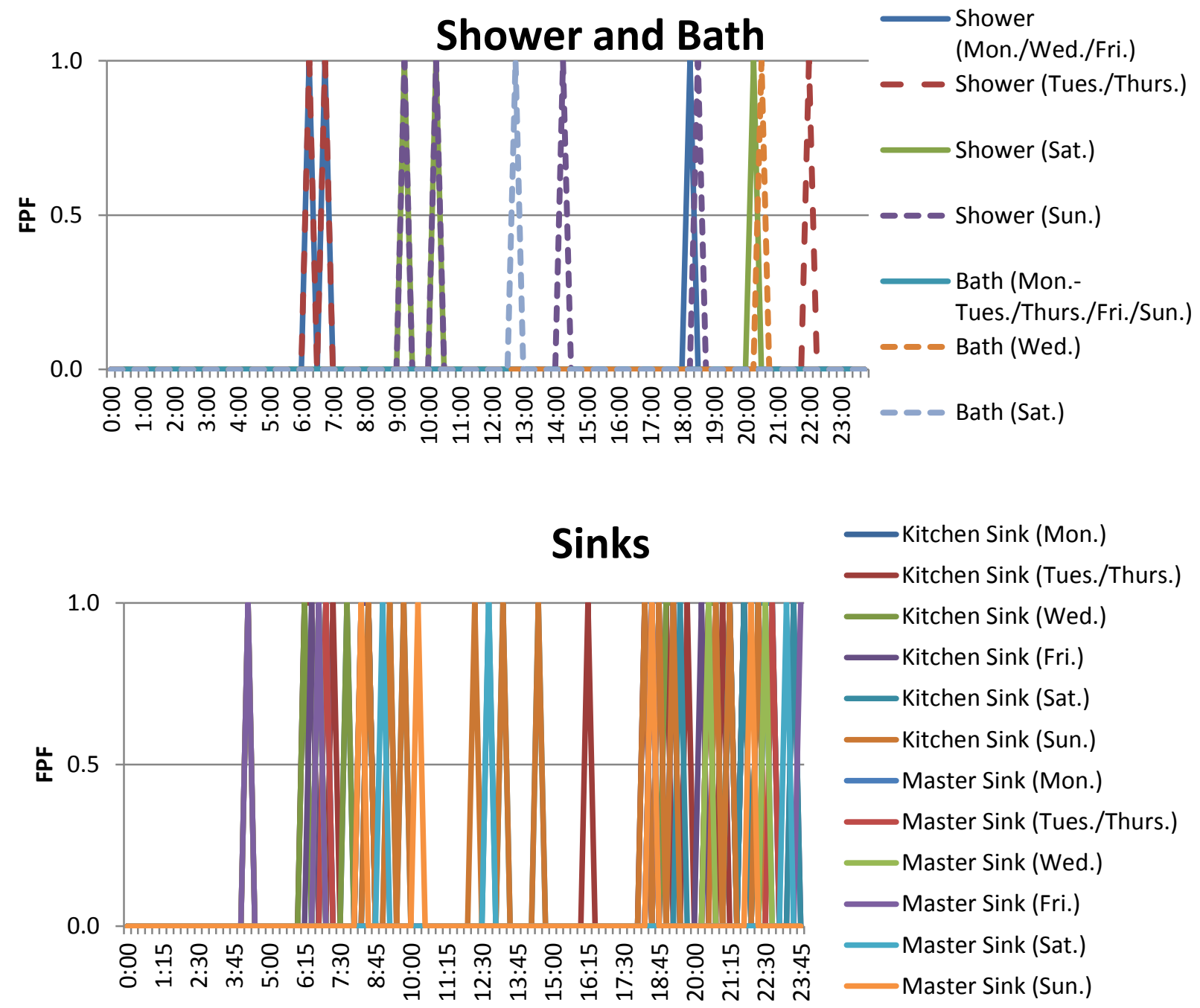

\section{Cothes Washer and Dishwasher}

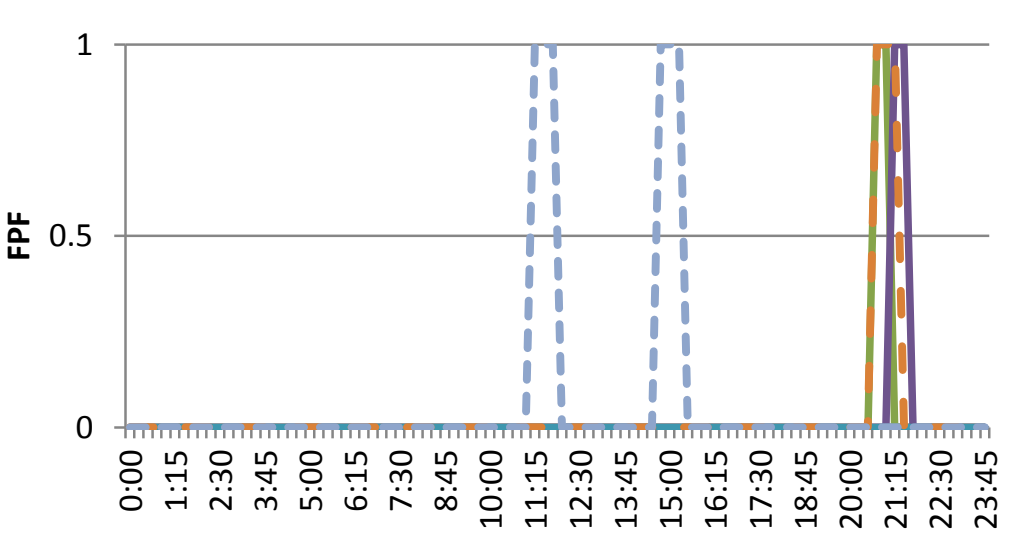

Dishwasher (Tues./Thurs.)

Dishwasher (Mon./Wed./Fri./Sun.)

Dishwasher (Tues./Thurs.)

Dishwasher (Sat.)

Clothes Washer (Mon-Tues., Thurs.-Fri.)

- Clothes Washer (Wed.)

Figure 2-7 Domestic Hot Water End Use Schedules - Fraction of Peak Flow 
Table 2-27 defines DHW use in terms of daily water use, water temperature, and heat gain fractions (fraction of energy in water that is released to the ambient environment). Hendron and Engebrecht (2010) is used to calculate daily water consumption and heat gains for each of the categories except for the dishwasher and clothes washer, which are based on Omar and Bushby (2013) and the equipment's Energy Star ratings.

Table 2-27 Domestic Hot Water Use and Thermal Load Fractions

\begin{tabular}{|l|r|r|r|r|}
\hline $\begin{array}{c}\text { DHW Use } \\
\text { Category }\end{array}$ & $\begin{array}{c}\text { Water Temp. } \\
{ }^{\circ} \mathbf{C}\left({ }^{\circ} \mathbf{F}\right)\end{array}$ & \multicolumn{1}{c|}{$\begin{array}{c}\text { Daily } \\
\text { L }(\text { Gal })\end{array}$} & $\begin{array}{c}\text { Sensible Load } \\
\text { Fraction }\end{array}$ & \multicolumn{1}{c|}{$\begin{array}{c}\text { Latent Load } \\
\text { Fraction }\end{array}$} \\
\hline Clothes Washer & $48.9(120.0)$ & $35.7(9.43)$ & 0.0 & 0.0 \\
Dishwasher & $48.9(120.0)$ & $4.2(1.12)$ & 0.0 & 0.0 \\
\hline Shower & $40.6(105.0)$ & $142.4(37.6)$ & 0.2127 & 0.005655 \\
Bath & $40.6(105.0)$ & $11.3(3.0)$ & 0.2083 & 0.0 \\
Sinks & $40.6(105.0)$ & $93.6(24.7)$ & 0.09869 & 0.00127 \\
\hline
\end{tabular}

The sink, shower, and bath water draws are assumed to be mixed water use at $40.6{ }^{\circ} \mathrm{C}\left(105.1^{\circ} \mathrm{F}\right)$. The sink flow rates are $5.7 \mathrm{~L}$ (1.5 gal.) per min while the shower and bath flow rates are $6.6 \mathrm{~L}$ (1.75 gal.) per min. The sensible and latent load fractions for the sink, shower, and bath draws are calculated by reverse engineering using the heat gain estimate equations in Hendron and Engebrecht (2010). Omar and Bushby (2013) defines sink draws in 21 second intervals while the $E+$ model can only model at one minute increments. The consolidation of draws results in the total length of draws for a week being 6 seconds longer than stated in Omar and Bushby (2013), or additional hot water use of $29.5 \mathrm{~L}$ (7.8 gal.). The additional DHW use will slightly overestimate electricity use relative to that provided by Omar and Bushby (2013).

The domestic hot water use equipment is assumed to use water at the exit target temperature of the water heater and has no sensible or latent heat gains resulting from the hot water use. The clothes washer is assumed to consume $46.4 \mathrm{~L}$ (12.25 gal.) per cycle. Total water use is the product of the water use per cycle and the number of loads per year (260) for a total of $12057 \mathrm{~L}$ (3185 gal.) per year or $33.0 \mathrm{~L}$ (8.73 gal.) per day. The dishwasher is assumed to consume $5.9 \mathrm{~L}$ (1.57 gal.) per cycle. Similar to the clothes washer, total water use is the product of the water use per cycle and the number of loads per year (260) for a total of $1545 \mathrm{~L}$ (408 gal.) per year or 4.24 L (1.12 gal.) per day.

\subsubsection{Solar Photovoltaic}

Energy efficient design reduces but does not eliminate electricity use by the NZERTF. Solar photovoltaic (PV) panels are installed on the roof of the NZERTF to produce at least as much electricity as is consumed by the NZERTF on an annual basis.

Figure 2-3 shows that there are 32 SunPower SPR-320E-WHT-U solar PV panels installed on the roof of the NZERTF in 4 horizontal rows of 8 panels each. Two rows are connected to two 
SunPower $5000 \mathrm{~m}$ LUT inverters for a total of 2 strings. The solar panel parameters are listed in Table 2-28.

\section{Table 2-28 Solar Photovoltaic Panel Parameters}

\begin{tabular}{|lc|c|}
\hline Field & Units & Value \\
\hline Cell Type & & Crystalline Silicon \\
Number of Cells in Series & & 96 \\
Active Area & $\mathrm{m}^{2}$ & 1.472 \\
Transmittance Absorptance Product & & 0.95 \\
Semiconductor Bandgap & $\mathrm{eV}$ & 1.12 \\
Shunt Resistance & $\mathrm{Ohms}$ & 1125 \\
Short Circuit Current & $\mathrm{A}$ & 6.24 \\
Open Circuit Voltage & $\mathrm{V}$ & 64.8 \\
Reference Temperature & ${ }^{\circ} \mathrm{C}$ & 25 \\
Reference Insolation & $\mathrm{W} / \mathrm{m}^{2}$ & 1000 \\
Module Current at Maximum Power & $\mathrm{A}$ & 5.86 \\
Module Voltage at Maximum Power & $\mathrm{V}$ & 54.7 \\
Temp. Coeff. Of Short Circuit Current & $\mathrm{A} / \mathrm{K}$ & 0.0035 \\
Temp. Coeff. Of Open Circuit Voltage & $\mathrm{V} / \mathrm{K}$ & -0.1766 \\
Nominal Operating Cell Temp. Test Ambient Temp. & ${ }^{\circ} \mathrm{C}$ & 20 \\
Nominal Operating Cell Temp. Test Cell Temp. & ${ }^{\circ} \mathrm{C}$ & 45 \\
Nominal Operating Cell Temp. Test Insolation & $\mathrm{W} / \mathrm{m}^{2}$ & 800 \\
Module Heat Loss Coefficient & $\mathrm{W} / \mathrm{m}^{2} \cdot \mathrm{K}$ & 30.4 \\
Total Heat Capacity & $\mathrm{J} / \mathrm{m}^{2} \cdot \mathrm{K}$ & 7984 \\
\hline
\end{tabular}

The solar PV inverter parameters for the SunPower 5000m LUT are listed in Table 2-29. The inverter efficiency is greatest at $50 \%$ of its maximum power and nominal voltage. The inverters are located in the main attic area, and the energy lost by the inverter enters the attic space. 
Table 2-29 Solar Photovoltaic Inverter Parameters

\begin{tabular}{|lc|c|}
\hline Field & Units & Value \\
\hline Availability Schedule Name & & Always Available \\
Zone Name & & Main Attic (Zone 4) \\
Radiative Fraction & & 0.05 \\
Rated Maximum Continuous Output Power & W & 5000 \\
Night Tare Loss Power & W & 0.1 \\
Nominal Voltage Input & V & 438 \\
Eff. At 10\% Power and Nominal Voltage & & 0.935 \\
Eff. At 20\% Power and Nominal Voltage & & 0.962 \\
Eff. At 30\% Power and Nominal Voltage & & 0.968 \\
Eff. At 50\% Power and Nominal Voltage & & 0.969 \\
Eff. At 75\% Power and Nominal Voltage & & 0.964 \\
Eff. At 100\% Power and Nominal Voltage & 0.957 \\
\hline
\end{tabular}




\section{Pre-Demonstration Phase Model Results}

This section will summarize the results from the pre-demonstration phase simulation results and compare those to the measured consumption during the demonstration phase.

\subsection{Total Electricity Consumption and Production}

The pre-demonstration phase simulation estimates total electricity consumption of the NZERTF to be $11156 \mathrm{kWh}$ and total electricity production to be $14222 \mathrm{kWh}$ (see Figure 3-1). The measured consumption is $16 \%$ higher (12927 kWh) and measured production is $5 \%$ lower $(13523 \mathrm{kWh})$ than the simulated results. The NZERTF reached its net-zero energy goal, but the excess production was lower than was forecasted by the model by $2471 \mathrm{kWh}$.

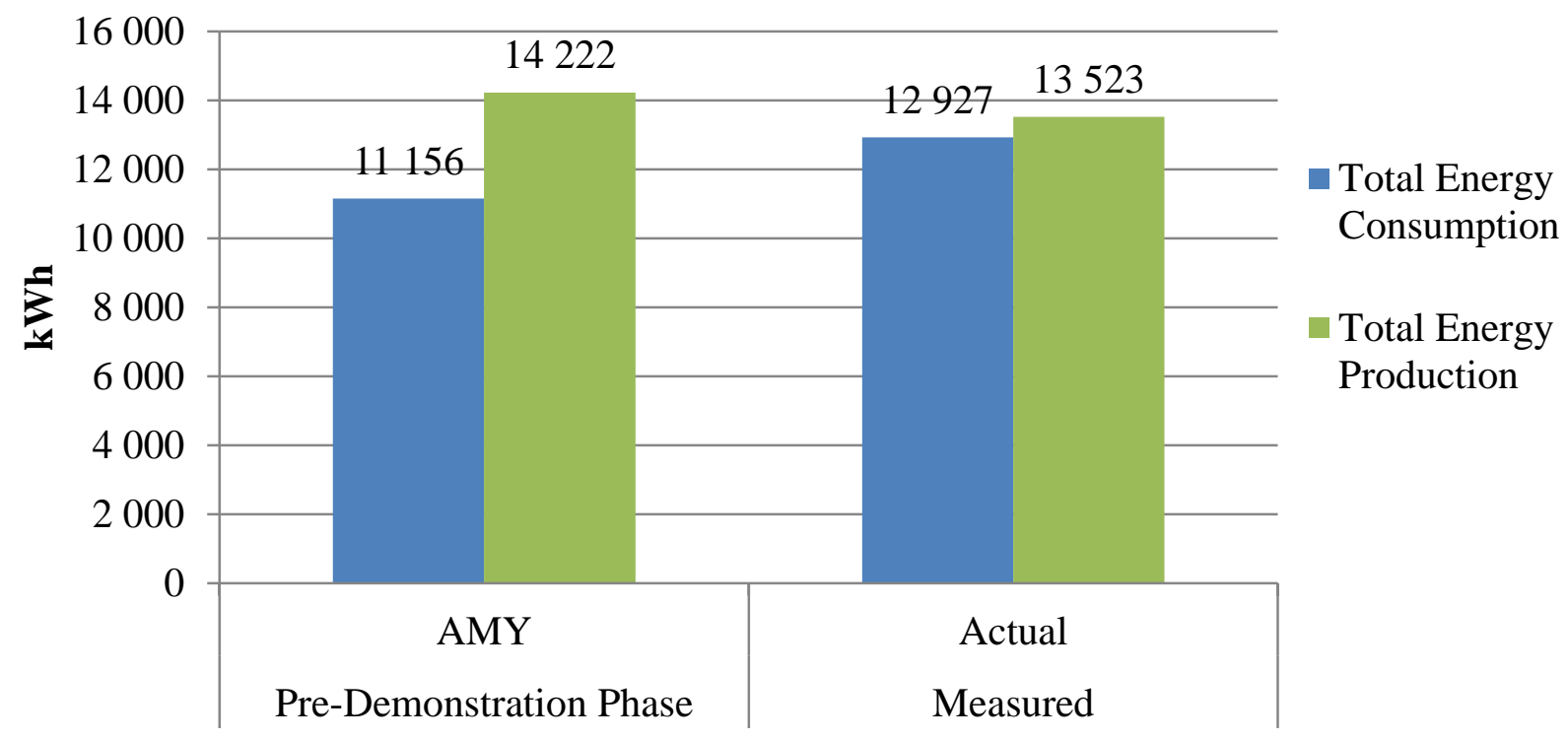

Figure 3-1 Annual Electricity Consumption and Production (kWh)

Electricity consumption by category for the simulation and measured performance is shown in Figure 3-2. The simulation overestimates consumption for three categories (Miscellaneous Electrical Loads - MELs - and appliances, lighting, and HRV) and underestimates consumption for three categories (heating and cooling, DHW, and solar loop pumps). ${ }^{8}$ The ranking of the magnitude differences (greatest to smallest) is as follows: heating and cooling $(-1960 \mathrm{kWh})$, plug loads/appliances (+718 kWh), DHW (-484 kWh), solar loop pumps (-243 kWh), lighting (+217 kWh), and the HRV (+44 kWh).

\footnotetext{
${ }^{8}$ The simulation estimates consumption by the solar PV inverters to be $3 \mathrm{kWh}$ annually. The measured performance data does not include such a category. Therefore, it is excluded from this discussion.
} 


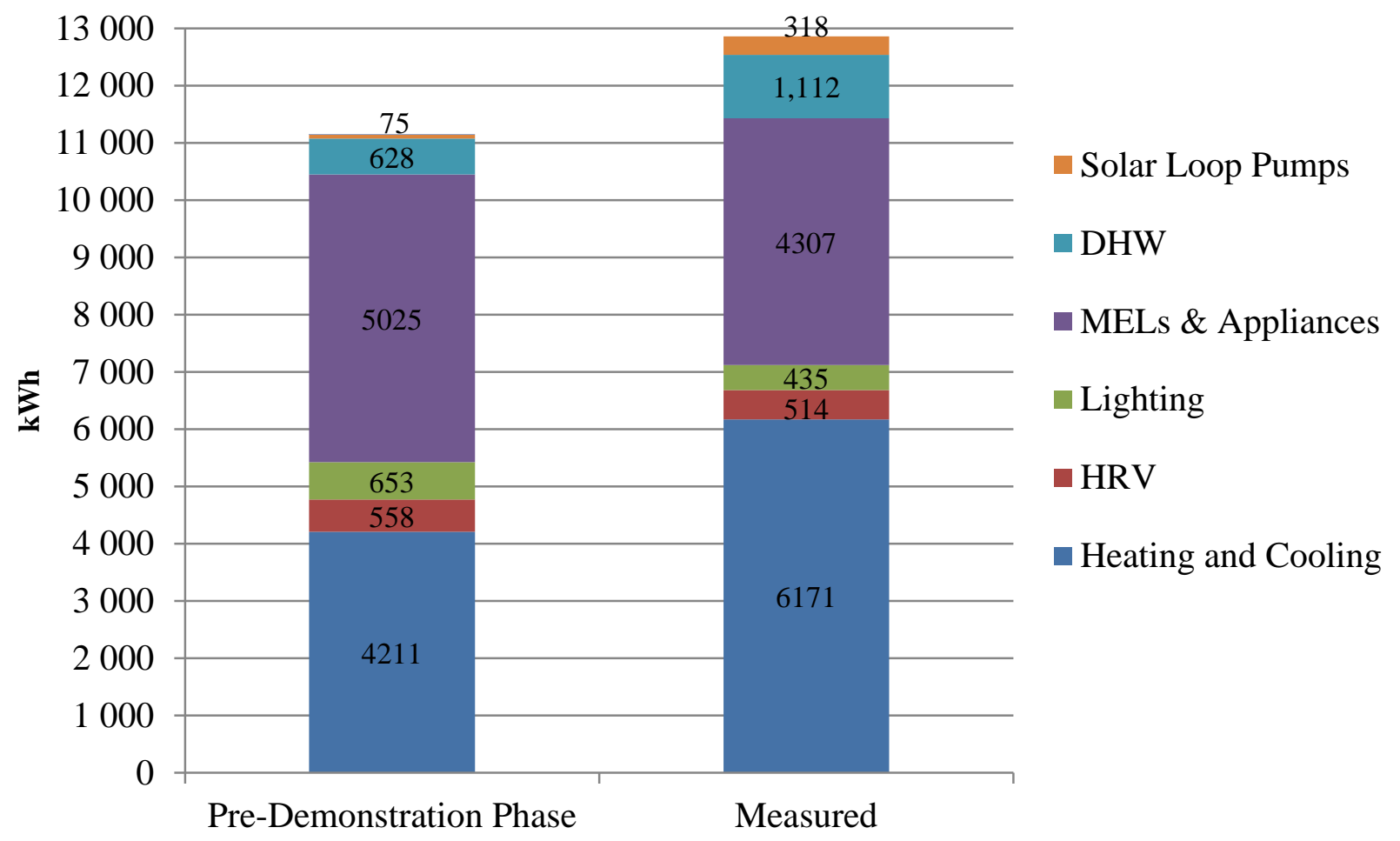

Figure 3-2 Total Electricity Consumption by Category - kWh

\subsection{MELs, Appliances, and Lighting}

Figure 3-3 shows the annual electricity consumption for all MELs and appliances. For appliances, the most significant difference in consumption occurs for the clothes dryer, which is overestimated in the simulation by $819 \mathrm{kWh}(151 \%)$, followed by the dishwasher $(187 \mathrm{kWh}$ or $194 \%)$. The simulation model underestimates consumption for the refrigerator, oven, and microwave ( $74 \mathrm{kWh}, 71 \mathrm{kWh}$, and $58 \mathrm{kWh}$, respectively) while consumption is slightly overestimated for the cooktop/range hood ( $11 \mathrm{kWh}$ ). The consumption by the MELs (a.k.a., plug loads) is overestimated in four rooms (living room, office, master bedroom/bathroom, and $3^{\text {rd }}$ bedroom) and underestimated in three rooms (basement, kitchen, and $2^{\text {nd }}$ bedroom). The most significant overestimations occur for the living room MEL (324 kWh) and office MEL consumption $(52 \mathrm{kWh})$. These overestimations account for most of the MELs in the basement (518 kWh) of the NZERTF, which are completely excluded from the simulation (see Figure 3-3). Basement MELs are primarily standby loads that were shifted from the main floor (living room and office) to the basement during the demonstration phase because the monitoring and control equipment in the basement were already consuming significant standby wattage and creating the associated heat loads. 


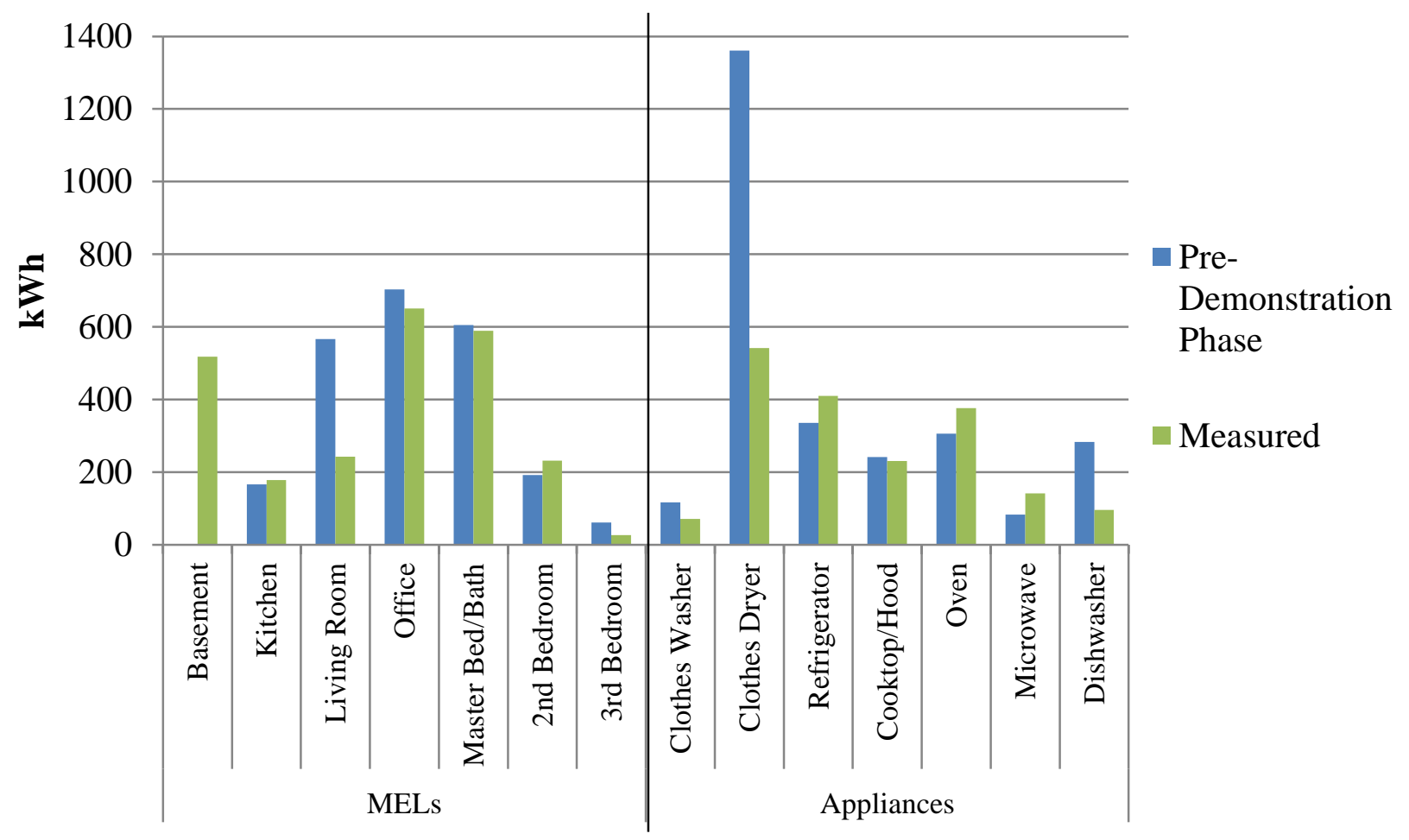

Figure 3-3 Appliances and Plug Loads (MELs) by Room - kWh

The annual lighting consumption in the simulation is $50 \%$ higher than the measured consumption. Figure 3-4 shows both the simulated and measured monthly electricity consumption for lighting. Both the simulated and measured lighting electricity consumption is relatively constant around $55 \mathrm{kWh}$ and $36 \mathrm{kWh}$, respectively. The overestimation is relatively constant, ranging between $40 \%$ and $54 \%$ (excluding August at $74 \%$ ).

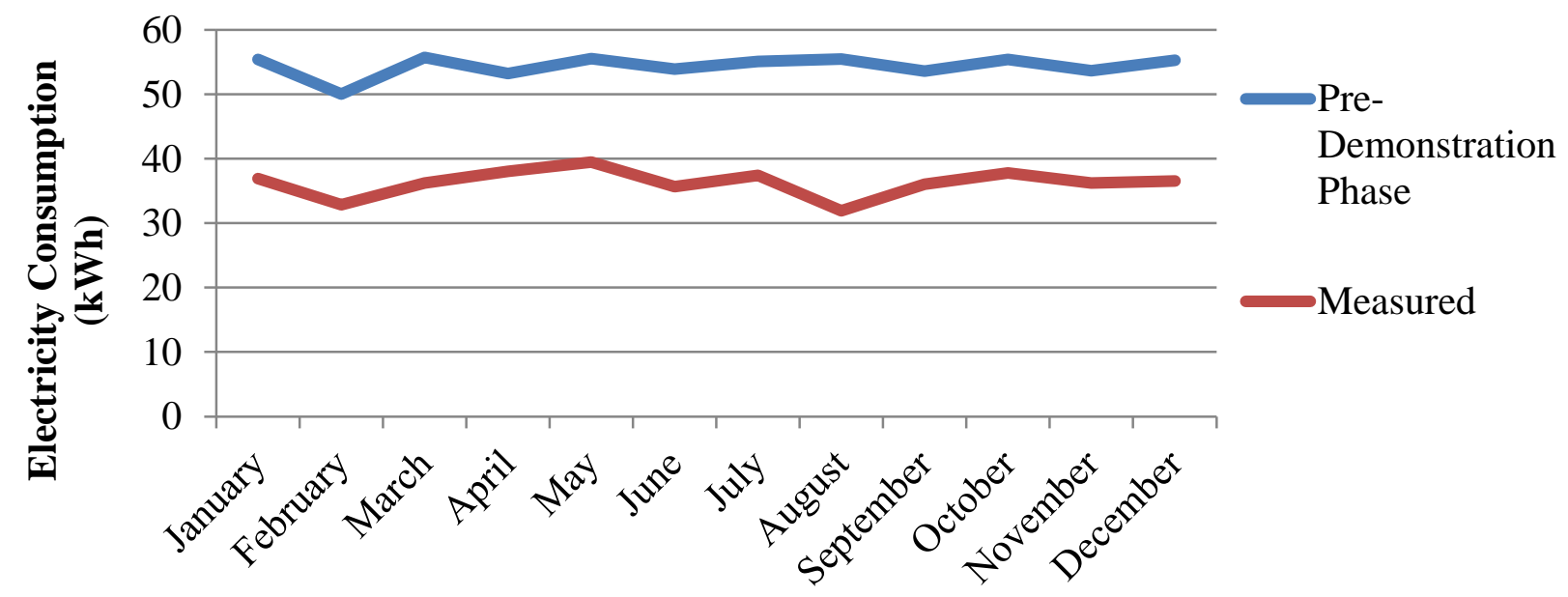

Figure 3-4 Lighting by Room $-\mathrm{kWh}$ 
The manner in which the simulation incorporates electrical equipment (plug loads and appliances) and lighting is straightforward. For each item, E+ requires a peak wattage and load schedule. In order to better represent the actual operation and measured consumption, both of these factors must be considered to see where the discrepancy occurs and adjust the simulation to match the actual activity and performance during the demonstration phase of the NZERTF. Additionally, particular interest should be placed on the measured performance of the NZERTF during the month of August.

\subsection{HVAC, DHW, and Solar Systems}

The complex systems (HVAC, DHW, solar thermal, and solar PV) in the NZERTF require detailed analysis to determine where the discrepancies are occurring because a significant number of assumptions must be defined and there may be interactions between systems.

\subsubsection{HVAC Equipment}

The heating and cooling equipment for the NZERTF includes the air-to-air heat pump with dehumidify-only mode and auxiliary electric back-up unit. As discussed in Section 2.3.4, the simulation includes zone dehumidifiers to incorporate dehumidify-only mode into the model. Figure 3-5 shows the electricity consumption by month to meet the heating and cooling loads of the NZERTF. The simulation results show comparable trends in the heating and cooling, but the total monthly consumption is consistently lower than the measured consumption regardless of season. The greatest differences occur during the coldest months of the demonstration phase (December through March). All assumptions and parameters should be reviewed and compared to measured performance data to determine how to better represent the installed equipment and its performance.

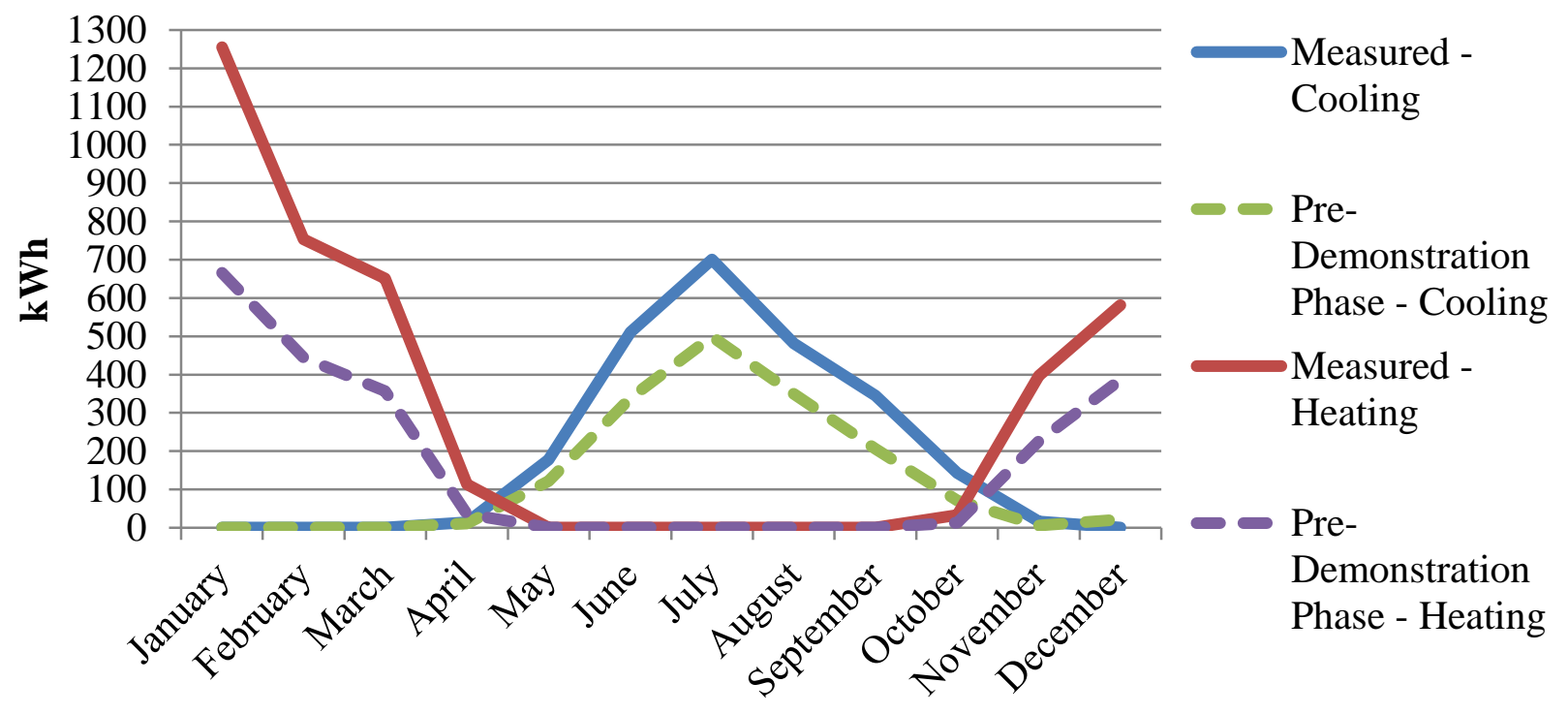

Figure 3-5 Heating and Cooling Consumption by Month - kWh 
The HRV system in the NZERTF consumes electricity at a relatively constant rate (see Figure 3-6), with total electricity consumption varying by month due to the number of days in a month. The simulation consistently consumes greater electricity than was measured during the demonstration phase. The most apparent is the month of August, in which the measurements show an anomalous dip below $40 \mathrm{kWh}$, and may be due to the lost data or equipment faults that occurred during the demonstration phase. The assumed wattage and air flow rate for the HRV should be reviewed to determine if the ventilation rate or wattage are set lower than was measured in the NZERTF.

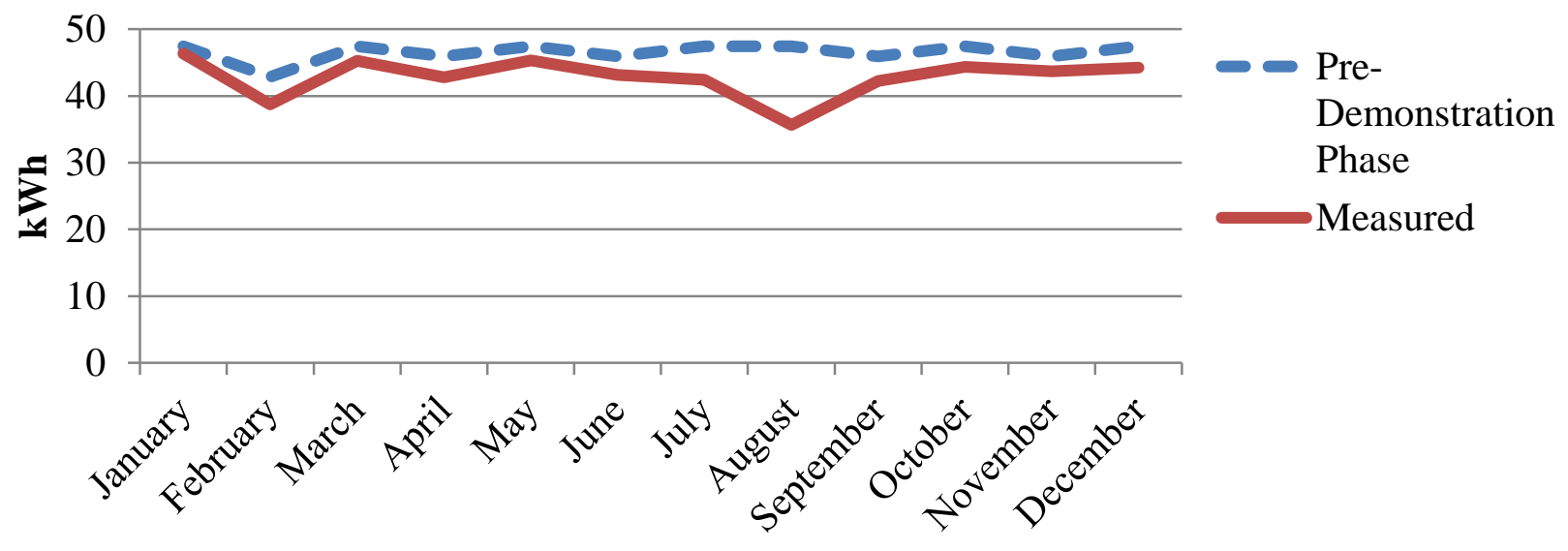

Figure 3-6 HRV Electricity Consumption by Month - kWh

\subsubsection{DHW and Solar Thermal System}

The DHW and solar thermal systems are integrated and require simultaneous consideration when analyzing electricity consumption of both systems. The solar loop pumps in the simulation consume only $24 \%$ of the measured solar loop pump electricity consumption. Similarly, the DHW system (heat pump water heater with electric auxiliary element) consumes only $56 \%$ of the measured heat pump electricity consumption. Although the consumption is much lower in the pre-demonstration simulation, the general trends hold in Figure 3-7, with more DHW electricity consumption and less solar collector loop operation during the colder months and vice versa during the summer months. Parameter values and assumptions of the DHW and solar loop in the simulation should be reviewed to determine what to change to better represent the measured performance. 


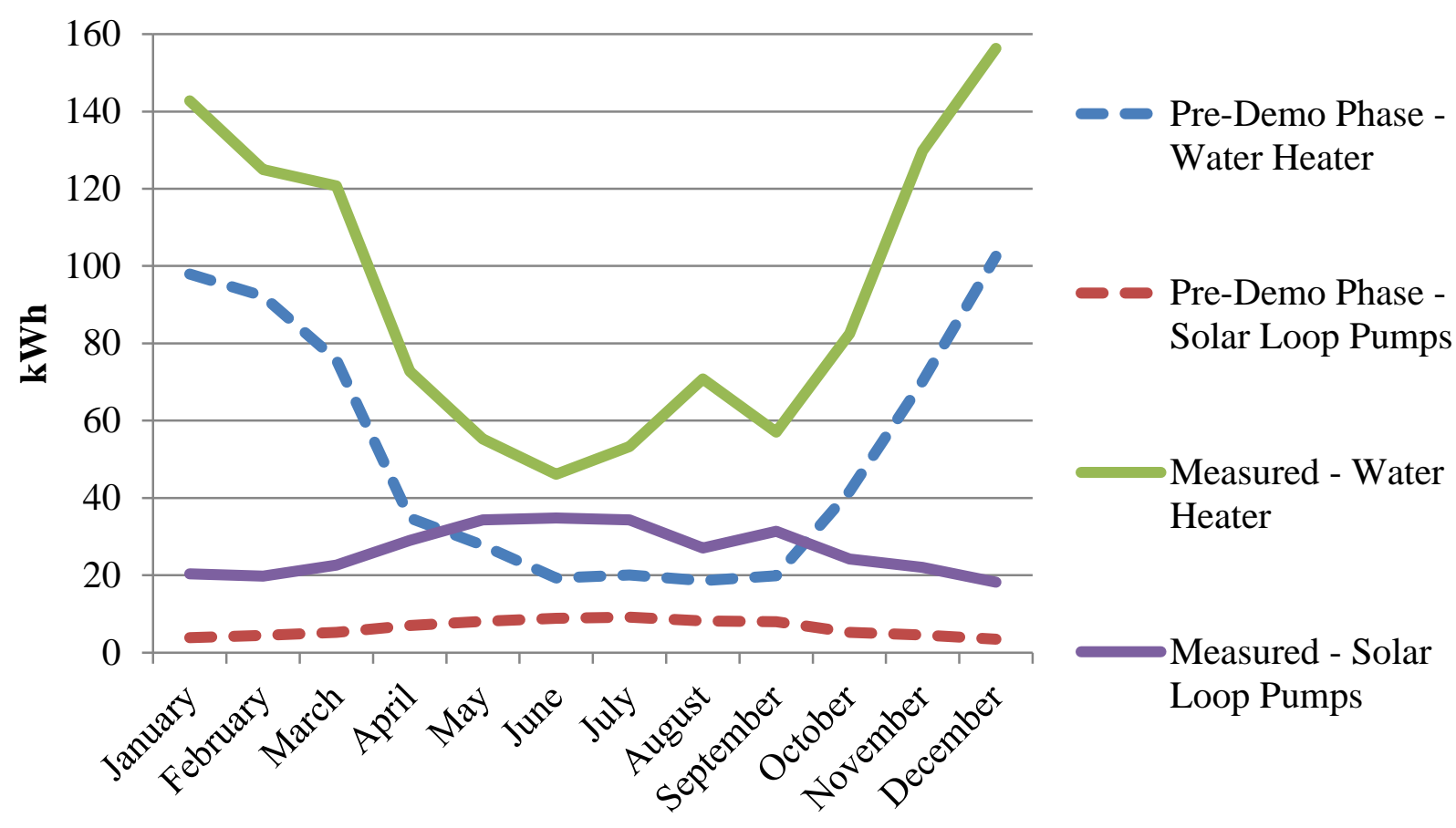

Figure 3-7 DHW and Solar Loop Pump Electricity Consumption by Month - kWh

Figure 3-8 shows that the average pre-heated storage tank and heat pump water heater tank temperatures from the simulation results map well to the measured tank temperatures. It is important to note that the measured tank temperatures are not internal measurements, but based on the tank outlet water temperature. As a result, it is likely that the average temperature for the entire tank would be lower than the temperature of the outlet water, which is drawn from the top of the tank. The parameters and assumptions of the solar loop and pre-heated storage tank in the simulation should be reviewed to determine what to change to better represent the measured performance, with particular focus on the results for August to determine if the difference is due to incorrect simulation assumptions or faults during operation. 


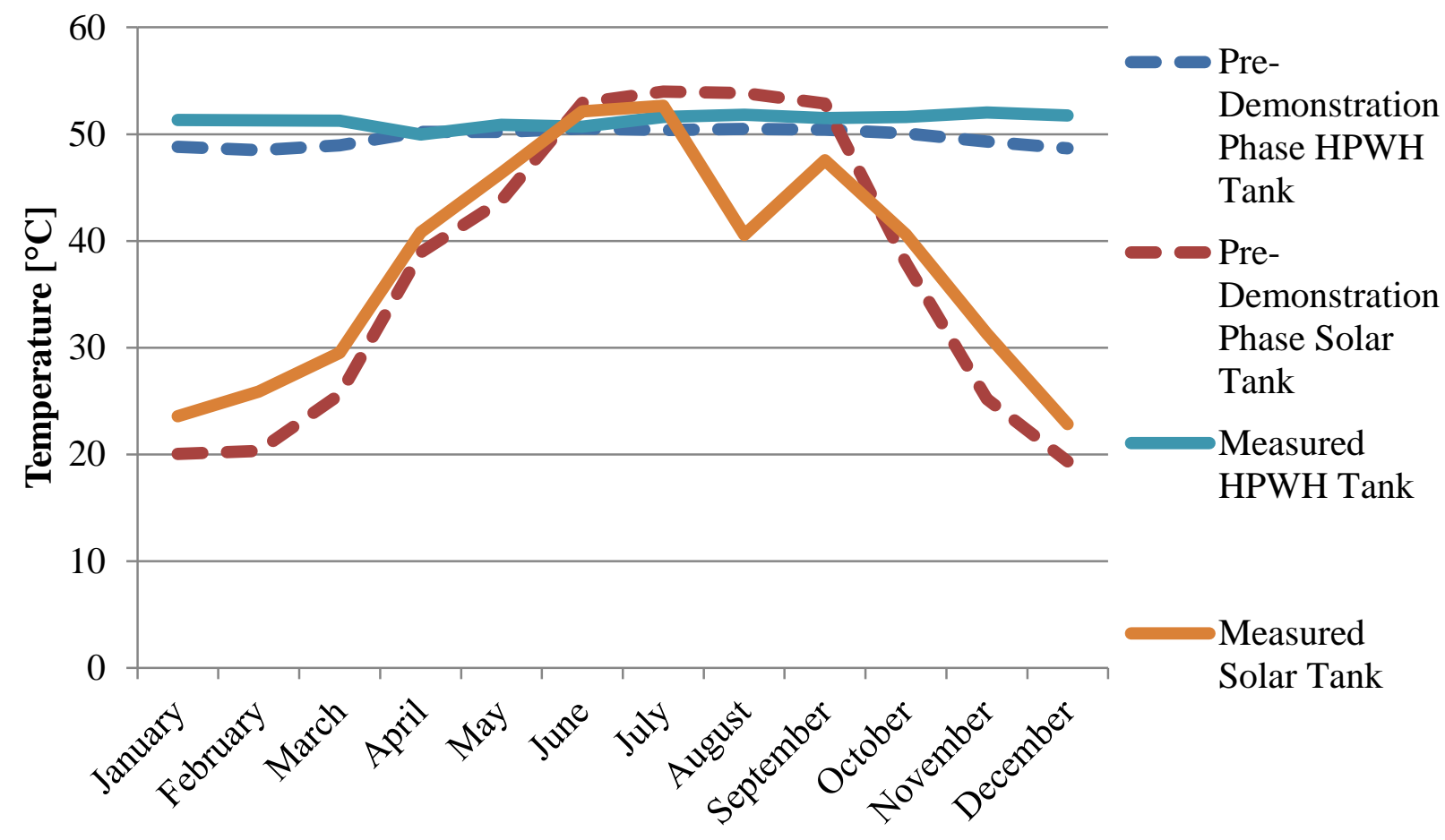

Figure 3-8 DHW and Solar Loop Pump Electricity Consumption by Month - kWh

Figure 3-9 suggests that daily water consumption is underestimated in the simulation by $7.5 \%$ relative to the measured performance, with overestimation for sink draws by $34 \%$ and underestimation for showers (11\%), baths (67\%), clothes washer (14\%), and dishwasher $(16 \%)$. Water flow rates and schedules in the simulation should be compared to those measured during the demonstration phase to determine where the simulation differs from actual operation of the NZERTF. 


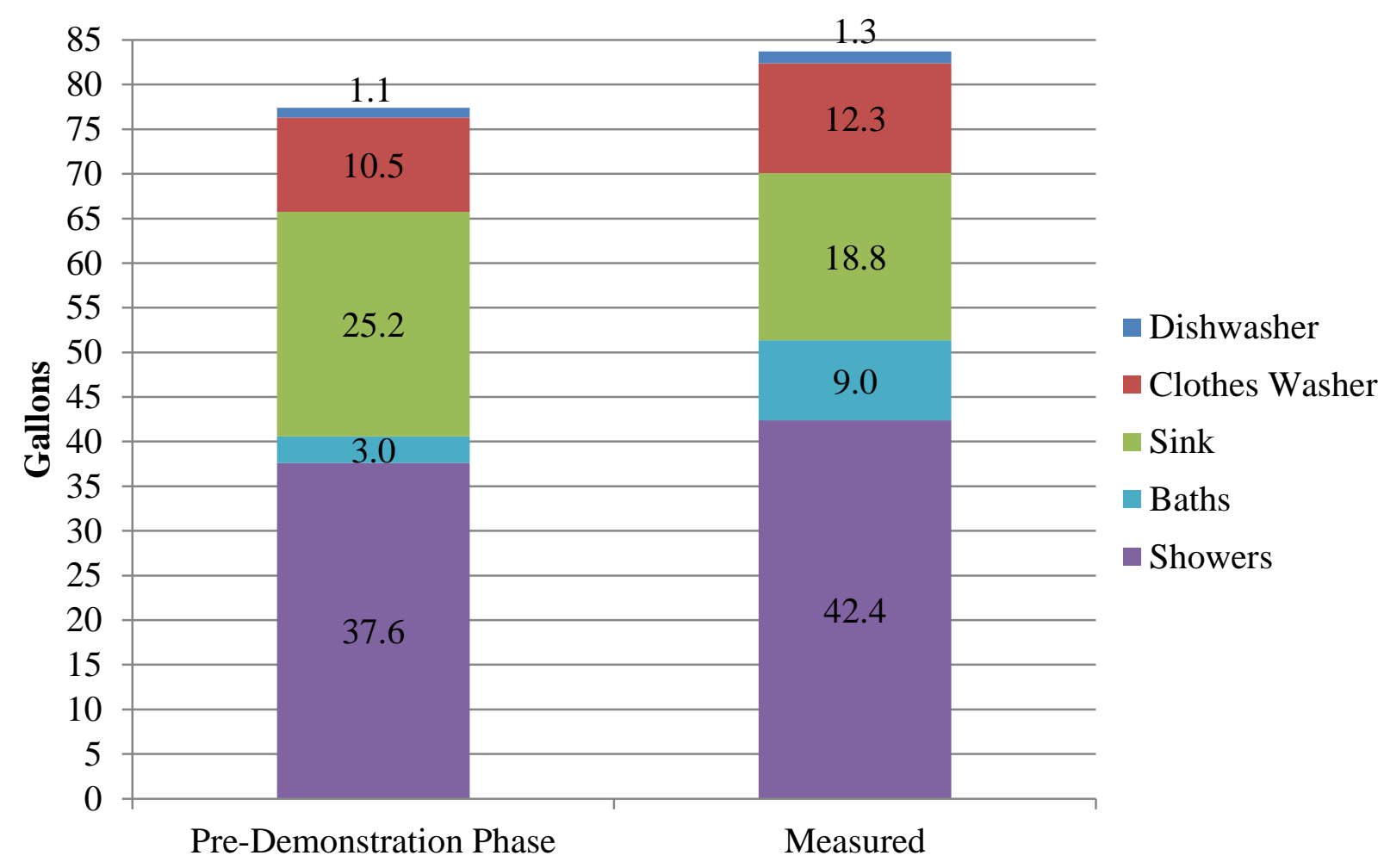

Figure 3-9 Daily Water Consumption - Gallons ${ }^{9}$

Since the hot water demand will impact the loads on the heat pump water heater and solar thermal system, it is possible that the underestimation of water consumption could lead to greater electricity consumption by both the DHW system and solar thermal system.

\subsubsection{Solar Photovoltaic Generation}

The simulation overestimates annual electricity production by $5 \%(698 \mathrm{kWh})$. Figure 3-10 shows that the simulation overestimates production for seven months and underestimates production for the other five months. The biggest deviations are for August $(384 \mathrm{kWh})$ followed by July (184 kWh), which together account for $80 \%$ of the overestimated production. The dip in July and August should be analyzed in greater detail to determine whether the difference is a result of faults in operation of the NZERTF or assumptions in the simulation.

\footnotetext{
${ }^{9} 1$ gallon $=3.785$ liters
} 


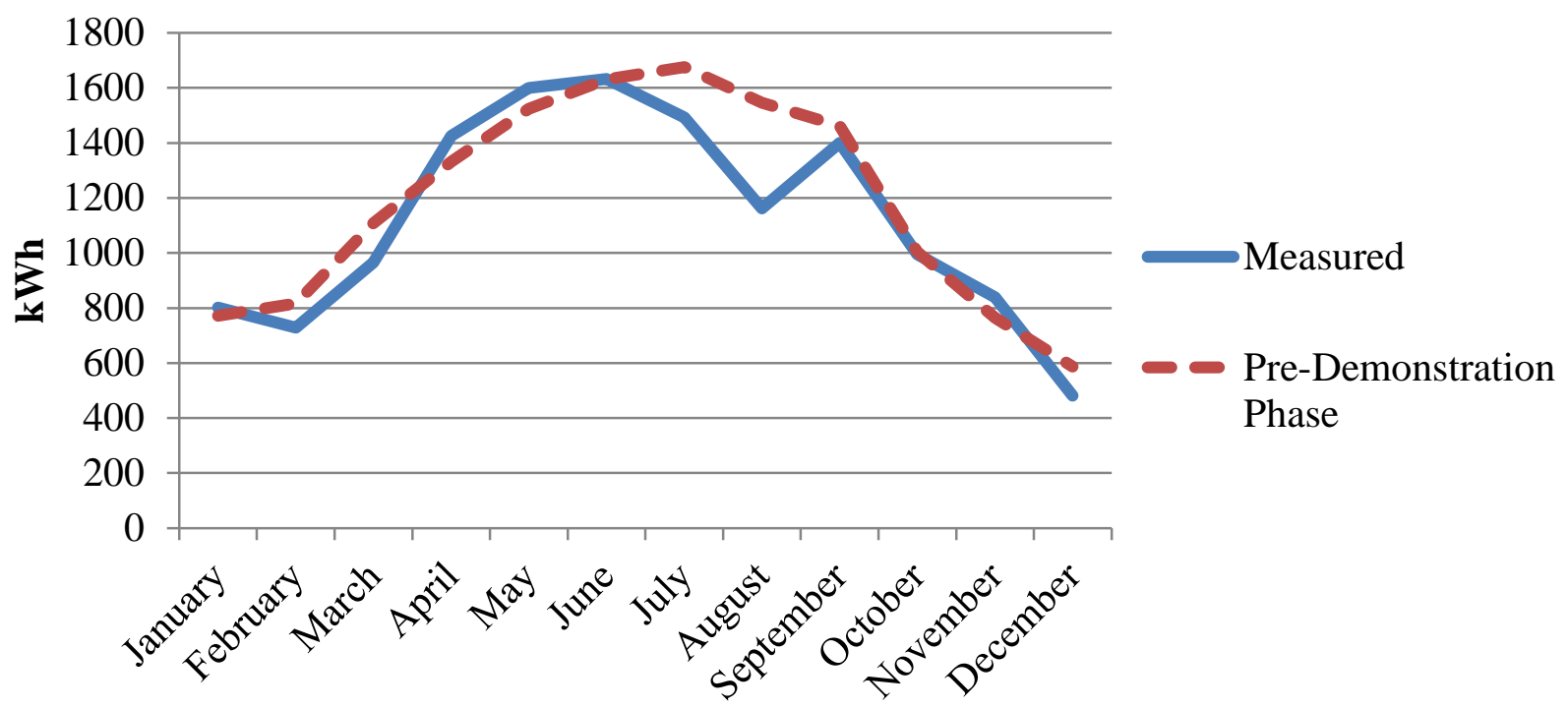

Figure 3-10 Total Electricity Consumption and Solar PV Production (kWh) - Monthly 


\section{Adjustments to Simulation Model}

Variations in energy consumption between the simulation and the measured performance are most significant for the DHW system, HVAC system, and solar thermal system. Adjustments are also made in the assumed infiltration rate, lighting, MEL loads, and appliance loads. There are no changes considered to the other aspects of the building envelope because the specifications are relatively straightforward to replicate in the simulation model.

\subsection{Infiltration}

The most recent air leakage test led to a higher infiltration rate of $0.223 \mathrm{~m}^{3} / \mathrm{s}$ (470 CFM) or 0.63 $\mathrm{ACH}_{50}$. The infiltration rate is converted to ELA, as is used in the pre-demonstration phase simulation (see Section 2.1), using the following formula from Chapter 16 in ASHRAE (2012):

$$
A_{L}=10000 * Q_{r} * \frac{\sqrt{\rho / 2 \Delta p_{r}}}{C_{D}}
$$

Where $A_{L}=$ equivalent or effective air leakage area $\left(\mathrm{cm}^{2}\right)$

$$
\begin{aligned}
& Q_{r}=\text { predicted airflow rate at } \Delta p_{r}\left(\mathrm{~m}^{3} / \mathrm{s}\right) \\
& \rho=\text { air density }\left(\mathrm{kg} / \mathrm{m}^{3}\right) \\
& \Delta p_{r}=\text { reference pressure difference }(\mathrm{Pa}) \\
& C_{D}=\text { discharge coefficient }
\end{aligned}
$$

ASHRAE (2012) states that ELA at $4 \mathrm{~Pa}$, as used in $E+$, typically assumes a discharge coefficient $\left(C_{D}\right)$ of 1.0. The reference pressure difference $\left(\Delta p_{r}\right)$ used in the blower door test is $50 \mathrm{~Pa}$. The air density $(\rho)$ is assumed to be $1.2922 \mathrm{~kg} / \mathrm{m}^{3}$. Filling in the equation leads to an estimated ELA of $253.5 \mathrm{~cm}^{2}$, which is an increase of $64.5 \mathrm{~cm}^{2}(34 \%)$ relative to the predemonstration phase simulation infiltration rate. As in Kneifel (2013), the infiltration is split between the $1^{\text {st }}$ floor $\left(132.6 \mathrm{~cm}^{2}\right)$ and $2^{\text {nd }}$ floor $\left(120.9 \mathrm{~cm}^{2}\right)$ based on total volume.

\subsection{MELs and Appliances}

The peak wattage parameter values used in the pre-demonstration phase simulation were based on specification sheets for the initial appliances and electronics (MELs) selected for installation in the NZERTF. However, some of the appliances installed in the NZERTF are different than those initially selected due to complexities related to the product acquisitions process. The peak wattage for each appliance is adjusted in the simulation, as shown in Table 4-1, based on updated specification sheets for the equipment actually installed in the NZERTF, measured performance data based on laboratory testing, or actual measured consumption during the demonstration phase. 
Table 4-1 Adjustments to Peak Wattage for Appliances and MELs

\begin{tabular}{|l|r|r|}
\hline Appliance & $\begin{array}{c}\text { Pre-Demonstration Phase } \\
\text { Peak Wattage }\end{array}$ & \multicolumn{2}{|c|}{$\begin{array}{c}\text { Adjusted Peak } \\
\text { Wattage }\end{array}$} \\
\hline Refrigerator & 45.7 & 56 \\
\hline Clothes Washer & 500 & 340 \\
\hline Clothes Dryer & 5200 & 2411 \\
\hline Dishwasher & 1090 & 546 \\
\hline Range - Oven & 5100 & 3950 \\
\hline Range - Cooktop & $3600^{*}$ & 75 \\
\hline Range - Hood & 330 & 1618 \\
\hline Microwave & 950 & \\
\hline
\end{tabular}

*Assumes the use of only 2 burners.

Note: Peak wattage is set based on either the average wattage over a cycle of operation or set to meet the target energy consumption for a given appliance.

\subsection{Lighting}

Figure 3-2 shows that the simulation over-consumes lighting-related electricity. After investigating the lighting loads during the demonstration phase, it was determined that the simulation assumed peak wattage to be higher than measured wattage during the demonstration phase for nearly every room in the NZERTF. The values shown in Table 4-2 are the pre-demonstration phase lighting wattages in the simulation and the actual wattages that were determined experimentally by turning on the lights in each room and physically measuring the actual wattage drawn. Total peak wattage (excluding the unused basement lighting) dropped from $614 \mathrm{~W}$ to $408 \mathrm{~W}$, which makes the pre-demonstration phase wattage $150 \%$ of the postdemonstration phase simulation values. Note that there is some uncertainty in the measured wattage because there are some errors in the electrical system, where some light fixtures are wired to a breaker that is inconsistent with the specifications (e.g., light in hallway may be wired to a bedroom breaker). These inconsistencies do not have an impact on total electricity consumption related to lighting, and negligible impacts on the associated heat loads. 
Table 4-2 Adjustments to Lighting Peak Wattage by Room

\begin{tabular}{|c|c|c|c|}
\hline Floor & Room & $\begin{array}{c}\text { Pre-Demonstration } \\
\text { Phase } \\
\text { (Watts) }\end{array}$ & $\begin{array}{c}\text { Post-Demonstration } \\
\text { Phase } \\
\text { (Watts) }\end{array}$ \\
\hline \multirow[t]{5}{*}{$1^{\mathrm{st}}$} & Kitchen & 118 & 81 \\
\hline & Dining Room & 65 & 34 \\
\hline & Living Room & 118 & 55 \\
\hline & Office & 0 & 0 \\
\hline & $1^{\text {st }}$ Floor Bath & 46 & 30 \\
\hline \multirow[t]{5}{*}{$2^{\text {nd }}$} & Master Bedroom & 41 & 41 \\
\hline & $2^{\text {nd }}$ Bedroom & 41 & 39 \\
\hline & $3^{\text {rd }}$ Bedroom & 41 & 33 \\
\hline & Master Bathroom & 81 & 82 \\
\hline & $2^{\text {nd }}$ Bathroom & 63 & 13 \\
\hline \multicolumn{2}{|c|}{ Basement* } & 217 & 217 \\
\hline
\end{tabular}

\subsection{HVAC System}

During the investigation of the measured performance of the HVAC system, many parameter values for the components in the HVAC system (cooling coil, heating coils, dehumidifiers, and HRV) should be adjusted in the pre-demonstration phase simulation to better represent the actual performance of the equipment during the demonstration phase of the NZERTF. Parameter values are based on the $E+$ rating conditions for each heating and cooling system component.

The cooling DX coil in the simulation represents the performance of the air-to-air heat pump in cooling mode. The rated capacity, sensible heat ratio, COP, and air flow rate were adjusted for both the low-speed and high-speed cooling operation mode of the heat pump (see Table 4-3). The cooling COP and rated capacity values decrease, which will increase electricity consumption required to meet the cooling load relative to the pre-demonstration phase simulation results.

\section{Table 4-3 Changes in Cooling DX Coil Parameters}

\begin{tabular}{|ll|c|c|}
\hline Field & Units & Values & Adjusted Values \\
\hline Availability & & Cooling Season & Always Available \\
Speed 1 Rated Total Cooling Capacity & $\mathrm{W}$ & 5483 & 5182 \\
Speed 1 Rated Sensible Heat Ratio & & 0.70 & 0.75 \\
Speed 1 Rated COP & & 3.73 & 3.66 \\
Speed 1 Rated Air Flow Rate & $\mathrm{m}^{3} / \mathrm{s}$ & 0.23 & 0.284 \\
Speed 2 Rated Total Cooling Capacity & $\mathrm{W}$ & 7751 & 6889 \\
Speed 2 Rated Sensible Heat Ratio & & 0.70 & 0.75 \\
Speed 2 Rated COP & & 3.69 & 3.04 \\
Speed 2 Rated Air Flow Rate & $\mathrm{m}^{3} / \mathrm{s}$ & 0.42 & 0.409 \\
Crankcase Heater Capacity (Represents Standby W) & $\mathrm{W}$ & 0 & 50 \\
\hline
\end{tabular}


The heating DX coil in the simulation represents the performance of the air-to-air heat pump in heating mode. The rated capacity, COP, and air flow rate were adjusted for both the low-speed and high-speed heating operation mode of the heat pump. As shown in Table 4-4, the air flow rate and capacity for both low-speed and high-speed operation modes increase while the rated COP for high-speed operation decreases. The measured COP of the heat pump is lower in heating mode because the original rated values are based on standard test procedure conditions, which do not account for the common occurrence of frost build-up in the refrigerant piping. Measured data is used to estimate static-state performance values with frost build-up that better represent "real world" operating conditions. ${ }^{10}$

The crankcase heater is added as a proxy to account for the standby electricity consumption of the heat pump during the heating season, with capacity of $50 \mathrm{~W}$ and maximum temperature of crankcase heater operation set at $100{ }^{\circ} \mathrm{C}\left(212^{\circ} \mathrm{F}\right)$. The defrost parameter values were adjusted based on actual equipment operation and experimental data collected during the demonstration phase. Heating coil defrost occurs when the outdoor temperature is below $1.7^{\circ} \mathrm{C}\left(35^{\circ} \mathrm{F}\right)$, and is accomplished by operating the $10 \mathrm{~kW}$ electric resistive auxiliary element approximately every 90 minutes. The median length of defrost cycle during the demonstration phase is 148 seconds, ranging from 60 seconds to 552 seconds. Based on the median defrost cycle length during the demonstration phase, the defrost time period fraction is 0.0273 .

\section{Table 4-4 Changes in Heating DX Coil Parameters}

\begin{tabular}{|ll|c|c|}
\hline Field & Units & Value & Adjusted Values \\
\hline Crankcase Heater Capacity & $\mathrm{W}$ & 0 & 50 \\
Maximum ODB Temp. for Crankcase Heater Operation & ${ }^{\circ} \mathrm{C}$ & 10 & 100 \\
Maximum ODB Temp. for Defrost Operation & ${ }^{\circ} \mathrm{C}$ & 7.22 & 1.7 \\
Defrost Strategy & & Reverse Cycle & Resistive \\
Defrost Control & & On Demand & Timed \\
Defrost Time Period Fraction & & 0.058333 & 0.0273 \\
Resistive Defrost Heater Capacity & $\mathrm{W}$ & Autosize & 10000 \\
Speed 1 Rated Total Heating Capacity & $\mathrm{W}$ & 4908 & 5159 \\
Speed 1 Rated COP & & 4.02 & 3.63 \\
Speed 1 Rated Air Flow Rate & $\mathrm{m} 3 / \mathrm{s}$ & 0.21 & 0.24 \\
Speed 2 Rated Total Heating Capacity & $\mathrm{W}$ & 7675 & 7545 \\
Speed 2 Rated COP & & 4.19 & 3.66 \\
Speed 2 Rated Air Flow Rate & $\mathrm{m}^{3} / \mathrm{s}$ & 0.42 & Autosize \\
\hline
\end{tabular}

The efficiency of the auxiliary electric resistance heating coil is decreased from 1.00 to 0.98 because no electric resistance coil is $100 \%$ efficient. The wattage of the auxiliary coil is changed from "autosized" by the $E+$ software to $10000 \mathrm{~W}$ to match the size of the actual heat pump installed in the NZERTF.

${ }^{10}$ Capacity and power curves based on measured data are available upon request. 
The efficiency of the HRV in the pre-demonstration phase simulation is greater than the measured performance of the HRV. Experimental data at or near the rated test conditions used in $E+$ is used to adjust the parameter values to those shown in Table 4-5. The effectiveness is reduced for all flow rates while the supply air flow rate $\left(0.0392 \mathrm{~m}^{3} / \mathrm{s}(83 \mathrm{CFM})\right.$ to $0.04956 \mathrm{~m}^{3} / \mathrm{s}$ (105 CFM)) is increased to match measured performance. The electric power wattage is adjusted based on the relative volume of the two floors.

Table 4-5 Changes in Heat Recovery Ventilator Parameters

\begin{tabular}{|l|rr|rr|}
\hline \multirow{2}{*}{ Parameter } & \multicolumn{2}{|c|}{ Pre-Demonstration Phase } & \multicolumn{2}{c|}{ Adjusted } \\
\cline { 2 - 5 } & \multicolumn{1}{|c|}{$1^{\text {st }}$ Floor } & $2^{\text {nd }}$ Floor & $1^{\text {st }}$ Floor & $2^{\text {nd }}$ Floor \\
\hline Nominal Supply Air Flow Rate $\left(\mathrm{m}^{3} / \mathrm{s}\right)$ & 0.0205 & 0.0187 & 0.02592 & 0.02364 \\
Sensible Effectiveness at 100\% Heating Air Flow & 0.72 & 0.72 & 0.62 & 0.62 \\
Sensible Effectiveness at 75\% Heating Air Flow & 0.78 & 0.78 & 0.68 & 0.68 \\
Sensible Effectiveness at 100\% Cooling Air Flow & 0.72 & 0.72 & 0.62 & 0.62 \\
Sensible Effectiveness at 75\% Cooling Air Flow & 0.78 & 0.78 & 0.68 & 0.68 \\
Nominal Electric Power & 27.0 & 27.0 & 28.2 & 25.8 \\
\hline
\end{tabular}

The dehumidification option on the air-to-air heat pump is simulated using zone dehumidifiers. The humidistat in the pre-demonstration phase simulation of $60 \%$ relative humidity is adjusted to $50 \%$, which is the setpoint during the demonstration phase of the NZERTF. The dehumidification equipment parameter values for water removal and energy factor in the predemonstration phase simulation were expected to be conservative estimates when selected. These parameters are adjusted as shown in Table 4-6 based on both the whole house dehumidifier's rated values and the measured performance of the dehumidify mode of the air-to-air heat pump.

Table 4-6 Changes in Dehumidifier Parameters

\begin{tabular}{|lc|c|c|}
\hline Field & Units & $\mathbf{1}^{\text {st }}$ Floor & $\mathbf{2}^{\text {nd }}$ Floor \\
\hline Rated Water Removal & L/day (pints/day) & 16.08 to $17.3(34.0$ to 36.6$)$ & 14.67 to 15.8 (31.0 to 33.4) \\
Rated Energy Factor & L/kWh & 1.00 to 1.65 & 1.00 to 1.65 \\
\hline
\end{tabular}

\subsection{DHW and Solar Thermal Systems}

The DHW and solar thermal systems were dramatically under-consuming electricity in the simulation results relative to measured consumption during the demonstration phase. All assumptions and parameters in the simulation were reviewed, which led to a number of key changes to the simulation, including system design, components, operation, and efficiency as well as hot water demand. The key change to the system design is to make the solar collectors in parallel as shown in Figure 4-1 instead of in series as shown in Figure 2-6. 


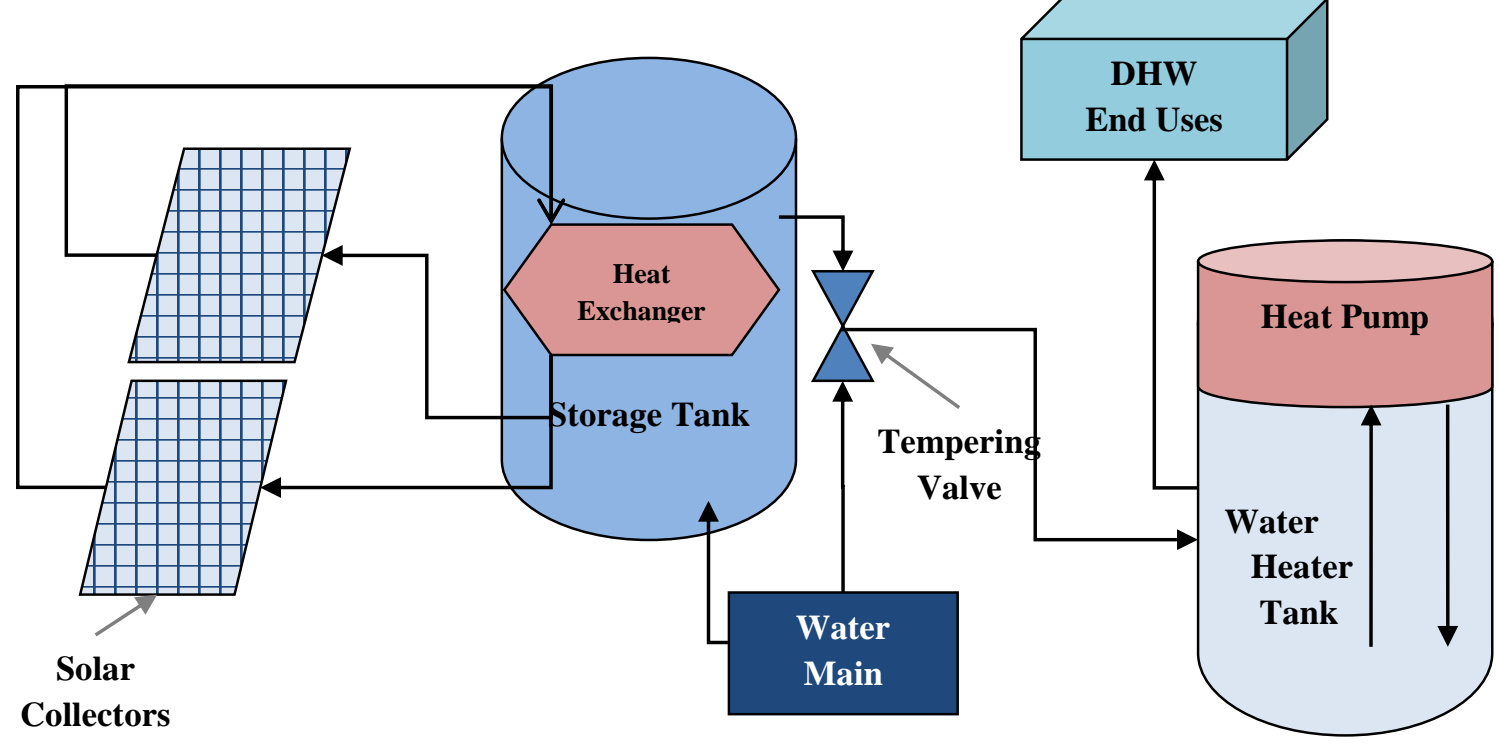

Figure 4-1 Adjusted Domestic Hot Water Heating System

A number of solar collector performance values (shown in Table 4-7) are adjusted using the Solar Rating and Certification Corporation (SRCC) Certified Solar Collector Rating, including the coefficients for the efficiency equation and incident angle modifier as well as the test flow rate and maximum flow rate through the tank (SRCC, 2014).

\section{Table 4-7 Solar Thermal Collector Parameters}

\begin{tabular}{|lc|r|r|}
\hline Field & Units & \multicolumn{1}{c|}{ Value } & Adjusted Value \\
\hline Test Flow Rate & $\mathrm{m}^{3} / \mathrm{s}$ & 0.0000498425 & 0.0000560 \\
Efficiency Equation Coefficient 1 & & 0.732 & 0.746 \\
Efficiency Equation Coefficient 2 & $\mathrm{W} / \mathrm{m}^{2}-\mathrm{K}$ & -4.1949 & -4.005 \\
Incident Angle Modifier Coefficient 2 & & 0.0581 & -0.09 \\
Incident Angle Modifier Coefficient 3 & & -0.2744 & 0 \\
Max Flow Rate & $\mathrm{m}^{3} / \mathrm{s}$ & 0.0000498425 & 0.0000262 \\
\hline
\end{tabular}

A number of parameter values were adjusted for the solar thermal system based on the measured performance data and expert experience with the installed system (shown in Table 4-8). The solar loop maximum flow rate parameter was changed from autosized ( $E+$ determined value) to $5.23649 \mathrm{E}-5 \mathrm{~m}^{3} / \mathrm{s}(0.83$ gallons per minute $(\mathrm{gpm}))$ based on measured flow rate data in the solar thermal loop. It is reasonable to assume that the maximum flow rate through each of the solar collectors is half the loop flow rate $\left(2.62 \mathrm{E}-5 \mathrm{~m}^{3} / \mathrm{s}\right.$ or $\left.0.415 \mathrm{gpm}\right)$.

The solar loop pump parameter values were adjusted to match the maximum solar loop flow rate and power consumption. Additionally, the differential setpoint for minimum solar loop pump 
operation was changed from $2.0^{\circ} \mathrm{C}\left(3.6^{\circ} \mathrm{F}\right)$ to $3.0^{\circ} \mathrm{C}\left(5.4^{\circ} \mathrm{F}\right)$ to match the actual operation conditions in the NZERTF.

Table 4-8 Solar Loop Pump Parameters

\begin{tabular}{|ll|c|c|}
\hline Field & Units & $\begin{array}{c}\text { Pre-Demonstration } \\
\text { Phase Values }\end{array}$ & Adjusted Values \\
\hline Rate Flow Rate & $\mathrm{m}^{3} / \mathrm{s}$ & 0.000099685 & 0.0000523649 \\
Rated Pump Head & $\mathrm{Pa}$ & 15000 & 179352 \\
Rated Power Consumption & $\mathrm{W}$ & Autosize & 160 \\
\hline
\end{tabular}

The pre-demonstration phase simulation excluded any heat losses through pipes (adiabatic) running to and from the solar collectors and the solar loop tank, or from the solar loop tank to the heat pump water heater tank. The adjusted model includes $6.1 \mathrm{~m}(20 \mathrm{ft})$ of outdoor pipe to and from the solar collectors to the interior of the NZERTF, $15.24 \mathrm{~m}(50.0 \mathrm{ft})$ of indoor pipe running to and from the outdoor pipe to the solar loop tank, and $3.2 \mathrm{~m}(10.5 \mathrm{ft})$ of pipe from the solar loop tank to the heat pump water heater tank. All pipes (indoor and outdoor) are assumed to be copper and rapped with $\mathrm{R}_{\mathrm{SI}}-0.7$ (R-4) insulation.

Due to the complexity of the DHW system and solar thermal system, the model was simplified by replacing the "stratified" water tanks (accounts for vertical stratification of water with the hottest at the top) for both the solar loop tank and heat pump water heater tank with "mixed" tanks (equal heat distribution throughout water). The $100 \%$ mixing of the tanks makes the temperature equal throughout the volume of water, leading to the location of inlet and outlets for each tank unimportant to the model. Additionally, some of the parameter values were changed (see Table 4-9) to better represent the performance of the installed tanks, including the maximum temperature limits and loss coefficients to ambient temperature for both tanks, deadband temperature difference and auxiliary electric heating element capacity for the heat pump water heater tank, and source-side effectiveness for the solar loop tank. ${ }^{11}$

${ }^{11}$ Note: The mixed tanks could be replaced with the stratified tanks to see if it changes the performance. 
Table 4-9 Changes in Storage Tank and Hot Water Heater Tank Parameters

\begin{tabular}{|lc|c|c|c|c|}
\hline Field & Units & \multicolumn{2}{|c|}{ Storage Tank } & \multicolumn{2}{c|}{ Water Heater Tank } \\
\hline & & Value & Adjusted Value & Value & Adjusted Value \\
\hline Tank Volume & $\mathrm{m}^{3}$ & 0.303 & 0.395 & & \\
Max. Temp. Limit & & 76.6 & 71.1 & 71.1 & 76.7 \\
Setpoint Temperature & ${ }^{\circ} \mathrm{C}$ & & & & \\
Deadband Temperature Difference & $\Delta^{\circ} \mathrm{C}$ & & & 5.0 & 8.33 \\
Heater Maximum Capacity & $\mathrm{W}$ & & & $7600^{*}$ & 3800 \\
Loss Coefficient to Ambient & $\mathrm{W} / \mathrm{m}^{2} \cdot \mathrm{K}$ & 0.846 & 1.64 & 0.41 & 1.64 \\
Temperature & to W/K & & & & \\
Source Side Effectiveness & & 0.80 & 0.44 & & \\
\hline *Two 3800 W Elements & \multicolumn{5}{|l}{} \\
\hline
\end{tabular}

A number of parameter values for the heat pump unit in the water heater were adjusted based on the updated performance specifications from the manufacturer, including the rated capacity, COP, and rated conditions as shown in Table 4-10.

Table 4-10 Changes in Hot Water Heat Pump Coil Parameters

\begin{tabular}{|lc|c|c|}
\hline Field & Units & Value & Adjusted Value \\
\hline Rated Capacity & $\mathrm{W}$ & 1375 & 1450 \\
Rated COP & W/W & 2.60 & 2.36 \\
Rated Evaporator Inlet Air DB Temp. & ${ }^{\circ} \mathrm{C}$ & 19.7 & 20.3 \\
Rated Evaporator Inlet Air WB Temp. & ${ }^{\circ} \mathrm{C}$ & 13.5 & 14.1 \\
Rated Condenser Inlet Water Temp. & ${ }^{\circ} \mathrm{C}$ & 57.5 & 58.0 \\
Condenser Pump Power Included in Rated COP & & No & Yes \\
\hline
\end{tabular}

Water demand was underestimated by $7.5 \%$, with water consumption at sinks being overestimated and water consumption for all other purposes being underestimated. There are two reasons for these differences. First, the pre-demonstration phase water consumption per cycle for the dishwasher (46.4 L or 12.3 gallons) and clothes washer (5.9 L or 1.6 gallons) were based on their rated consumption. However, the experimental data from the demonstration phase of the NZERTF show that the consumption per cycle is higher in actual operation at $56.7 \mathrm{~L}$ (15.0) gallons and 7.0 L (1.9 gallons), respectively. Second, the simulation defines a water draw using the flow rate and the length (time) of the flow rate while the experimental water draw length is based on the volume of water drawn. Flow rates for sinks, showers, and baths are reverse engineered to match the measured water consumption as shown in Table 4-11. 
Table 4-11 Domestic Hot Water Use and Thermal Load Fractions

\begin{tabular}{|l|c|c|c|c|c|c|}
\hline \multirow{2}{*}{$\begin{array}{c}\text { DHW Use } \\
\text { Category }\end{array}$} & \multicolumn{2}{|c|}{ Per Cycle } & \multicolumn{2}{c|}{ Daily } & \multicolumn{2}{c|}{ Flow Rate } \\
\cline { 2 - 7 } & $\begin{array}{c}\text { Pre-demon. } \\
\text { Phase } \\
\mathbf{m}^{\mathbf{3}}(\mathbf{G a l}) / \mathbf{C y c l e}\end{array}$ & $\begin{array}{c}\text { Adjusted } \\
\mathbf{m}^{\mathbf{3}}(\mathbf{G a l}) / \mathbf{C y c l e}\end{array}$ & $\begin{array}{c}\text { Pre-demon. } \\
\text { Phase } \\
\mathbf{m}^{\mathbf{3}}(\mathbf{G a l})\end{array}$ & $\begin{array}{c}\text { Adjusted } \\
\mathbf{m}^{\mathbf{3}}(\mathbf{G a l})\end{array}$ & $\begin{array}{c}\text { Pre-demon. } \\
\text { Phase } \\
\mathbf{m}^{\mathbf{3}} / \mathbf{s}\end{array}$ & $\begin{array}{c}\text { Adjusted } \\
\mathbf{m}^{\mathbf{3}} / \mathbf{s}\end{array}$ \\
\hline Clothes & $46.6(12.3)$ & $56.8(15.0)$ & $39.8(10.5)$ & $48.5(12.8)$ & 0.00003582 & 0.00002122 \\
Dishwasher & $4.9(1.3)$ & $7.2(1.9)$ & $4.2(1.1)$ & $4.9(1.3)$ & 0.00000196 & 0.000001989 \\
\hline Shower & NA & NA & $142.3(37.6)$ & $160.5(42.4)$ & 0.00011000 & 0.00012561 \\
Bath & NA & NA & $11.4(3.0)$ & $33.3(8.8)$ & 0.00032386 & 0.00033736 \\
Sinks & NA & NA & $95.4(25.2)$ & $71.2(18.8)$ & 0.00009500 & 0.00007176 \\
\hline
\end{tabular}

The target water temperature for each of the fixture types are adjusted as shown in Table 4-12, which are based on measured data from the demonstration phase. All target temperatures are lower except for the bath draw. The greatest change occurs for the clothes washer because the pre-demonstration phase simulation assumed the clothes washer uses $100 \%$ hot water. However, the clothes washer was set to warm water for the wash portion and cold water for the rinse portion of the cycle. As a result, the average water temperature for a full cycle is much lower than $48.9^{\circ} \mathrm{C}\left(120^{\circ} \mathrm{F}\right)$, ranging from $15.0^{\circ} \mathrm{C}\left(59^{\circ} \mathrm{F}\right)$ to $24.4^{\circ} \mathrm{C}\left(76^{\circ} \mathrm{F}\right)$ depending on the month. The post-demonstration phase simulation uses the average temperature across all months at the target water temperature for the clothes washer. ${ }^{12}$

Table 4-12 Domestic Hot Water Target Temperature

\begin{tabular}{|l|c|c|}
\hline \multirow{1}{*}{\multicolumn{1}{c|}{$\begin{array}{c}\text { DHW Use } \\
\text { Category }\end{array}$}} & \multicolumn{2}{|c|}{$\begin{array}{c}\text { Target Water Temperature } \\
{ }^{\circ} \mathbf{C}\left({ }^{\circ} \mathbf{F}\right)\end{array}$} \\
\cline { 2 - 3 } & Value Phase & Adjusted Value \\
\hline Clothes Washer & $48.9(120)$ & $19.4(67)$ \\
Dishwasher & $48.9(120)$ & $40.6(105)$ \\
\hline Shower & $40.6(105)$ & $38.9(102)$ \\
Bath & $40.6(105)$ & $44.4(112)$ \\
Sinks & $40.6(105)$ & $37.7(100)$ \\
\hline
\end{tabular}

\subsection{Occupancy}

The assumed occupant activity levels in the pre-demonstration phase simulation and the resulting sensible and latent heat gains shown in Table 2-6 are based on Hendron and Engebrecht (2010). The simulation model is adjusted to the values shown in Table 4-13 and defined in Omar and Bushby (2013), which states that the sensible and latent loads simulated in the NZERTF during the demonstration phase were maintained at $70 \mathrm{~W} /$ person and $45 \mathrm{~W} /$ person, respectively.

\footnotetext{
${ }^{12}$ Note that a more complex temperature schedule could lead to more accurate draws from the hot water heater.
} 
Table 4-13 Occupant Activity Level

\begin{tabular}{|l|c|c|c|}
\hline \multirow{2}{*}{$\begin{array}{l}\text { Occupant } \\
\text { Internal Load }\end{array}$} & \multicolumn{2}{|c|}{$\begin{array}{c}\text { Pre-Demon. Phase } \\
\text { W (Btu/Hr) }\end{array}$} & $\begin{array}{c}\text { Adjusted } \\
\text { W (Btu/Hr) }\end{array}$ \\
\cline { 2 - 4 } & $1^{\text {st }}$ Floor & $2^{\text {nd }}$ Floor & Constant \\
\hline Sensible & $67(230)$ & $61(210)$ & $70(239)$ \\
\hline Latent & $56(190)$ & $41(140)$ & $45(154)$ \\
\hline
\end{tabular}

\subsection{Missing Experimental Data and Equipment Faults for the Demonstration Phase}

It is important to note that during the investigation into the differences between the simulation and the measured performance during the demonstration phase of the NZERTF, several key operation faults as well as a number of missing data events were identified. Data for all systems (DHW, HVAC, and solar PV) were lost for August 2, 2013 through August 6, 2013, which could be the reason for the outlier results that occur for most systems in the month of August. The missing data for August as well as the other events listed in Table 4-14 should be considered when comparing the simulation results to the measured performance of the NZERTF.

Table 4-14 Missing Experimental Data

\begin{tabular}{|l|l|}
\hline System & Dates \\
\hline DHW & July 1; August 2-August 6 \\
\hline Solar Thermal & July 1; August 2-August 6 \\
\hline Solar PV & August 2-August 6; December 4-December 5*; December 27 \\
\hline HVAC** & August 2-August 6 \\
\hline * Portion of date \\
** The heating and cooling component data are available for these days because \\
there is an additional monitoring system collecting the data. However, the data \\
are removed for consistency with the remainder of the collected data. \\
\hline
\end{tabular}

Operational and performance issues shown in Table 4-15 were primarily realized in meeting the DHW demand, both with the solar thermal system and DHW system. The clothes washer did not operate July 2, 2013 through July 7, 2013 or August 12, 2013 through August 18, 2013, which would lead to less than scheduled water consumption. The solar loop pump did not operate from August 24, 2013 through September 3, 2013, which would lead to a greater demand on the heat pump and auxiliary water heating components during that timeframe. The controller wiring on the heat pump water heater led to the inoperability of the heat pump compressor from November 25, 2013 through December 4, 2013, which should increase the demand on the auxiliary water heating element. The length of pipe between solar loop tank to the heat pump water heater tank was decreased from approximately $8.1 \mathrm{~m}$ (27 ft) to $3.2 \mathrm{~m}$ (10.5 ft) on September 26, 2013 (included improvements to the pipe insulation). The longer, less insulated pipe will lead to greater than expected heat losses to the basement for July 2013 through September 2013. These 
issues in operations during the demonstration phase should be considered when comparing the results from the simulation to the measured performance of the NZERTF.

Table 4-15 Equipment Faults

\begin{tabular}{|l|l|}
\hline System & Details \\
\hline Clothes Washer & No draws - July 2-July 7; August 12-August 18 \\
\hline Solar Loop Pump & August 24-September 3 \\
\hline Heat Pump Water Heater & November 25-December 4 \\
\hline Pipe between DHW Tanks & Length shortened and insulation improved on September 26 \\
\hline
\end{tabular}

One last item that is not technically an equipment "fault" is the air-to-air heat pump operation in heating mode. The E+ simulation operates the heat pump and auxiliary electric resistance element based on the capacity capabilities of the heating coils. The auxiliary element rarely operates because the heat pump has the capacity to meet the heating load in most situations. The heat pump installed in the NZERTF during the demonstration phase is operated based on time instead of capacity. The heat pump runs in low speed for 40 minutes. If the setpoint has not been met, the heat pump shifts to high speed operation. If the setpoint is not met after another 40 minutes, the auxiliary element is also turned on until the setpoint is met. In many cases when the auxiliary heating was operated during the demonstration phase, high speed operation was effectively increasing the temperature towards in the NZERTF set point, but because of the timing controls the auxiliary element operated.

Figure 4-2 shows heating component operation and resulting heat pump return air and living room ambient temperature measurements for December 3 of the demonstration phase from 2:07 AM to 3:40 AM, during which a full operation cycle occurs for the heating equipment. The heat pump begins the cycle in low-speed operation and shifts to high-speed operation at 2:47 AM. While in high-speed mode, the living room (location of thermostat) air temperature is consistently rising up to $20.6{ }^{\circ} \mathrm{C}\left(69.0^{\circ} \mathrm{F}\right)$. In fact, the air returning to the heat pump is higher than the target setpoint temperature at $21.5^{\circ} \mathrm{C}\left(70.7^{\circ} \mathrm{F}\right)$. However, instead of maintaining operation in high-speed mode to raise the room temperature by $0.5^{\circ} \mathrm{C}\left(1^{\circ} \mathrm{F}\right)$ to meet the setpoint, the electric resistance auxiliary element turns on to support the heat pump from 3:27 AM to 3:40 AM. The electric resistance does not significantly impact the rate of increase in temperature measured in the living room while drastically increasing the electricity consumption and lowering the combined COP of the entire heating system. The power usage increases from $2000 \mathrm{~W}$ to $12000 \mathrm{~W}$ and the efficiency is cut in half from a COP of over 3.5 down to a COP of less than 1.5. The thermostat turns off the heating equipment at 3:40 AM, at which time the living room temperature is $20.7^{\circ} \mathrm{C}\left(69.3^{\circ} \mathrm{F}\right)$. The heat pump operating in high-speed mode would have been able to increase the living room temperature by $0.2^{\circ} \mathrm{C}\left(0.3^{\circ} \mathrm{F}\right)$ more efficiently. 


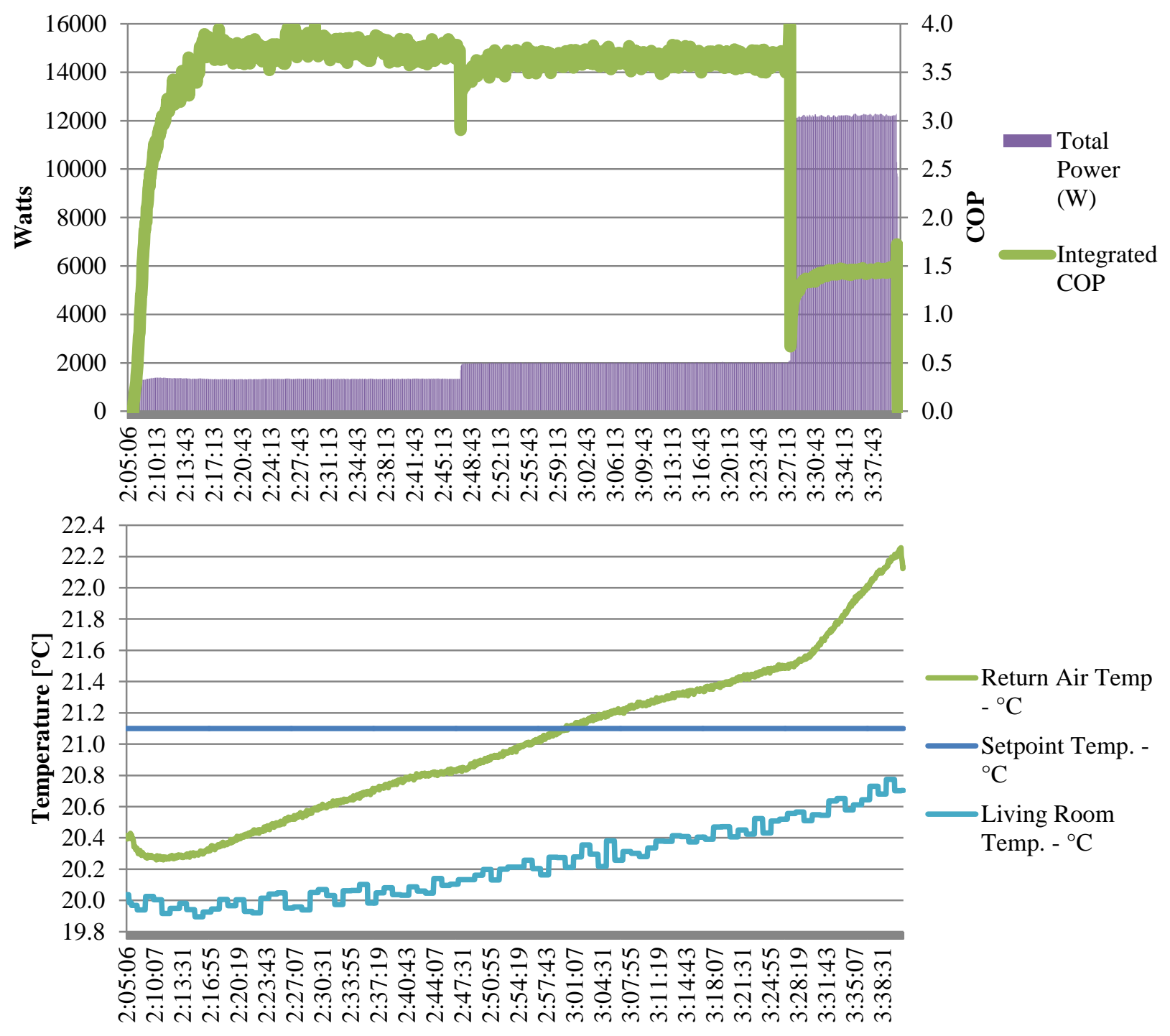

Figure 4-2 Air Temperature, Total Heating Electricity Consumption, Auxiliary Electricity Consumption, and Combined Heating COP - December 1, 2013 


\section{Validated Model Results}

This chapter considers the adjustments made to the pre-demonstration phase simulation, how these changes impact electricity consumption, and how the new results compare to the measured performance during the demonstration phase. In addition to the validated model (Post-Demonstration Phase), an additional simulation model is developed that incorporates the most significant equipment faults and data collection losses during the demonstration phase for the NZERTF (Post-Demonstration Phase*). An additional simulation is developed to analyze the DHW system performance and will be discussed in Section 5.5.

\subsection{Total Electricity Consumption and Production}

Figure 5-1 shows that the adjustments made in the post-demonstration phase simulation lead to an increase of $1361 \mathrm{kWh}$ in annual electricity consumption from $11156 \mathrm{kWh}$ to $12517 \mathrm{kWh}$, which is still $411 \mathrm{kWh}(3.3 \%)$ lower than the measured consumption of $12927 \mathrm{kWh}$. The incorporation of the faults and data losses during the demonstration phase leads to a decrease in both total annual consumption (133 kWh) and production ( $333 \mathrm{kWh}$ ) relative to the post-demonstration phase simulation. As a result, estimated annual consumption (with faults) is $544 \mathrm{kWh}$ lower than measured consumption while estimated annual production (with faults) is $366 \mathrm{kWh}$ is higher than measured production.

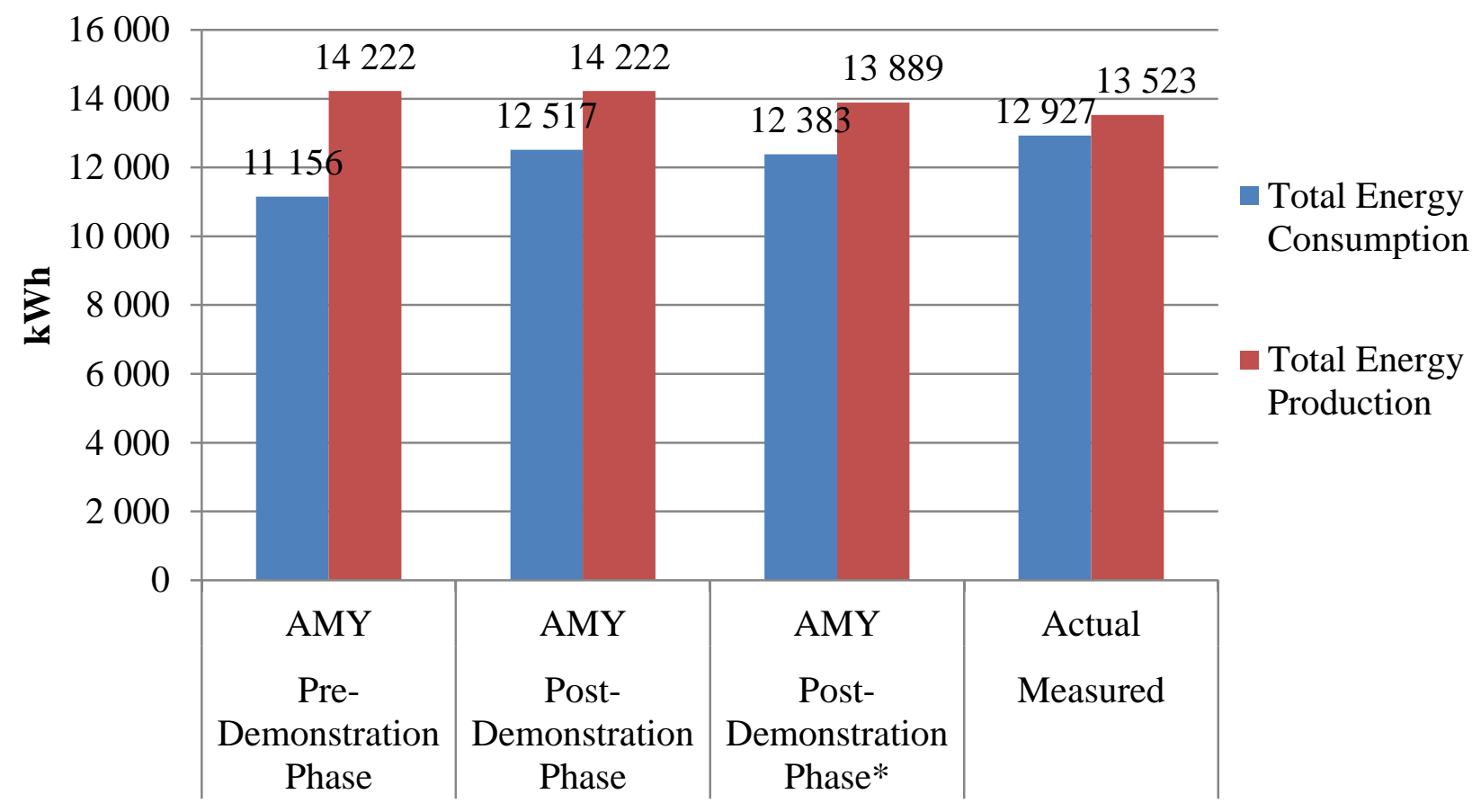

Figure 5-1 Annual Electricity Consumption and Production - kWh

Monthly electricity consumption for each of the three simulations and the measured performance are shown in Figure 5-2. The adjustments from the pre-demonstration phase simulation to the 
post-demonstration phase simulation lead to the simulation results increasing for all months. Once the faults and lost data are accounted for in the model, consumption matches relatively well for April through December.

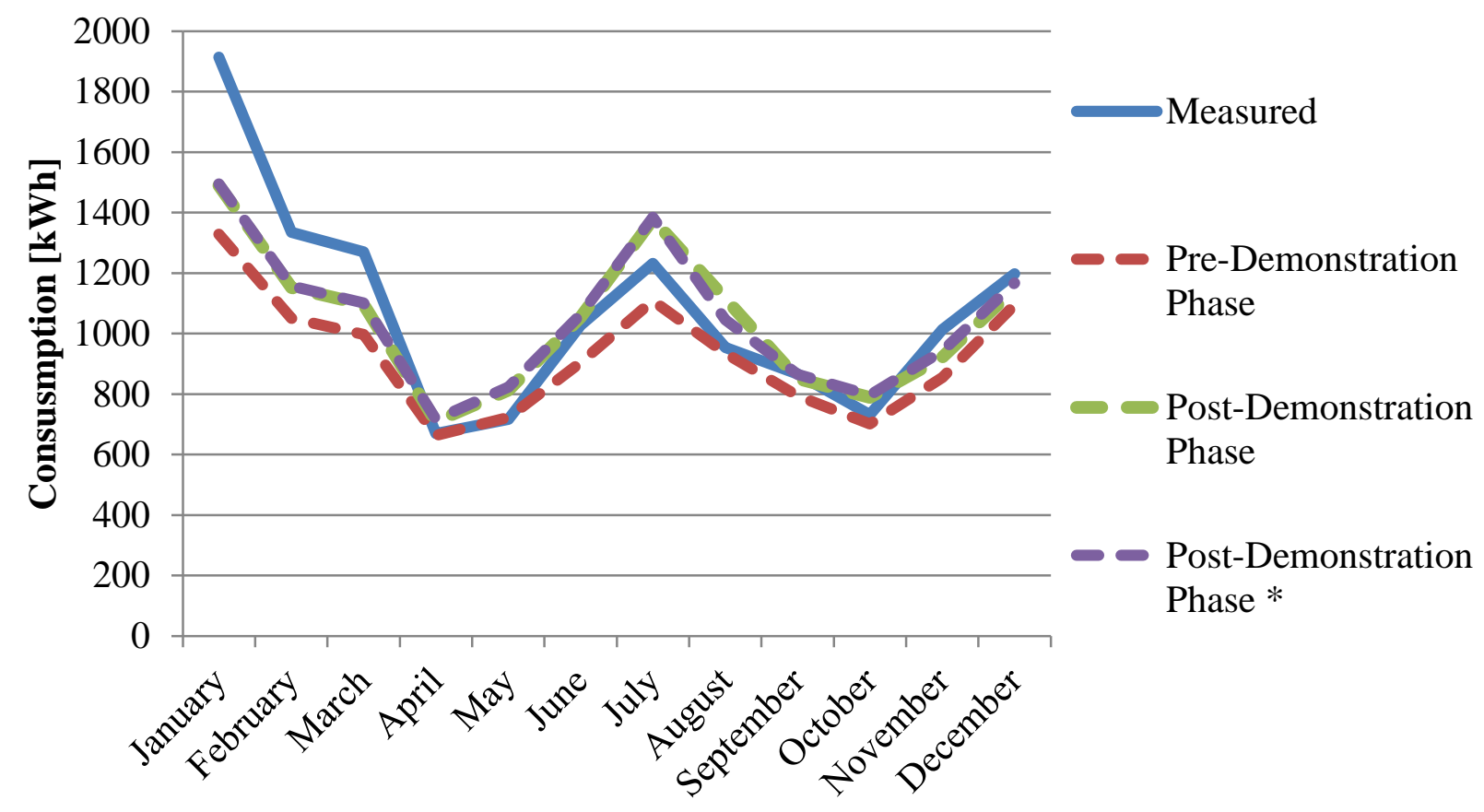

Figure 5-2 Monthly Electricity Consumption and Production - kWh

Figure 5-3 shows annual consumption by category for each of the three simulations and the measured performance. The post-demonstration phase simulation more closely maps to the measured performance than the pre-demonstration phase simulation for all six categories. The greatest remaining difference occurs for meeting the heating and cooling loads of the NZERTF, with the post-demonstration phase simulation (with faults) underestimating consumption by $315 \mathrm{kWh}$. Given that the largest differences occur for heating and cooling the NZERTF and those differences are realized in January through March of the demonstration phase, it appears that the post-demonstration phase simulation is consistently underestimating consumption to meet the heating load for the NZERTF.

The simulation results for the other five categories are relatively similar for the post-demonstration phase simulation and the measured performance. After accounting for the faults and missing data, estimated annual consumption for the solar loop pumps, lighting, and HRV are within $1 \mathrm{kWh}, 7 \mathrm{kWh}$, and $39 \mathrm{kWh}$ of the measured performance, respectively. Based on the complexities associated with simulation design, only the HRV consumption appears to be outside the margin of error for these four categories. The estimated consumption by the MELs and Appliances category is within $76 \mathrm{kWh}$ of the measured performance. The simulated DHW system consumption is $115 \mathrm{kWh}(10 \%)$ less than the measured performance. Each of these categories will be analyzed in detail. 


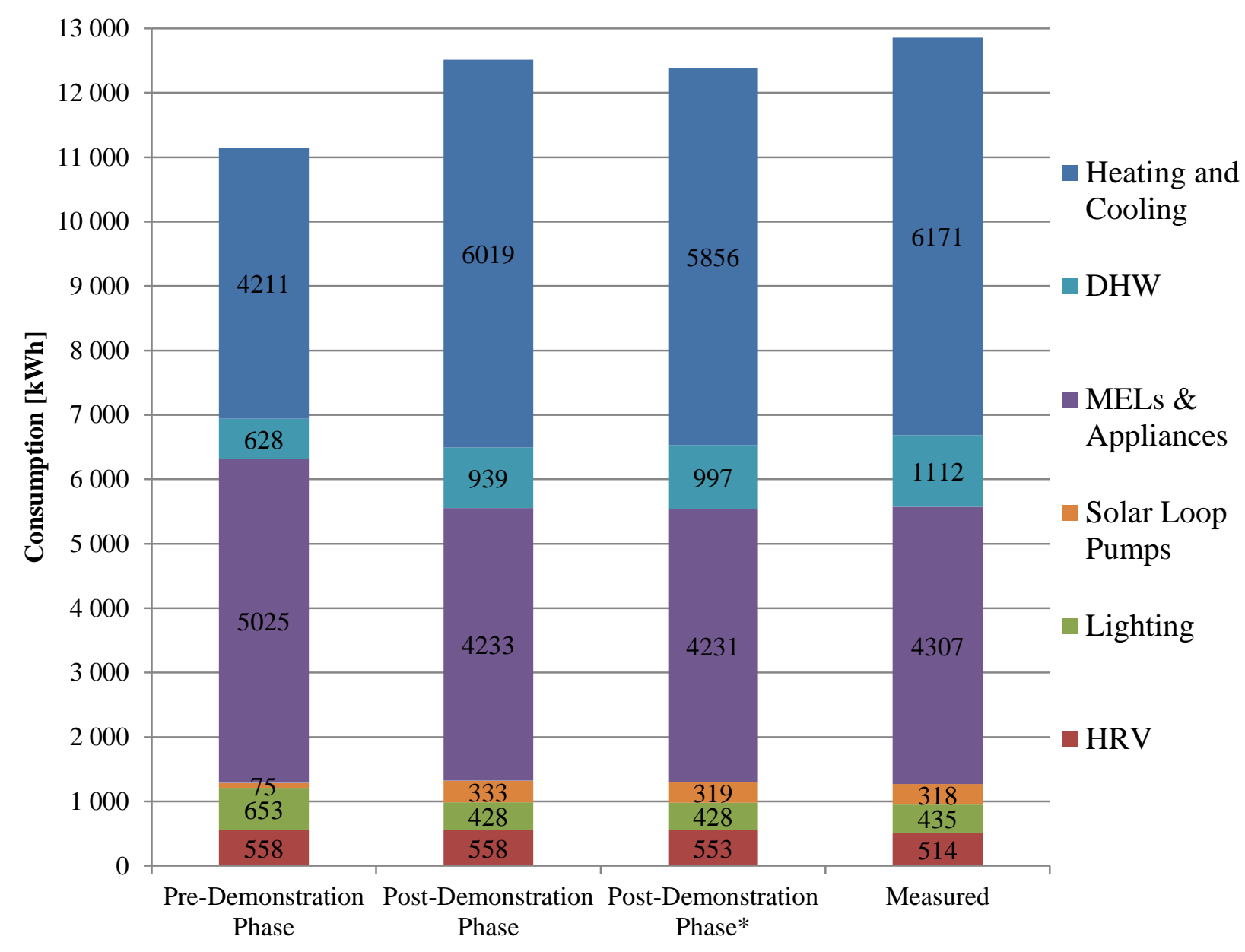

Figure 5-3 Total Electricity Use by Month - kWh

\section{$5.2 \quad$ Lighting}

Figure 5-4 shows that the post-demonstration phase simulation slightly underestimates annual consumption $(7 \mathrm{kWh})$. The accuracy of this estimate is a result of the reverse engineering of the peak wattage parameter values. The faults and data collection issues do not change the estimated consumption. 


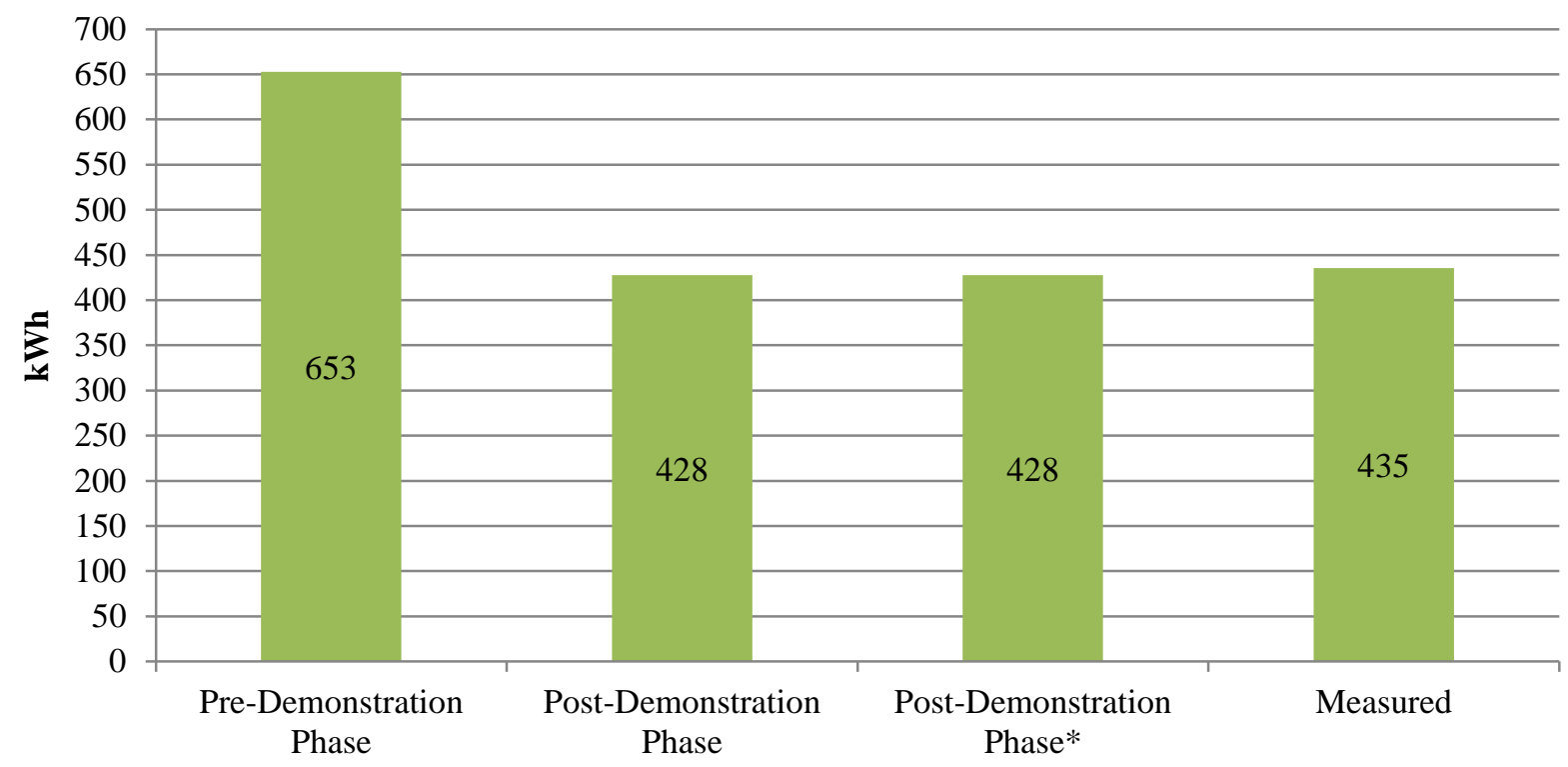

Figure 5-4 Annual Lighting Electricity Use - kWh

Figure 5-5 shows that the estimated monthly lighting electricity consumption is relatively constant from month to month, with variation driven primarily by the number of days in the month. Meanwhile, measured lighting consumption shows greater variation. For example, consumption in April and May shows higher lighting usage while consumption in August shows lower lighting usage. Unlike other building systems, lighting consumption is not removed for August 2 through August 6 because it would be time consuming to adjust each of the lighting schedules. Instead a more anecdotal approach is implemented to explain the variation. The 5 days of lost data (5 out of 31 days or $84 \%$ ) results in lower consumption in August (32 kWh), which is $86 \%$ of consumption in July $(37 \mathrm{kWh})$. The variations for April and May could have been driven by faults in operation. 


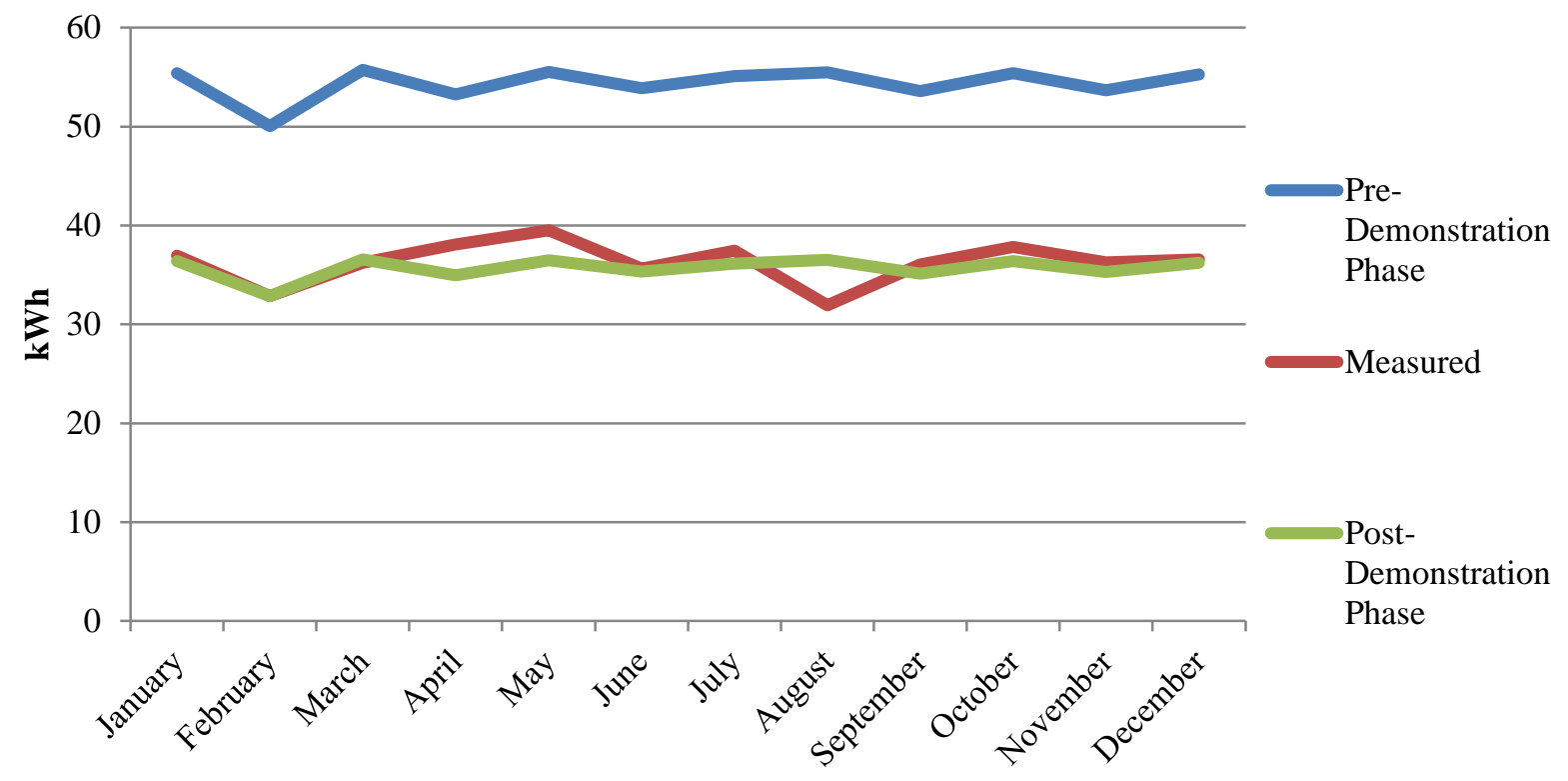

Figure 5-5 Lighting Electricity Use by Month - kWh

\subsection{MELs and Appliances}

Appliance electricity usage required significant adjustments because there is minimal information regarding how appliances operate and consume electricity under "real world" conditions. The post-demonstration phase model underestimates total MEL electricity consumption by $6 \%(143 \mathrm{kWh})$ and overestimates total appliance electricity consumption by $4 \%(69 \mathrm{kWh})$, leading to an underestimation of $2 \%(74 \mathrm{kWh}) .{ }^{13}$

Figure 5-6 shows that consumption for the clothes dryer required the most significant adjustment, which was a result of the conservative assumptions used in the pre-demonstration phase simulation. Similarly, the clothes washer and dishwasher were adjusted from the conservative parameter values to more accurate values that map better to measured consumption. The pre-demonstration phase simulation underestimated electricity consumption for the refrigerator because it was based on the EnergyStar rated annual consumption, which excludes icemaker operation. The post-demonstration phase simulation maps to the measured performance now that the icemaker operation is included. Changes were also made to the cooking appliances to match actual operation during the demonstration phase.

\footnotetext{
${ }^{13}$ Note that the MEL electricity consumption estimated in Post-Demo Phase and Post-Demo Phase* are identical because the Post-Demo Phase* simulation does not account for the data losses in August 2 through August 6 for electrical equipment electricity consumption. Given that electrical loads are reverse engineered and would vary significantly in real-life scenarios, it was determined that the time and effort to adjust each load profile would not significantly benefit the validation process.
} 


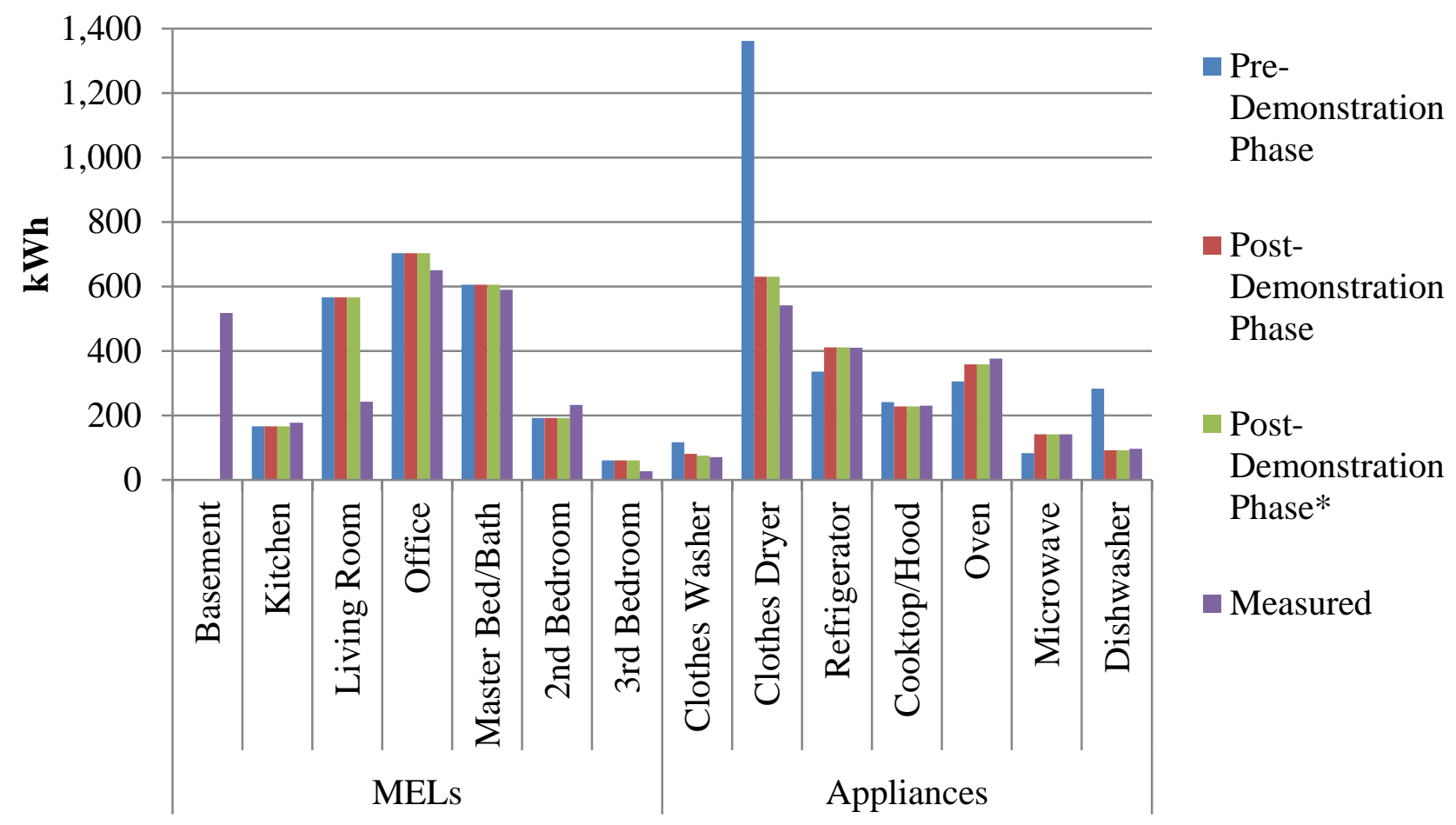

Figure 5-6 Equipment Electricity Use - kWh

\subsection{HVAC System}

Figure 5-7 shows the monthly electricity consumption for heating and cooling the NZERTF. The adjustments made to the post-demonstration phase simulation (with faults) leads to nearly identical consumption to meet the cooling load (excluding the overestimation in July). The estimated consumption to meet the heating load increases going from the pre-demonstration phase simulation to the post-demonstration phase simulation, but remains well below measured consumption for November through March. There is minimal impact from the incorporation of faults and missing data into the simulation for heating. 


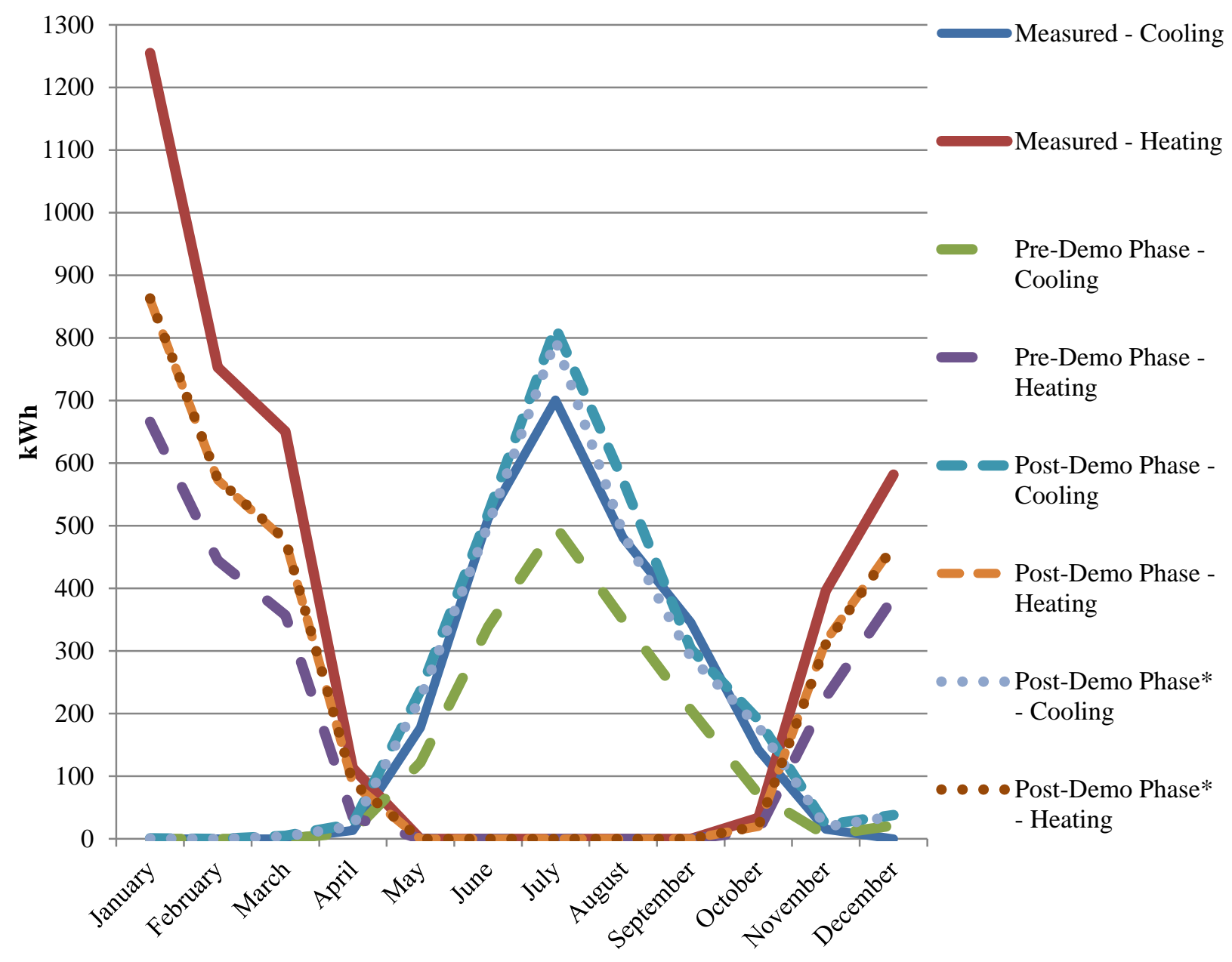

Figure 5-7 Heating and Cooling Electricity Consumption - kWh

Figure 5-8 shows the monthly heating-related electricity consumption for both the heat pump and the electric resistance auxiliary element. The post-demonstration phase simulation underestimates annual consumption by both the heat pump (227 kWh or $9 \%)$ and resistive heating element ( $615 \mathrm{kWh}$ or $53 \%)$, with underestimation occurring every month throughout the heating season. 


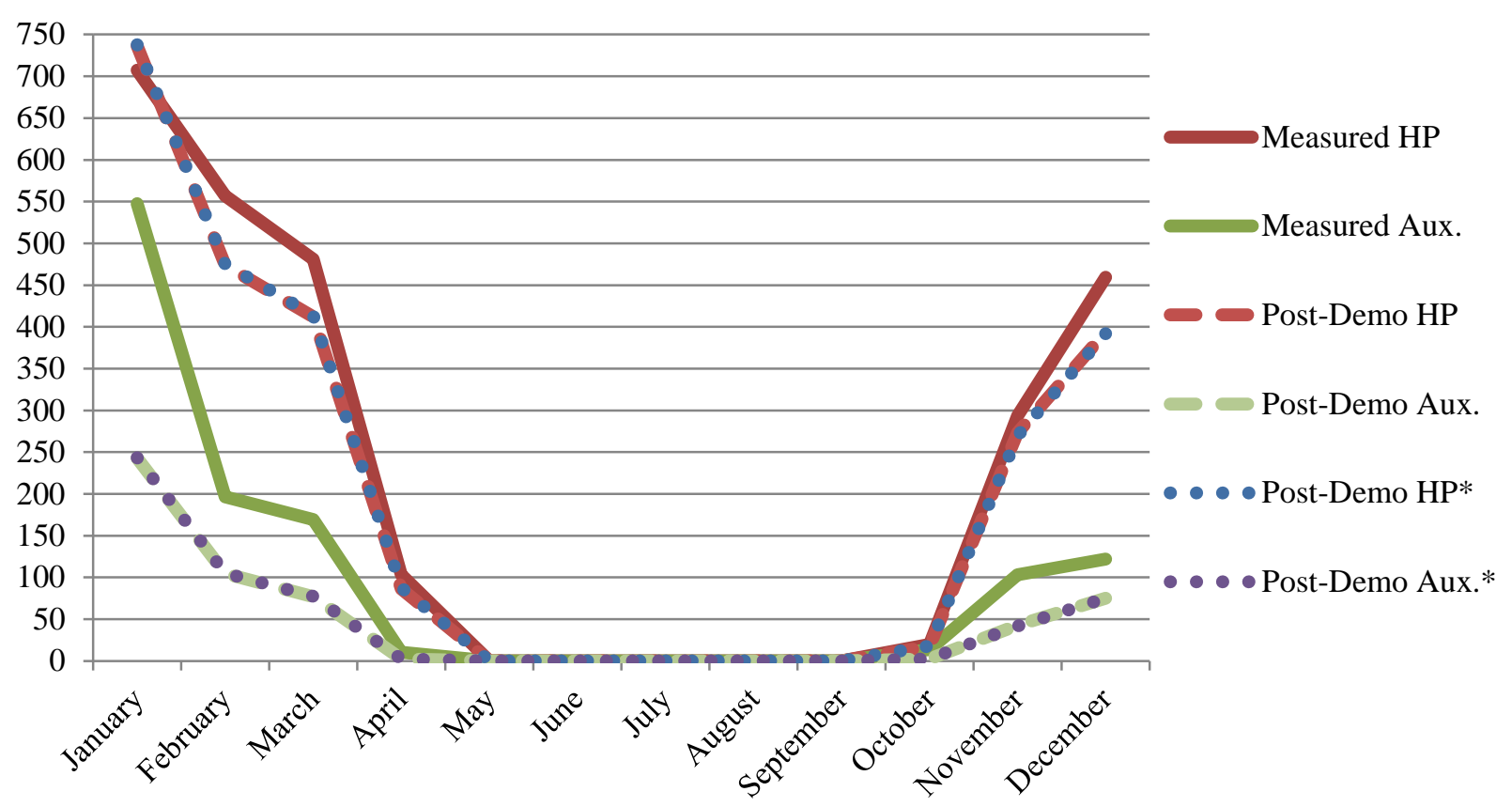

Figure 5-8 Monthly Heating Electricity Consumption by Component - kWh

In order to further diagnose the reason for the differences in the simulation results and the measured performance, it is necessary to dissect heating electricity consumption in greater detail. For this reason, defrost cycle and heat pump standby electricity consumption are analyzed.

Figure 5-9 shows that monthly defrost consumption is greatest for the coldest months, with the simulation results matching well to the measured performance for all months. The greatest differences occur in January and December at $11 \mathrm{kWh}$ and $7 \mathrm{kWh}$, respectively. Estimated annual defrost consumption is $12 \mathrm{kWh}$ lower (3\%) than the measured defrost consumption. One reason for the underestimation is the manner in which the heat pump controls handle the defrost cycle. In cases where the heat pump stops operation during a defrost cycle, it caches where in the cycle it stops and continues the cycle where it left off the next time the heat pump begins operation. The simulation model will not operate in the same way, leading to less total time running in defrost mode. 


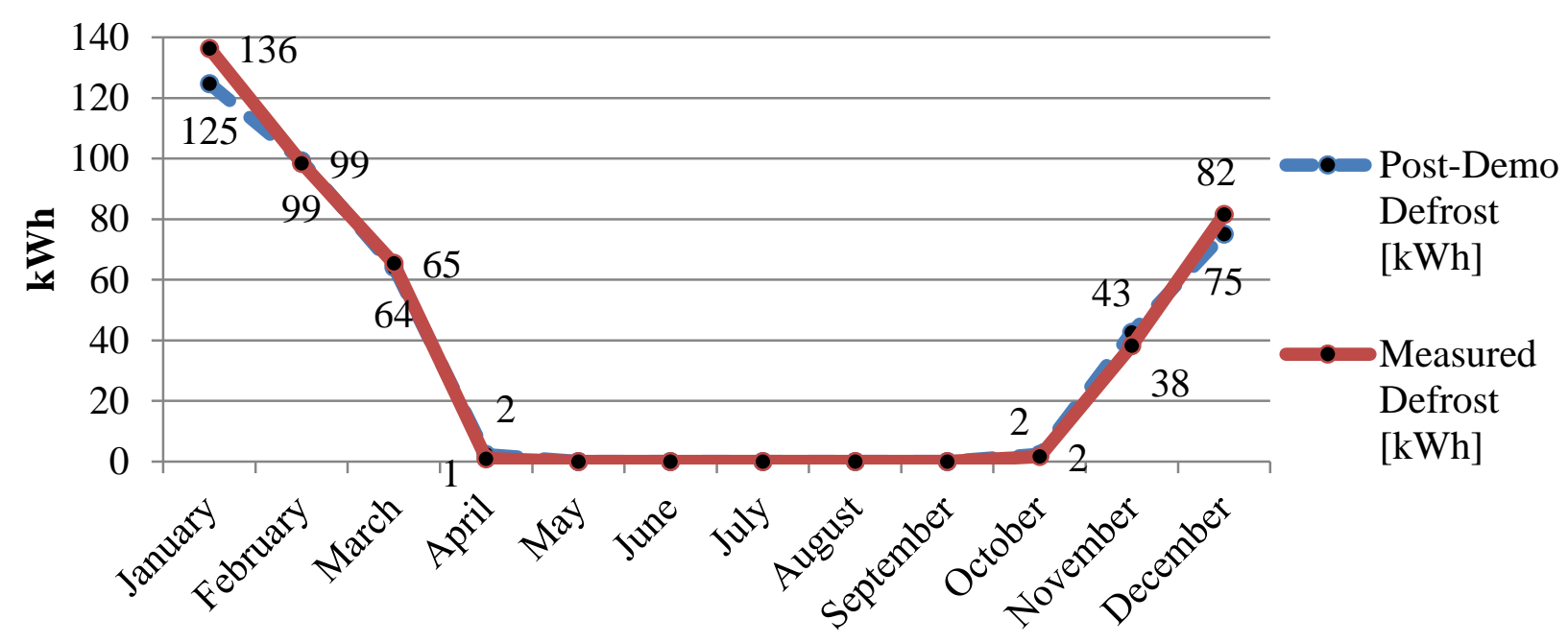

Figure 5-9 Monthly Defrost Electricity Consumption - kWh

Standby energy consumption (see Figure 5-10) estimated by the simulation model maps well to the measured consumption and varies by month, with the greatest standby energy consumed during the mild seasons because the equipment is in operation less often, the greater the standby electricity consumption. The simulation estimates are greater than the measured performance for April through October and lower for November through March. The simulation underestimates the amount of time for which cooling equipment is in operation and overestimates the amount of time for which heating equipment is in operation. The estimated annual standby consumption is $8 \mathrm{kWh}(3 \%)$ greater than the measured standby consumption. Controlling for the 5 days of lost data in August would decrease estimated standby electricity consumption by approximately $4 \mathrm{kWh}$ to equal the measured standby consumption of $17 \mathrm{kWh}$.

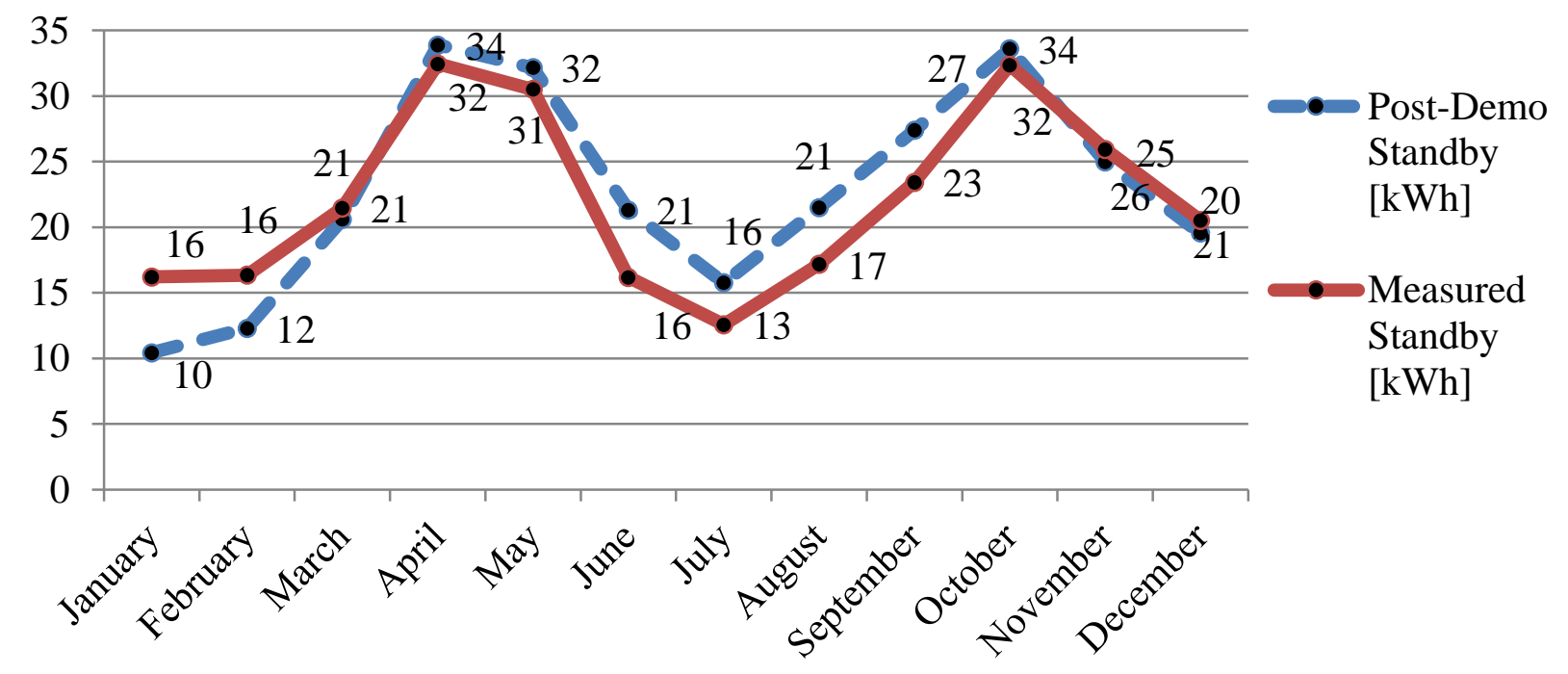

Figure 5-10 Monthly Heat Pump Standby Electricity Consumption - kWh 
After analyzing consumption to meet the heating load of the NZERTF, it is apparent that the simulation cannot replicate the operating conditions of the heat pump and electric resistance auxiliary element discussed in Section 4.7. The operation controls of the heating components in the NZERTF have been adjusted, and are currently being tested in a follow-up demonstration phase. The capacity of the auxiliary resistive heating element has been reduced by half from $10 \mathrm{kWh}$ to $5 \mathrm{kWh}$. Dehumidification control was shifted from the heat pump to a whole house dehumidifier. The thermostat is currently being operated based on an average of the $1^{\text {st }}$ floor and $2^{\text {nd }}$ floor temperatures. Additionally, the HRV system is now cycling on at $0.057 \mathrm{~m}^{3} / \mathrm{s}$

(120 CFM) for 40 minutes out of every hour, leading to an hourly average of $0.038 \mathrm{~m}^{3} / \mathrm{s}$ (80 CFM). The post-demonstration phase simulation has been adjusted to account for the reduction in the resistive heating capacity, and rerun with 2014 weather data (AMY for KGAI weather station) to determine if the simulation effectively replicates the new controls for meeting the heating load of the NZERTF for October through December of 2014.

Figure 5-11 compares the post-demonstration phase simulation results to the measured performance for the heating and cooling system (excluding the dehumidifiers) during October through December of 2014. The post-demonstration phase simulation results more closely align with the measured consumption, with minimal overestimation in October ( $3 \mathrm{kWh}$ or $3 \%)$ and an underestimation in November (27 kWh or $9 \%$ ) and December $(12 \mathrm{kWh}$ or $3 \%)$. Total consumption estimated by the simulation for October through December is $834 \mathrm{kWh}$, which is within $4 \%$ of the measured consumption of $871 \mathrm{kWh}$. In contrast, the simulation underestimated consumption for October through December of the demonstration phase (year 2013) by $206 \mathrm{kWh}$ or $20 \%$.

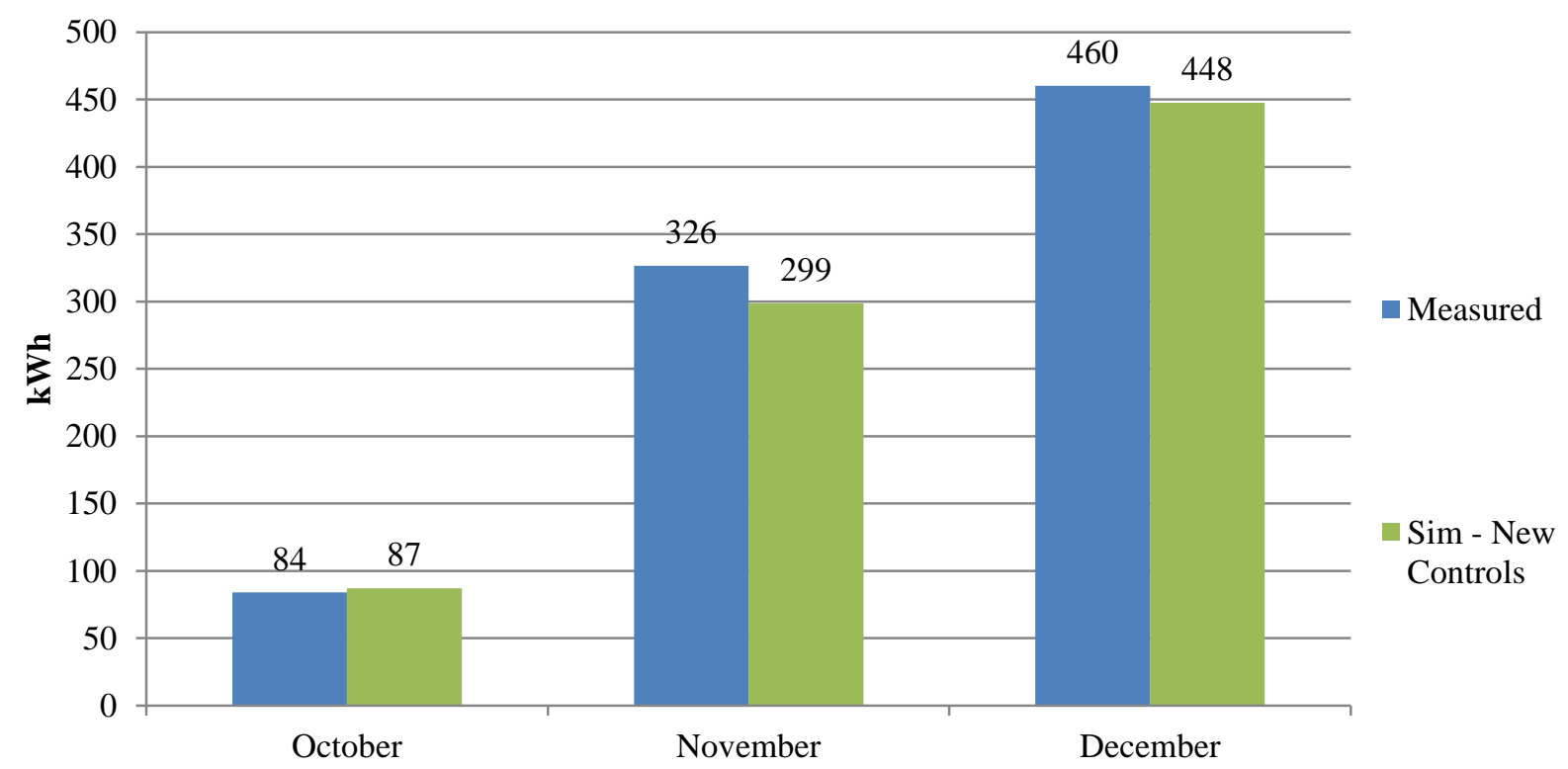

Figure 5-11 Updated Heating Electricity Consumption (2014) - kWh 
A disaggregated analysis is shown in Figure 5-12, where consumption by each component is provided. Previously, the post-demonstration phase simulation model underestimated both the heat pump and resistive heat electricity consumption in November and December. The new model more closely matches the measured performance with the new NZERTF controls. Estimated heat pump consumption is $51 \mathrm{kWh}(6 \%)$ lower than the measured heat pump consumption for October 2014 through December 2014. The heat pump is not operating as often in the simulation model, leading to greater standby electricity consumption ( $6 \mathrm{kWh}$ or $8 \%$ ) relative to the measured consumption. Auxiliary resistive heat is not operated for heating the NZERTF throughout the 3 months, and is operated only during defrost cycles. The model overestimates defrost electricity consumption by $14 \mathrm{kWh}(44 \%)$. Based on these results, it is reasonable to assume that the new simulation model is now sufficiently replicating the performance of the HVAC system.

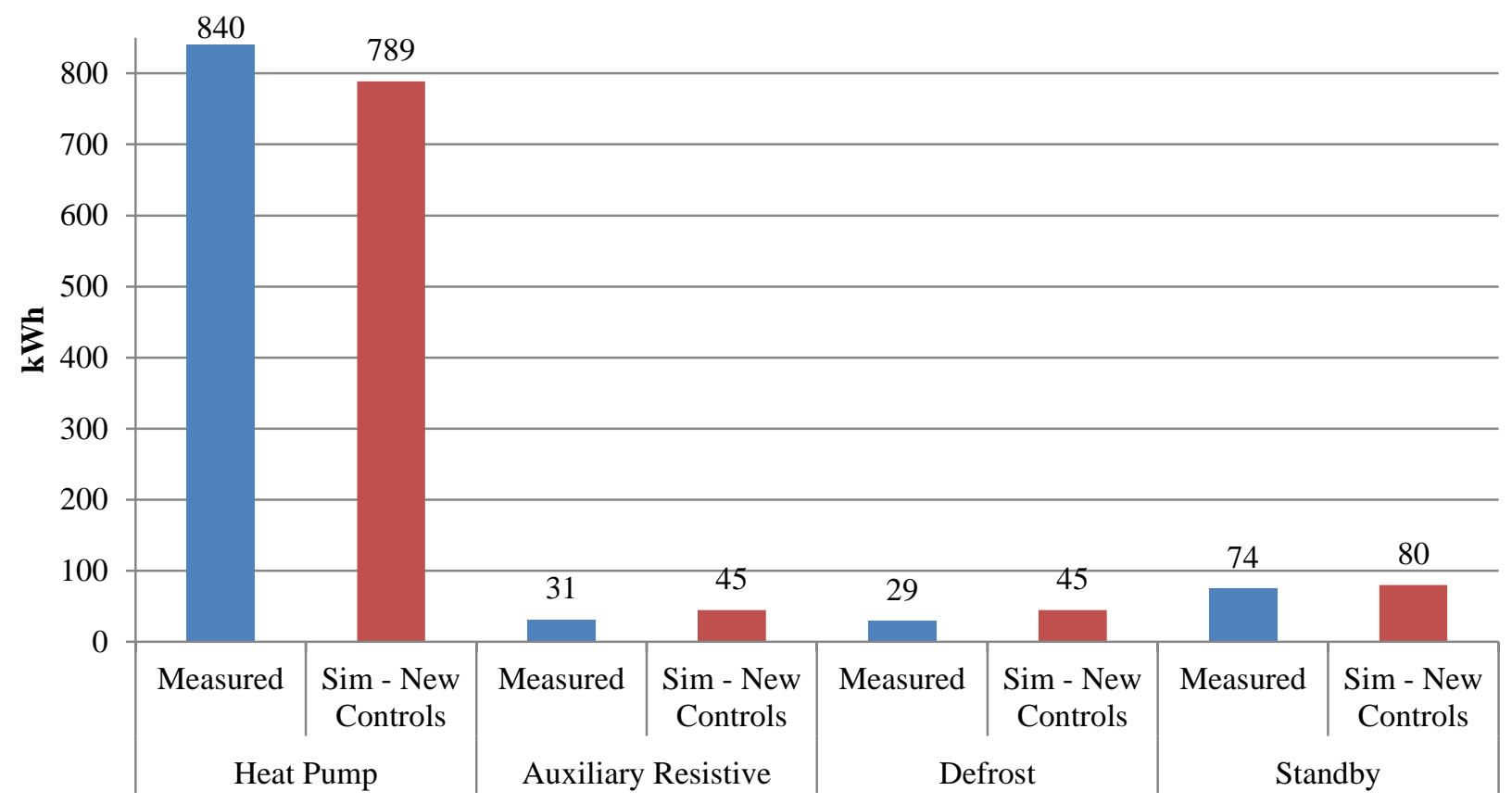

Figure 5-12 Updated Heating Electricity Consumption by Component $-\mathbf{k W h}$

Figure 5-13 shows electricity consumption for the HRV system. The adjustment made to the post-demonstration phase simulation (shift in electric power between zone-level HRVs) only impacted estimated consumption of the HRV system for 11 of 12 months, which overestimates consumption relative to the measured performance. The dip in the measured data in August is a result of the missing data for August 2 through August 6, which can be seen in the pre-demonstration phase simulation (with faults) result. 


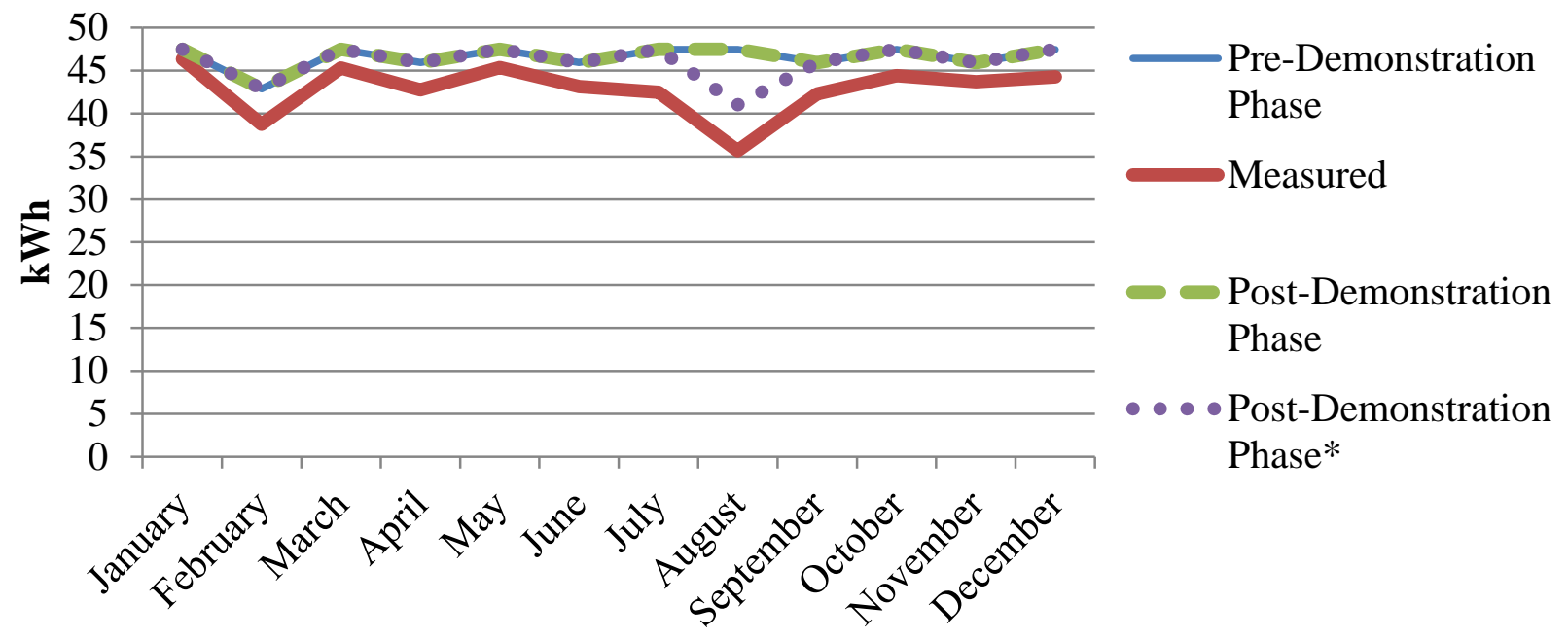

Figure 5-13 HRV Electricity Consumption by Month - kWh

\subsection{Domestic Hot Water Electricity Consumption}

Figure 5-14 shows measured consumption and results for the pre-demonstration phase (Pre-Demo Phase), post-demonstration phase (Post-Demo Phase), and post-demonstration phase with operation faults and changes to piping (shortening and improved insulation of the piping between the two tanks) made on September 26 (denoted as "Post-Demo Phase**"). The adjustments in the post-demonstration phase simulation for both DHW demand and performance specifications significantly increased the solar loop pump electricity consumption, which maps well to the measured performance except for July and August. The heat pump water heater electricity consumption (combination of consumption by the heat pump and electric resistance auxiliary element internal to the heat pump water heater tank) increases for all months from the adjustments in the post-demonstration phase simulation (Post-Demo Phase). Monthly consumption is similar to the measured performance for February through May, but is consistently low for June through January with the largest underestimation occurring in July and August.

After accounting for the faulty operation of the heat pump and solar loop pumps and the issues related to the piping between tanks in Post-Demo Phase**, electricity consumption for the heat pump water heater increases for most months. The largest increases occur in August and September due to the inoperability of the solar loop pumps in late August and early September and the longer piping and poor insulation on plumbing between July 1 and September 26. Consumption increases in November and December due to inoperability of the heat pump in late November and early December, causing greater demand on the less efficient electric resistance auxiliary heating element in the water heater tank. The solar loop pump electricity consumption in Post-Demo Phase** maps well to the measured solar loop pump consumption. 


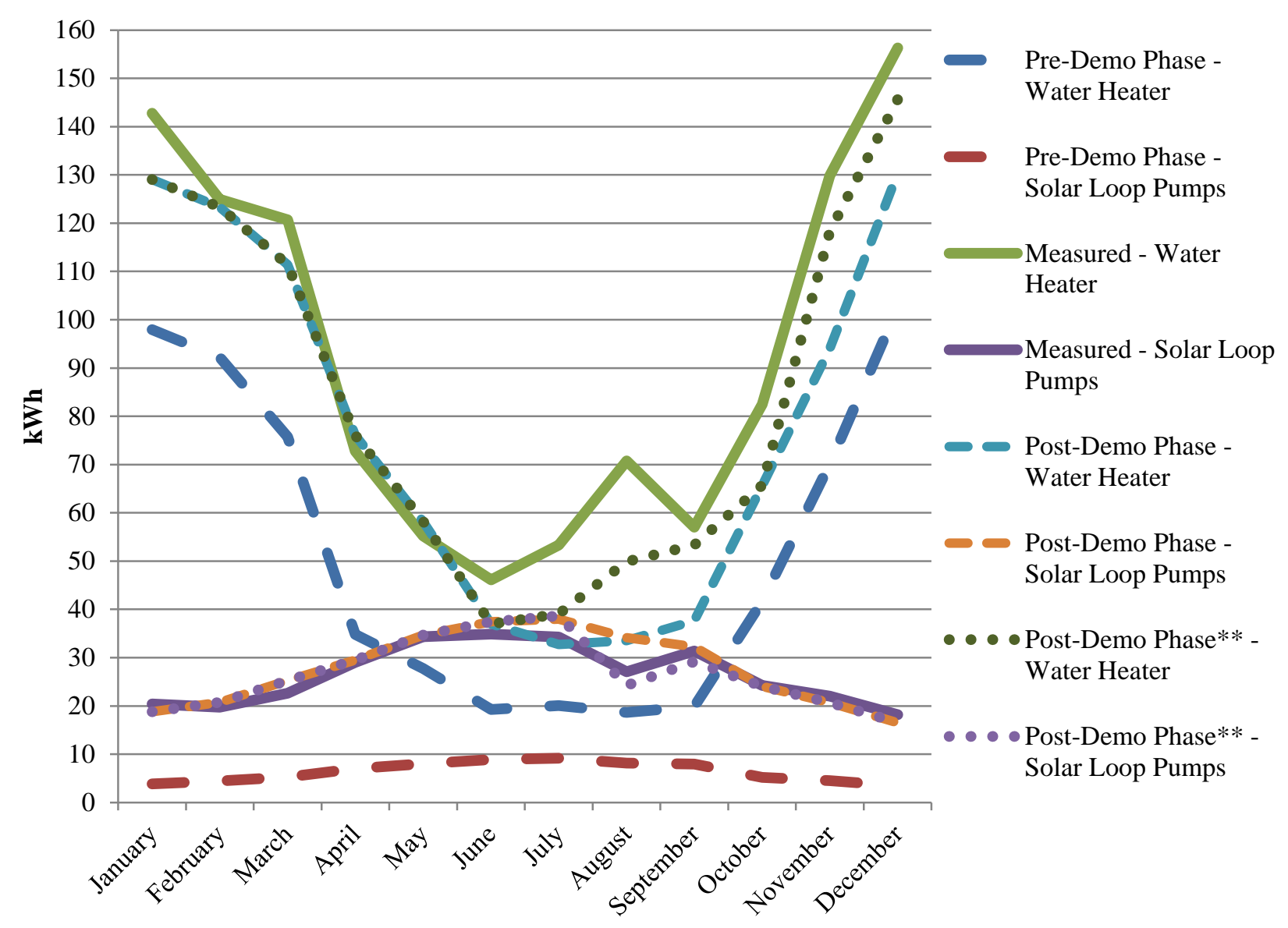

Figure 5-14 Heat Pump Water Heater and Pump Electricity Use (kWh) - Monthly

Two reasons for the lower estimated consumption have been identified, although cannot be addressed at this time. The first reason is the rated COP and associated efficiency performance curve of the heat pump water heater. The model may not effectively capture the reduction in efficiency of the heat pump as the temperature of the water entering the water heater increases due to the water pre-heating by the solar thermal system. The second reason is that simulation models are restricted in their ability to replicate the water draws (hot and cold) because the operation of the NZERTF leads to water draws that are shorter than the minimum allowed one minute simulation timestep. Since the simulation assumes fewer, longer water draws to meet the target water consumption, the demand profile on the water heater will be different.

The pre-heated solar tank and heat pump water heater tank temperatures are shown in Figure 5-15. The change from the stratified tank and mixed tank objects in the post-demonstration phase simulation leads to the measured tank temperature to be lower than the temperature measured at the outlet of the pre-heated solar storage tank. Accounting for the inoperability of the solar loop pumps leads to a drop in the tank temperature in the simulation for August, which mirrors the drop in the measured tank temperature. 


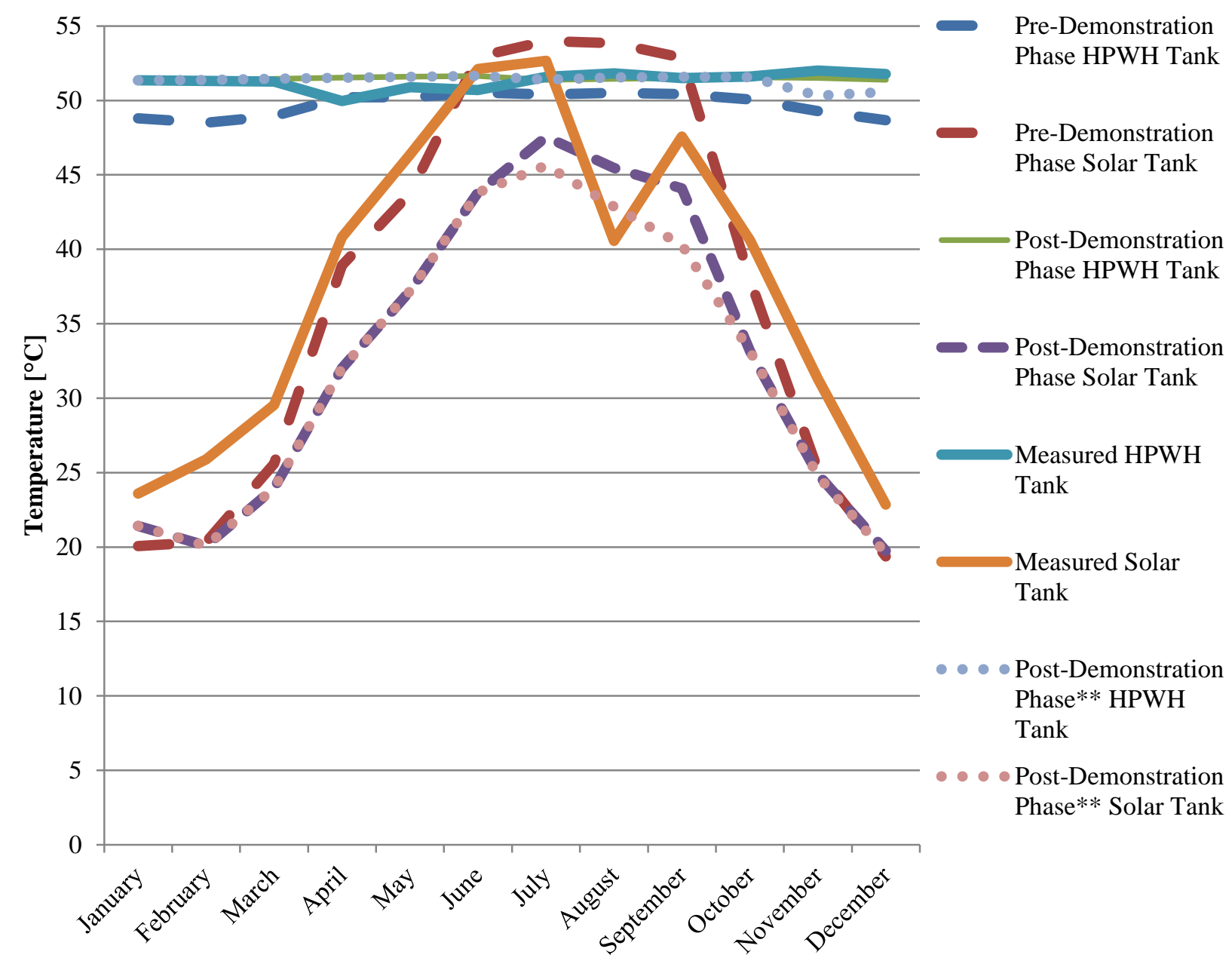

Figure 5-15 DHW Tank Average Water Temperatures $\left({ }^{\circ} \mathrm{C}\right)$ - Monthly

\subsection{Domestic Water Consumption}

Figure 5-16 shows that all five DHW demand categories were adjusted in volume of total water drawn (hot and cold) in the post-demonstration phase simulation. Total water consumption in the post-demonstration phase simulation is $324 \mathrm{~L}$ ( 85.5 gallons) per day, which is $7 \mathrm{~L}$ ( 1.8 gallons) per day greater than measured water consumption ( $317 \mathrm{~L}$ or 83.7 gallons). The flow rates were decreased for sink draws and increased for shower, bath, clothes washer, and dishwasher draws. After accounting for faulty operation of the clothes washer, estimated consumption exactly matches the measured consumption. The simulation models are restricted in their ability to replicate the water draws (hot and cold) because the operation of the NZERTF leads to water draws that are shorter than the minimum allowed one minute simulation timestep, which may impact the end uses of both water volume and electricity consumption. 


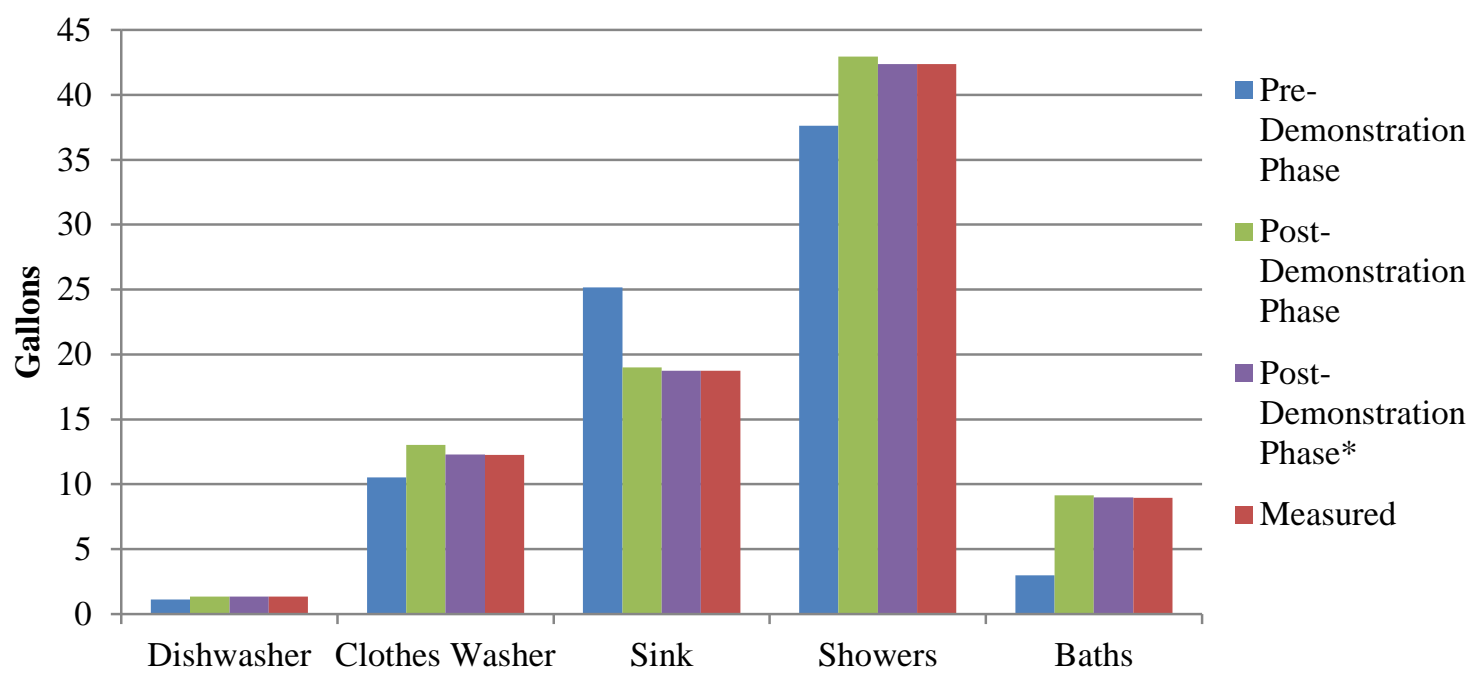

Figure 5-16 Daily DHW Water Consumption - Gallons per Day ${ }^{14}$

\subsection{Solar Photovoltaic Generation}

Figure 5-17 shows the electricity production for each of the three simulations and the measured performance. The estimated production better matches the measured performance once the simulation accounts for the missing measured data in July, August, and December. The most significant adjustment is realized for August because there were five days of missing data while there were only two days in December and one day in July. The overestimation of production during February, March, and November may be a result of the variation in snow cover on the PV panels during and after the uncommon snowstorms during those months. It is possible that the data collection equipment at the local weather station experienced snow cover for a shorter period of time than the PV panels on the NZERTF, either due to quicker melting or manual instrument cleaning. An approach that could help to resolve any differences is to incorporate solar irradiance data collected at the NZERTF into the AMY file.

\footnotetext{
${ }^{14} 1$ gallon $=3.7854 \mathrm{~L}$
} 


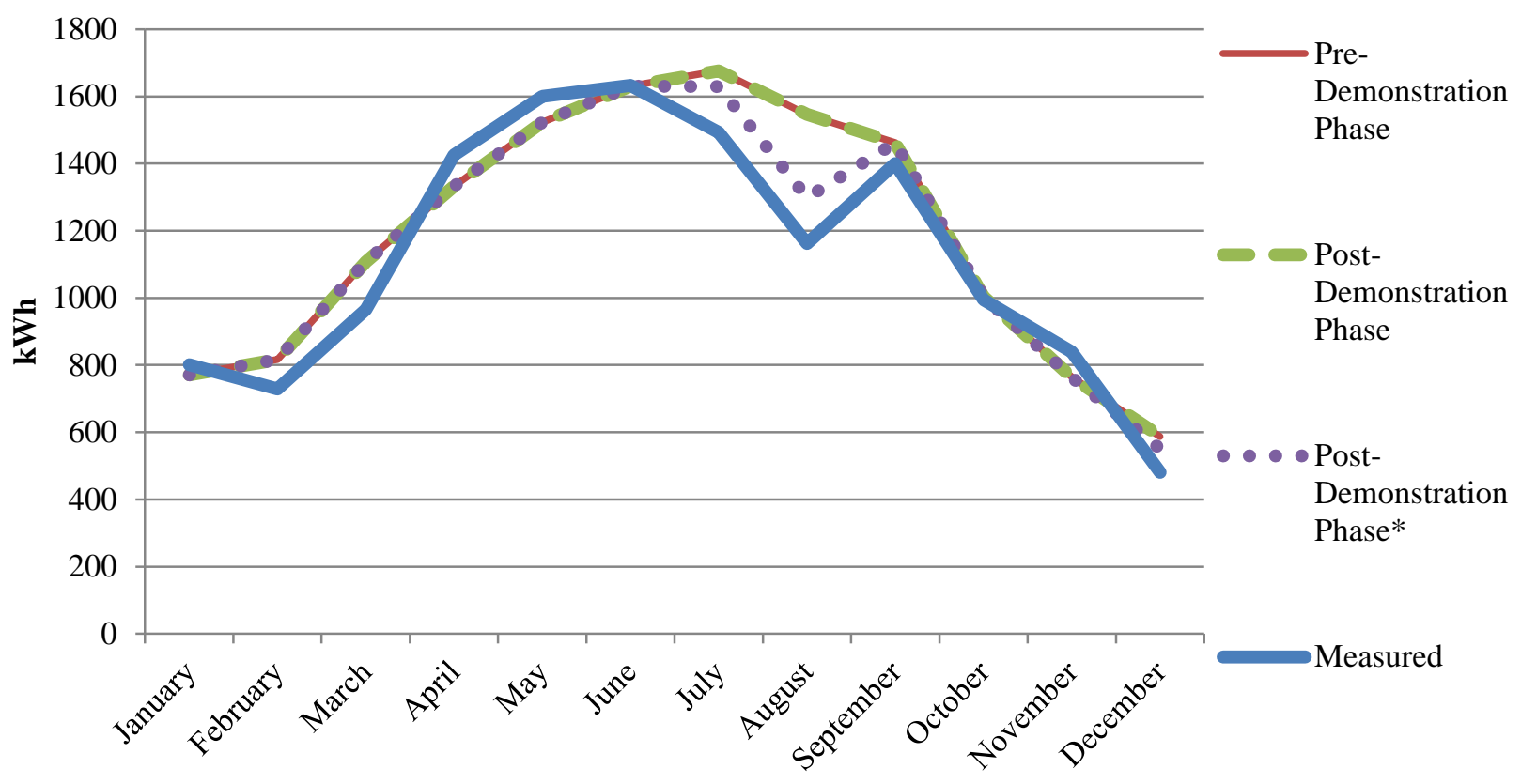

Figure 5-17 Total Solar PV Electricity Production (kWh) - Monthly 


\section{Limitations}

Whole building energy simulation software is limited in its abilities to estimate real world energy performance for a number of reasons. It is difficult to control for all potential variables that can impact the thermal conditions in a building and the resulting operation of equipment to meet the needs of the occupants. There are a number of reasons that the estimated performance from the $E+$ model may vary from the actual performance of the NZERTF. A few are discussed below.

First, air infiltration may not be accurately estimated in the $E+$ models. The infiltration rate due to building envelope leakage in the $E+$ model is simplified to an ELA based on a recent air leakage test. However, this infiltration will not match actual infiltration because the infiltration rate will differ depending on the outdoor weather conditions, relative pressure in the building, and location of the leakage areas. The $E+$ model currently does not control for these factors.

Second, discrepancies between the $E+$ model and the actual NZERTF design are the most prominent reasons for variations in energy performance. The $E+$ model does not include the stairway/foyer opening, which restricts thermal transfer between the floors and increases the conditioned floor area relative to the actual NZERTF design. The greater conditioned floor area will impact the thermal load needed to meet the thermostat set points as well as the minimum ventilation rates required for the HVAC equipment.

Third, $E+$ cannot directly replicate some of the currently installed building equipment or the actual operation schedules. The whole house ventilation system was simulated using two zonelevel systems. The dehumidify-only mode for the air-to-air heat pump was simulated using zone-level dehumidifiers. The current model could not directly simulate the close-looped nature of the solar thermal system. The sink water draws during the demonstration phase were less than one minute in length, which is shorter than the allowed timestep in $E+$. The dynamics of the domestic hot water demands cannot be accurately replicated in the simulation design, including short water draws (less than one minute), varying water draw temperatures, and intermittent water draws during dishwasher and clothes washer cleaning cycles. The model does not account for any non-simulated occupant-related infiltration and heat loads, such as researchers and tours entering, occupying, and leaving the NZERTF. There is a lack of data associated with the efficiency of the heat pump water heater because the water temperature entering the heat pump was not measured during the demonstration phase. There may be additional faults or missing data beyond those discussed in this document that has not yet been accounted for in the simulation model. All of these factors can lead to uncertainty in the model results.

Fourth, the AMY weather file may not reflect exactly the same conditions as those experienced by the NZERTF. Weather can vary across the five mile distance between the NIST campus and the KGAI weather station. The equipment used to collect weather data at the KGAI weather station may not accurately measure some of the variables reported in the AMY file, such as snow cover. 
These limitations will be addressed whenever possible to improve the accuracy of the $E+$ simulation results in future research. However, there is a balancing act between complexity and accuracy in simulation model design. It is important to determine what level of accuracy is considered precise enough for the model to be considered "validated." 


\section{Discussion and Future Research}

The estimated performance of the NZERTF based on the pre-demonstration phase simulation model differed from the measured performance during the demonstration phase for five main reasons. First, the initial simulation assumptions were incorrect due to a lack of information on the specifications of the installed equipment. Second, where information was lacking, conservative parameter values were used in the model in order to not underestimate consumption. Third, there was an inability to directly model some of the installed equipment in the software. Fourth, the operation schedules and controls of the NZERTF were adjusted throughout the preparation for the demonstration phase. Finally, there were faults and adjustments in the operation of the NZERTF during the demonstration phase.

A detailed review of the simulation assumptions and the measured data from the demonstration phase was completed in order to identify what adjustments should be made to the simulation model to better replicate the operation of the NZERTF during the demonstration phase. The resulting post-demonstration phase simulation leads to results that more closely match the measured performance, within $4 \%$ of total electricity consumption and $3 \%$ of electricity production.

The post-demonstration phase model does not closely replicate the electricity consumption to meet the heating load for the NZERTF during the demonstration phase of the NZERTF because of the manner in which the heating equipment is operated. The simulation model's heating equipment operation is based on the capability of the equipment to meet the heating load, while the installed heating equipment operated based on time-oriented controls in the installed thermostat. The time-based controls led the electric resistance auxiliary heating element to operate at times when the heat pump was effectively increasing the room temperature (maintaining "comfortable" occupant conditions) but when the setpoint temperature was not achieved quickly enough. As a result, the electric resistance auxiliary element consumed $1162 \mathrm{kWh}$ while the simulated consumption was estimated to be $547 \mathrm{kWh}$. The NZERTF is currently in a second demonstration phase, which includes changes to the operating controls for the heating equipment. Measured data for October 2014 through December 2014 and associated weather data is used to rerun the simulation, and shows that estimated heating- and coolingrelated electricity consumption is within $4 \%$ of measured consumption. Given the new heating operation controls for the NZERTF, the validated post-demonstration phase simulation is effective at replicating the measured performance.

Issues experienced during the demonstration phase lead to many of the remaining differences between the post-demonstration phase simulation and the measured performance. There were several instances for which data collection errors occurred, which impacted all building systems (HVAC, DHW, solar thermal, and solar PV). Faults in equipment operation led to differences in the HVAC, DHW, and solar thermal systems. After accounting for the most significant faults 
and data collection issues, the simulation results are even closer to the measured performance during the demonstration phase.

The validated post-demonstration phase model does not identically replicate the NZERTF experimental operation. Estimated heat pump consumption is marginally lower than the measured consumption, which could be driven by factors that are directly related to the heat pump parameter values and indirectly related to heat pump operation through the integrated aspects of building components. Similarly, the DHW system underestimates consumption, which may be due to the assumed COP of the heat pump water heater. There was not data collected during the demonstration phase that could determine the performance of the heat pump water heater based on the difference in entering water temperature.

The post-demonstration phase simulation model will be useful to assist in research in a number of areas, both directly related to the NZERTF demonstration phase as well as future, broader research topics. The results from the post-demonstration phase simulation and the detailed database collected from the demonstration phase can be used to analyze the relative performance of the simulation to experimental results for each individual building component: building envelope, HVAC system, DHW system, solar thermal system, and solar PV system. The detailed analysis of these systems can assist in determining the parameters that are necessary for the model to have relatively accurate results. Additionally, the level of accuracy can be weighted with the time and effort required to determine the diminishing returns of such accuracy, allowing modelers to determine the required level of accuracy given their ultimate goals.

The simulation model can be used to make relative comparisons of the NZERTF to alternative building designs. The most obvious comparison would be to an identical house that meets the Maryland state energy code for residential buildings. The energy performance savings can be compared to the additional costs of the efficiency improvements. Sensitivity analysis can be used to look at a number of interesting research areas. Sensitivity analysis can look at the incremental changes between the Maryland code compliant house and the NZERTF to determine which energy efficiency measures result in the greatest energy reductions, the most cost-effective measures, and how energy efficiency measures interact. The validated simulation model can be used to test the sensitivity of the NZERTF performance to varying weather conditions by using historical weather data (annual AMY for the past 30 years). The simulation model can also be altered to determine how additional energy efficiency measures would impact the energy performance of the NZERTF, including equipment that is already installed in the NZERTF. For example, each of the three geothermal heat pump systems could be included in the analysis to determine the impacts of systems on the NZERTF's energy performance. Occupant behavior can be altered to determine how sensitive the results are to the assumed occupant activity. Natural ventilation could be introduced by opening and closing windows based on the outdoor temperature to account for common human behavior. 


\section{References}

ASHRAE Fundamentals, 2012, American Society of Heating, Refrigerating and AirConditioning Engineers, Inc., www.ashrae.org.

ASHRAE Standard 90.2, 2007, American Society of Heating, Refrigerating and AirConditioning Engineers, Inc., www.ashrae.org.

Building Science Corporation. 2009. 65 \% Net Zero Energy Residential Test Facility Construction Documents Set.

Christensen, D. and Winkler, J. December 2009. Laboratory Test Report for ThermaStor UltraAire XT150H. NREL Technical Report NREL/TP-550-47215.

Davis, M, Healy, W., Boyd, M., Ng, Lisa, Payne, V., Skye, H., Ullah, T., 2014, Monitoring Techniques for the Net-Zero Energy Residential Test Facility, National Institute of Standards and Technology, NIST Technical Note 1854, DOI: http://dx.doi.org/10.6028/NIST.TN.1854.

Department of Energy (DOE), 2013, Building Technologies Program, EnergyPlus energy simulation software Version 8.0.0, http://apps1.eere.energy.gov/buildings/energyplus/.

Energy Star. 2012, Product databases for clothes washers, dishwashers, and refrigerators. http://www.energystar.gov/index.cfm?c=products.pr_find_es_products

Everyday Green, 2012, Building Leakage Test of the Net Zero Energy Residential Facility.

Fanney, Hunter et al., 2015, Net-Zero and Beyond! Design and Performance of NIST's Net-Zero Energy Residential Test Facility, Energy and Buildings, currently in revisions.

Heliodyne, 2008, HPak Systems Installation Guide. www.heliodyne.com.

Heliodyne, 2008, Solar Hot Water Technical Specifications. www.heliodyne.com.

Hendron, R., Engebrecht, C., September 2010, Building America house simulation protocols, National Renewable Energy Laboratory, Building Technologies Program.

Hubbell, 2011, Heat Pump Water Heater Model PBX specifications. http://www.hubbellheaters.com/model/pbx/.

Kneifel, Joshua, October 2012, Annual Whole Building Energy Simulation of the NIST Net Zero Energy Residential Test Facility Design, NIST TN 1767, DOI: http://dx.doi.org/10.6028/NIST.TN.1767. 
Kneifel, Joshua, September 2013, Energy Performance of the NIST Net Zero Energy Residential Test Facility Relative to a Maryland Code- Compliant Design, NIST TN 1166.

Kneifel, Joshua, June 2014, Life-Cycle Cost Comparison of the NIST Net Zero Energy Residential Test Facility to a Maryland Code-Compliant Design, NIST SP 1172. DOI: http://dx.doi.org/10.6028/NIST.SP.1172.

Lstiburek, Joseph, 2010, Building Science Corporation. BSI-030: Advanced Framing. Building Science Insights. http://www.buildingscience.com/documents/insights/bsi-030-advancedframing/\#F04

Omar, Farhad and Bushby, Steven. November 2013. Simulating Occupancy in The NIST NetZero Energy Residential Test Facility. NIST Technical Note 1817.

Petit, Betsy et al., 2015, Design Challenges of the NIST Net Zero Energy Residential Test Facility, NIST Technical Note 1847.

Sunpower 320 solar photovoltaic panel specifications. 2011. www.sunpower.com.

Sunpower 5000m inverter specifications. 2011. www.sunpower.com.

Ultra-Aire 65H Ventilating Dehumidifier specifications. 2011. www.Ultra-Aire.com.

Venmar AVS HRV EKO 1.5 specifications. 2009. http://www.venmar.ca/en/product/rootcategory/air-exchangers/venmar-avs/products/eko-15-hrv124.aspx?id_page_parent $=775$.

Solar Rating and Certification Corporation (SRCC). 2014, Certified Solar Collector Rating for Heliodyne GOBI 406 001, http://www.solar-rating.org/index.html.

Weather Analytics, 2014, Actual Meteorological Year (AMY) formatted weather data for July 1, 2013 through June 30, 2014. 